University of Rhode Island

DigitalCommons@URI

Open Access Dissertations

1990

\title{
Varying Isotope Response of Freshwater Molluscs to Environmental Change: Equatorial Africa
}

Leo Lawoe Amegashitsi

University of Rhode Island

Follow this and additional works at: https://digitalcommons.uri.edu/oa_diss

\section{Recommended Citation}

Amegashitsi, Leo Lawoe, "Varying Isotope Response of Freshwater Molluscs to Environmental Change: Equatorial Africa" (1990). Open Access Dissertations. Paper 684.

https://digitalcommons.uri.edu/oa_diss/684

This Dissertation is brought to you for free and open access by DigitalCommons@URI. It has been accepted for inclusion in Open Access Dissertations by an authorized administrator of DigitalCommons@URI. For more information, please contact digitalcommons-group@uri.edu. 
VARYING ISOTOPE RESPONSE OF FRESHWATER MOLLUSCS

TO ENVIRONMENTAL CHANGE : EQUATORIAL AFRICA

BY

LEO LAWOE AMEGASHITSI

A DISSERTATION SUBMITTED IN PARTIAL FULFILLMENT OF THE REQUIREMENTS FOR THE DEGREE OF

DOCTOR OF PHILOSOPHY

IN

CHEMISTRY

UNIVERSITY OF RHODE ISLAND 
DOCTOR OF PHILOSOPHY DISSERTATION

OF

LEO LAWOE AMEGASHITSI

Approved :

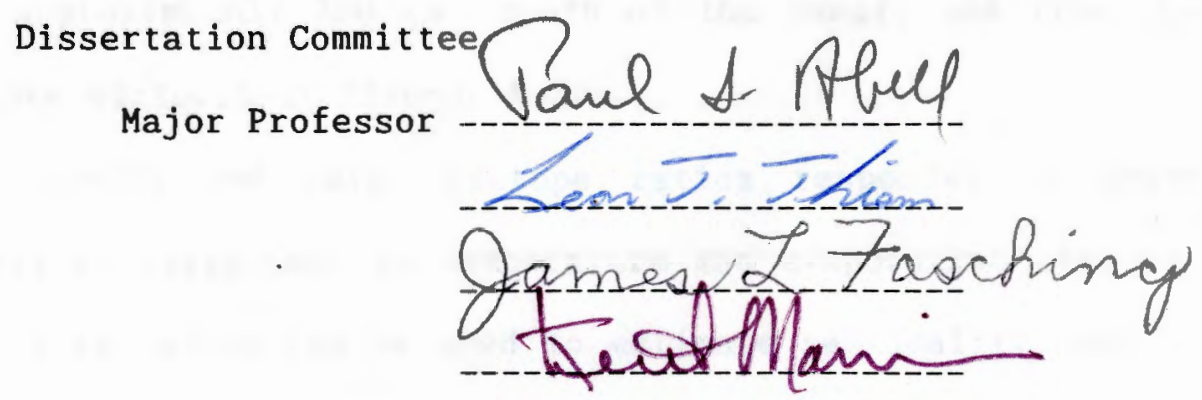

DEAN OF THE GRADUATE SCHOOL

UNIVERSITY OF RHODE ISLAND

1990 


\section{ABSTRACT}

Stable oxygen and carbon isotope ratios from modern African freshwater molluscs and water samples were examined to ascertain the reliability of such information as a proxy in the study of paleoclimates and paleoenvironments.

In this study, the isotope ratios of the freshwater molluscan shell samples were determined from both the apertures and at interval of accretionary growth of individual shells collected at monthly intervals, from four sites. These ratios were examined to ascertain the extent to which they correlate with temperature, rainfall, water isotope ratios and other ambient condiditons.

The samples studied were collected from a tributary of the River Pra at Krobo, in the Western Region, River Densu at Achimota, in the Greater-Accra Region and a stream in Sunyani, Brong-Ahafo Region, all in southern Ghana approximately $700 \mathrm{~km}$ south of the Sahel, and from the Winam Gulf of Lake Victoria at Kisumu, Kenya.

Molluscan shells and water isotope ratios responded to heavy rainfall, as well as variations in temperature and evaporative effects. 0xygen isotope ratio values can be used to estimate seasonality, and in turn, the life span of the molluscs. For application of this method to fossil molluscan shells for elucidation of paleoclimates, however, additional geological and geographical data are desirable. 


\section{ACKNOWLEDGEMENT}

Upon completion of this dissertation, I wish to acknowledge those whose earthly paths have crossed mine in a very significant manner while untertaking this study. My sincere gratitude goes to my major Professor, Dr. Paul I. Abell, who initiated this study and offered me the necessary support and encouragement to complete it.

To the faculty and staff of the Chemistry department, I offer my sincere gratitude for their interest and assistance whenever the need arose. I am, particularly, thankful to Dr. James L. Fasching, chairman of the department and a member of my committee, and Dr. Leon Thiem, who has expanded my knowledge in water chemistry. The assistance of the Isotope Geochemistry group at the Graduate School of 0ceanography is very much appreciated especially those of Joseph Orchardo, Jim Burdett, Dr. Mike Arthur and Dr. Mike Bender.

I greatly appreciate the support, concern and encouragement of the members of Dr. Abell's research group who have become an integral part of my life, Dr. Joseph McClory, Miguel Muzzio, Joseph Yong, Yi Lin. To all my close associates who have made my stay in Rhode Island a pleasant and fulfilling experience, especially, Gabriel Fosu, Hsiu-Ling Liu, Kwabena Anyane-Yeboa and family, a special note of gratitude is registered.

The faithfulness and the relentless efforts of the sample collectors, Leonard Amegashitsi, Richard 0scar Fynn, Rev. Joseph Tsiquaye, Sr. MagaretMary Nimo, Peter Adodo and Ben Amegashitsi has been a source of inspiration, not forgetting those who came to my aid 
when inter-governmental bureaucratic machinations almost brought this research to a halt. I owe Mr. C. K. Dewornu (former IGP), Mr. S. Y. Apedoe, Peter Adodo, Ben. K. Amegashitsi, William Park and Rev. Tettey Bleboo a heartfelt gratitude for their assistance and support.

The National science Foundation grant for this research is thankfully acknowledged. 
PREFACE

The varying isotope response of freshwater molluscs to environmental change in equatorial Africa is presented. The manuscript format was adopted for the dissertation presentation according to the guidelines of the Graduate School of the University of Rhode Island. The dissertation body is composed of two papers and an appendix.

The first paper examines the oxygen and carbon isotope ratios in the shells of a freshwater gastropod, Melanoides tuberculata as proxies for environmental change in southern Ghana.

In the second paper, the varying isotopic response of modern freshwater molluscs genera, Bellamya, Corbicula, Mutela, and Aspatharia, to environmental changes in the Winam Gulf of Lake Victoria were studied.

The appendix is a comprehensive dissertation bibliography 


\section{TABLE OF CONTENTS}

1. OXYGEN AND CARBON ISOTOPE RATIOS IN THE SHELLS OF FRESHWATER GASTROPODS AS PROXIES FOR ENVIRONMENTAL CHANGE : GHANA.......................................... 2 .

2. VARYING ISOTOPIC RESPONSE OF FRESHWATER MOLLUSCAN SPECIES OF ENVIRONMENTAL CHANGES: LAKE VICTORIA............ page 95 .

3. APPENDIX A

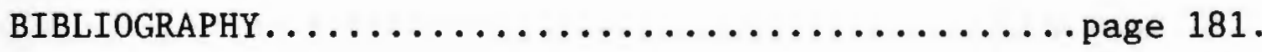




\section{LIST OF TABLES}

TABLE

PAGE

1.1...Meteorological data from the Airforce base at Takoradi...32

$1.2 \ldots$ Seasonality and $\delta^{18} 0$ values...................

1.3... Maxima, Minima and Average Temperatures ${ }^{\circ} \mathrm{C} \ldots \ldots \ldots \ldots . . .72$

1.4... Summary of Correlation values.................

1.5... Aquarium Experimental data...................... 79

2.1... Summary of Temperature and Rainfall values...........161

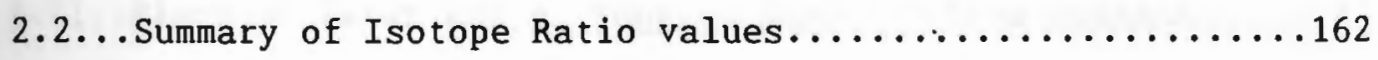

2.3... Summary of Correlation values...................... 
1.1...Map of Ghana showing major towns and collection sites..12 1.2...Relief Map of Ghana........................ 14

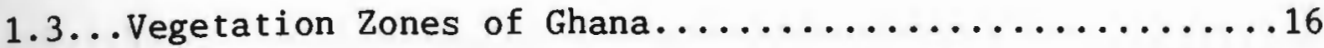

1.3B... Sectioning Procedure of Molluscs.................22

1.4...Plots of Monthly water temperatures during sampling...29 1.5...Average monthly relative humidies at noon in Ghana....31 1.6...Plots of $\delta^{18} 0$ from Sunyani, Krobo and Achimota.......35 $1.7 \ldots$ Plots of $M$. Tuberculata $\delta^{18} 0$ from the three sites.....37 1.8...Plots of $\mathrm{M}$. Tuberculata $\delta^{13} \mathrm{C}$ from the three sites.....39 $1.9 \ldots$ Plots of Water and $M$. Tuberculata $\delta^{18} 0$ from Krobo....41 1.10..Plots of Water and $\underline{M}$. Tuberculata $\delta^{18} 0$ from Achimota...43 1.11..Plots of Water and $M$. Tuberculata $\delta^{18} 0$ from Sunyani...45 1.12..Plots of Krobo water and Melanoides $\delta^{18} 0$ shifted.....47 1.13..Plots of Achimota water and Melanoides $\delta^{18} 0$ shifted...49 1.14..Plots of Sunyani water and Melanoides $\delta^{18} 0$ shifted....51 1.15..Plots of April sequential Melanoides $\delta^{18} 0$ from 3 sites.53 1.16..Plots of April sequential Melanoides $\delta^{13} \mathrm{C}$ from 3 sites.55 1.17..Plots of Dec. ' 85 sequential $\delta$ values from the 3 sites.57 1.18..Plots of Feb. ' 86 sequential $\delta$ values from the 3 sites. 59 1.19..Plots of Apr. ' 86 sequential $\delta$ values from the 3 sites.61 
2.1... Map of East Africa showing Winam Gulf............98

2.2... Map of Lake Victoria showing sampling site.........100

2.3... Map of East Africa showing types of vegetation.......110

$2.4 \ldots$... Plots of Winam Gulf air and water temperatures......112

2.5...Rainfall plot at Winam Gulf during sampling........114

2.6...Water and Bellamya isotope ratio plots...........116

2.7...Water and Corbicula isotope ratio plots...........118

2.8...Water and Mutela isotope ratio plots............. 120

2.9...Water and Aspatharia isotope ratio plots........... 122

2.10.. Monthly aperture $\delta^{18} 0$ plots of the four molluscs.....124

2.11.. Monthly aperture $\delta^{13} \mathrm{C}$ plots of the four molluscs.....126

2.12.. Isotope ratio plots from detailed sequential analysis of

October, 1986 Mutela shell................... 128

2.13.. Sequential $\delta^{18} 0$ plots of Mar. ' 86 molluscan species...130

2.14..Sequential $\delta^{18} 0$ plots of Apr. ' 86 molluscan species...132

2.15.. Sequential $\delta^{18} 0$ plots of May ' 86 molluscan species....134

2.16..Sequential $\delta^{18} 0$ plots of Jun. ' 86 molluscan species...136

2.17..Sequential $\delta^{18} 0$ plots of Jul. ' 86 molluscan species...138

2.18.. Sequential $\delta^{18} 0$ plots of Aug. ' 86 molluscan species...140

2.19..Sequential $\delta^{18} 0$ plots of Sep. ' 86 molluscan species...142

2.20..Sequential $\delta^{13} \mathrm{C}$ plots of Mar. ' 86 molluscan species... 144

2.21..Sequential $\delta^{13} \mathrm{C}$ plots of Apr. '86 molluscan species...146

2.22.. Sequential $\delta^{13} \mathrm{C}$ plots of May ' 86 molluscan species....148

2.23.. Sequential $\delta^{13} \mathrm{C}$ plots of Jun. ' 86 molluscan species...150

2.24.. Sequential $\delta^{13} \mathrm{C}$ plots of Jul. ' 86 molluscan species...152

2.25.. Sequential $\delta^{13} \mathrm{C}$ plots of Aug. ' 86 molluscan species... 154 
2.26.. Sequential $\delta^{13} \mathrm{C}$ plots of Sep. ' 86 molluscan species...156 2.27 . Isotope ratios in West African rivers.............. 171 
MANUSCRIPT 1 
OXYGEN AND CARBON ISOTOPE RATIOS IN THE SHELLS OF FRESHWATER GASTROPODS AS PROXIES FOR ENVIRONMENT CHANGE : GHANA.

BY

LEO L. AMEGASHITSI, PAUL I. ABELL

Department of Chemistry

The University of Rhode Island

Kingston, Rhode Island, 02881

\author{
WESLEY OKIEI \\ Department of Chemistry \\ University of Lagos \\ Akoka, Yaba, Lagos \\ Nigeria.
}

and

JEAN HOUNGBOSSA

Universite Nationale du Benin

F.A.S.T. - Chimie

B. P. 526, Cotonou

Republic of Benin. 
OXYGEN AND CARBON ISOTOPE RATIOS IN THE SHELLS OF FRESHWATER GASTROPODS AS PROXIES FOR ENVIRONMENTAL CHANGE: GHANA

\section{INTRODUCTION}

Stable oxygen and carbon isotope ratios from modern African freshwater gastropods and water samples were examined to ascertain the reliability of such information as a proxy in the study of paleoclimates. The geographical patterns of the stable oxygen isotope ratios obtained from whole shell analysis of individual African freshwater shells have already been established by Abell (1985). In the study reported here, the oxygen and carbon isotope ratios of freshwater gastropod shell samples, taken from the apertures (in order to sample the most recent shell growth) of the individual shells collected at monthly intervals from three sites in Ghana were examined to ascertain their correlation with weather, temperature, rainfall, water isotope ratios and other ambient conditions. Also examined were isotope ratios in sequential samples from the growth spiral of gastropods collected from the three sites. The gastropods and water samples studied were collected at monthly intervals from a tributary of the River Pra at Krobo in the Western Region, River Densu at Achimota in the GreaterAccra Region and a Stream in Sunyani, Brong Ahafo Region, all in Southern Ghana approximately $700 \mathrm{~km}$ south of the Sahel.

How this information on modern African freshwater gastropods can be applied to interpret the oxygen isotope ratios of fossil shells is also examined. If clear correlations exist, then we may achieve our ultimate goal of interpreting paleoclimates from shell isotope data. 
BACKGROUND

Despite Urey's (1947) suggestion that isotope ratios of carbon and oxygen in naturally occurring carbonates bear the potential for calculation of paleotemperatures, it is only recently that freshwater gastropods have been investigated as paleoclimatic indicators. Weber and La Rocque (1962) examined the whole-shell isotope ratios of several genera of freshwater gastropods from Plum Lake, Wisconsin, and one from Lake Erie. Primarily interested in the carbon isotope ratios, they suggested that a substantial contribution to the carbon of the shell came from organic sources, rather than the dissolved inorganic carbon (DIC) of the water, and that this organic carbon was probably in the form of carbon dioxide released by decay of the isotopically light plant debris. The Lake Erie dwelling species pleurocera acutum, with the three species living in close association with pond weed had mean carbon isotope ratios of $-6.88,-4.50$ and $-8.85 \%$ v vS PDB standard. It has been established that both marine and freshwater mollusks form their shells at or close to oxygen isotope equilibrium with the water in which they dwell (Epstein et al., 1951; Fritz and Poplawski, 1974), and Keith and Weber (1964) have studied the ${ }^{13} \mathrm{C}$ composition of freshwater molluscs by comparing marine and freshwater shells. Studies carried out on the Mackenzie River drainage system by Hitchon and Krouse (1972) concluded that the major source of the dissolved inorganic carbon ${ }^{13} \mathrm{C}$ is from biogenic $\mathrm{HCO}_{3}{ }^{-}$. Stuiver (1970) has examined the extent to which $\delta^{13} \mathrm{C}$ and $\delta^{18} 0$ of fresh-water carbonates can be utilized as climatic indicators by studying carbonates and molluscs from sediments of four 
lakes in Maine, New York, Indiana and South Dakota. He observed that while temperature changes account for most of the $\delta^{18} 0$ variations, temperature dependence of $\delta^{13} \mathrm{C}$ is small. The portion of $\delta^{13} \mathrm{C}$ changes that appeared to correlate with climatic changes was attributed to evaporation-rate changes or photosynthetic activity associated with temperature changes. The work of Fritz and Poplawski (1974) was an extension of the investigation of Weber and La Rocque (1962) in which, again, whole shell isotope ratios were measured. While this sampling scheme may be satisfactory for the shells from cool temperature regions, where growth is likely to halt completely during the winter months, it may ignore differential growth rates and temporarily variable isotope ratios for shells from subtropical or tropical bodies of water. The use of isotope ratios of the shells of freshwater gastropods as proxies of past African climates have been examined with fossil gastropods of Africa (Abell, 1982, 1985; Abell and Nyamweru, 1988; Abell and Williams, 1989). In one of the recent studies which covered much of the African continent (Abell, 1985), geographical patterns of the stable oxygen isotope ratios obtained from whole shell analysis of individual modern African freshwater shells were established. These recent studies have revealed that sequential analysis along the growth spirals of the shells gives information on changing environmental conditions during the lifetime of the gastropod. We report a detailed study on gastropods collected from three tropical sites with similar rainfall patterns in Ghana, West Africa. Many freshwater gastropods have life spans of about a year, (Lévêque, 1968) and might be expected to preserve useful environmental records over that span of time. 
Amongst the several proxies available for the study of environmental changes none provide sharp definitions of those changes. Some of the paleoclimatic proxies that have been and are currently being used include the distribution of pollen grains in sediments and the deposition of Coleoptera beetles in sediments to give a rough indication of prevailing climatic conditions. Also the deposition of fine layers of windblown dust, loess, can serve as a paleoclimatic proxy, while the oceans with their accumulation of sand, mud, gravel, plant and animal fossils also provide geological paleoclimatic indicators (Schneider 1984). The inability to correlate these proxies with short term seasonal changes is the major limitation. That is, on the time scale of hundreds or thousands of years, many proxies give us much the same information about major climatic changes. But animal habitability, including human, of an area depends as much or more on the annual range of temperatures and the length and severity of annual dry seasons as on average conditions. The short life span of most species of freshwater gastropods and their isotopic ratio sensitivity to their environment makes them unique proxies to the range of annual climatic conditions; i.e., seasonality.

The technique described herein involves the comparison of the relative amounts of the stable isotopes of oxygen and carbon using their two most common isotopes, with natural abundances of ${ }^{16} 0,99.76 \% ;{ }^{18} 0$, $0.20 \%$ and ${ }^{12} \mathrm{C}, 99 \% ;{ }^{13} \mathrm{C}, 0.01 \%$ respectively. For example, the stable oxygen isotope measurements give the relative differences between the sample and the laboratory standard ratios of ${ }^{18} 0 /{ }^{16} 0$ from the following formula : 


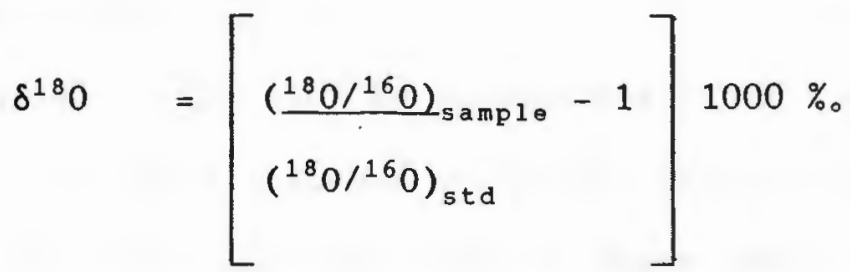

A negative $\delta^{18} 0$ value means there is less ${ }^{18} 0$ in the sample than in the standard against which it is compared and the reverse if $\delta^{18} 0$ is positive. It is also known that an increase in $\delta^{18} 0$ of only 1 per mil in calcium carbonate shells corresponds to a change in water temperature of about $4.0^{\circ} \mathrm{C}$ to $5.0^{\circ} \mathrm{C}$ (Craig, 1953). But temperature is not the only variable over the life span of a mollusc; fresh inputs of rainwater and/or evaporation of the host body of water can also affect oxygen isotope ratios. The short life spans of most species of freshwater gastropods and their isotopic ratio sensitivity to their environment makes them unique proxies to the range of annual climatic conditions. Much work is still being done to understand the life cycle or reproductive strategies of the freshwater gastropods (Brown, 1980; Lévêque, 1968), but it is known that some correlations exist between isotopic ratios of modern shells and the environment in which they grow (Abell, 1985).

Obviously, an understanding of how the oxygen isotope ratios of freshwater gastropod shells vary with the environment in which they grow could facilitate the application of the isotopic ratio measurements to continental paleoclimatology.

Why African climates? The geographical limitations of this study were dictated by both practical and theoretical reasons: 
(1) The African continent provides a wide range of modern climates for comparisons with past climates.

(2) The latitudinal range of the continental land mass, from approximately $30^{\circ} \mathrm{N}$ to $30^{\circ} \mathrm{S}$ gives a useful range of climatic conditions, without encountering extremely low temperatures where molluscs may be dormant over large portions of the year.

(3) Initial surveys (Abell, 1985) were made possible by the availability of good museum collections of gastropod shells collected, at least in part, because of public health problems associated with freshwater gastropods.

(4) It was also hoped that one consequence of this study would be application to paleoclimatic influences on the development of early man, whose original home was Africa.

(5) Finally, past African climates are of interest because we would like to know if the expansion of the Sahara desert in Africa is a cyclical process or not. Such knowledge would help in the formulation of land use policies based on expectations of probable changes rather than merely hoping for the best.

In addition to these primary reasons for selection of Africa as our study area, knowledge of ancient climatic variations could provide answers to some questions raised in the evolutionary process and in geology. The geographical conditions of past water basins could be deciphered, and the validity of the assumptions linking environmental change to the process of evolutionary change might be confirmed. According to current climatic theory, global weather patterns exist because different parts of the globe receive and absorb varying amounts 
of solar insolation; upper air currents and ocean currents are mechanisms for restoring heat balance (Budyko, 1978; Barnett, 1978). Inherent in the global weather patterns is seasonality. Knowledge regarding past seasonality on land has, for the most part, been derived indirectly. None of the techniques can give climatic ranges (seasonality) within the year; all of the proxies yield long term trends.

The influence of climatic factors and the complexities of their interplay at any one given time have greatly inhibited the use of oxygen isotope ratios in freshwater carbonates as continental climatic indicators. As it turns out, there is a good correlation between oxygen isotope ratios and general climatic conditions and the factors which influence precipitation and eventually determine the $\delta^{18} 0$ of the environment of the freshwater gastropods have been examined by Yurtsever (1975) and Dansgaard (1964). We hope to apply these factors in the discussion of our results from southern Ghana, as we expect seasonal variations in the $\delta^{18} 0$ values from the sites.

The modern sites were selected on the basis of differences in regional vegetation cover, permanency of. the body of water, and the closeness of the sample collector to the collection site. A transient body of water would only give partial seasonal information. For example, a pond selected at Tamale $9^{\circ} 25^{\prime} \mathrm{N} 0.8^{\circ} \mathrm{W}$ in the northern savannah region of Ghana closer to the Sahel may dry up after a few months of collection. The all year round availability of living gastropods, the permanency of the body of water and the closeness of the collaborators affords us a natural laboratory where the gastropods and the collectors 
experience similar climatic changes. A country-wide survey by one of us in 0ctober 1985 resulted in the selection of three sites and six willing collectors to fulfill our quest for natural laboratories at Krobo, Sunyani and Achimota, where three moving bodies of water were located.

\section{THE SITES AND THEIR ENVIRONMENTS}

The three sites in Ghana, which were selected for this study all lie between the Kwahu-Wenchi Plateau and the Gulf of Guinea (Fig. 1). The sites consist of two rivers and a stream. River Pra was sampled at Krobo, in the Western Region, Sunyani stream at Sunyani, in the BrongAhafo Region and River Densu at Achimota in the Greater Accra Region. The Kwahu-Wenchi Plateau is a highland mostly over 460 meters high area which stretches from Koforidua to Wenchi. (Figure 2). Also referred to as the country's watershed, it is where most of the chief rivers of the country rise (Adams, 1960). These highlands harbour some of the forest reserves in Ghana. The permanent forest of this area protects vegetation and some streams from the severe effects of the tropical continental air. The Kwahu-Wenchi Plateau, in which lies the Sunyani Stream is almost always humid and cool because of plant respiration and the retention of rainwater by adequate vegetation cover. 


\section{FIGURE 1}

MAP OF GHANA SHOWING MAJOR TOWNS AND THE COLLECTION SITES.

(ADAPTED FROM GHANA MINISTRY OF INFORMATION PUBLICATION - GHANA TODAY 1984) 


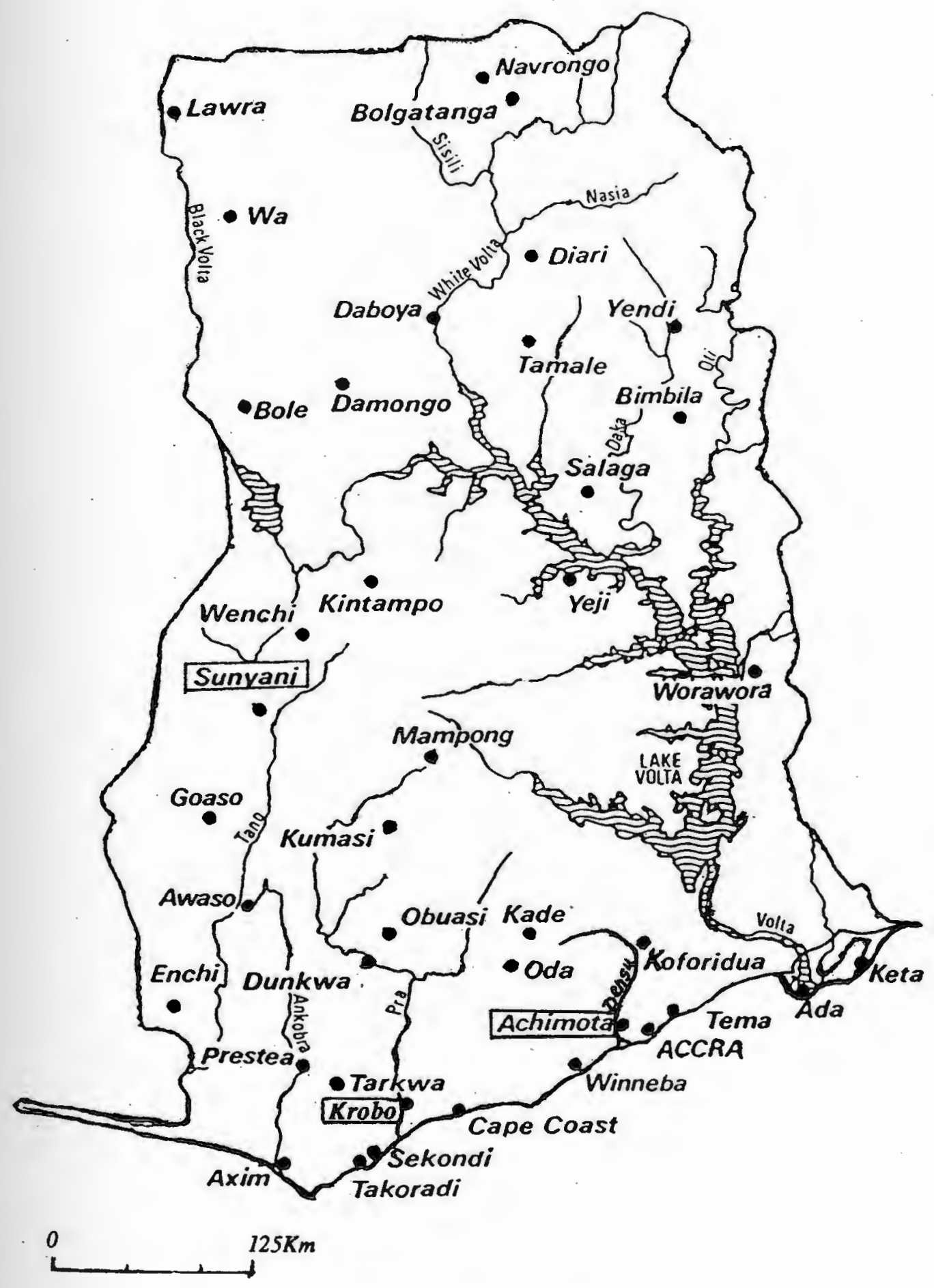

MAP OF GHANA 
FIGURE 2

RELIEF MAP OF GHANA

(ADAPTED FROM BOATENG (1967)) 


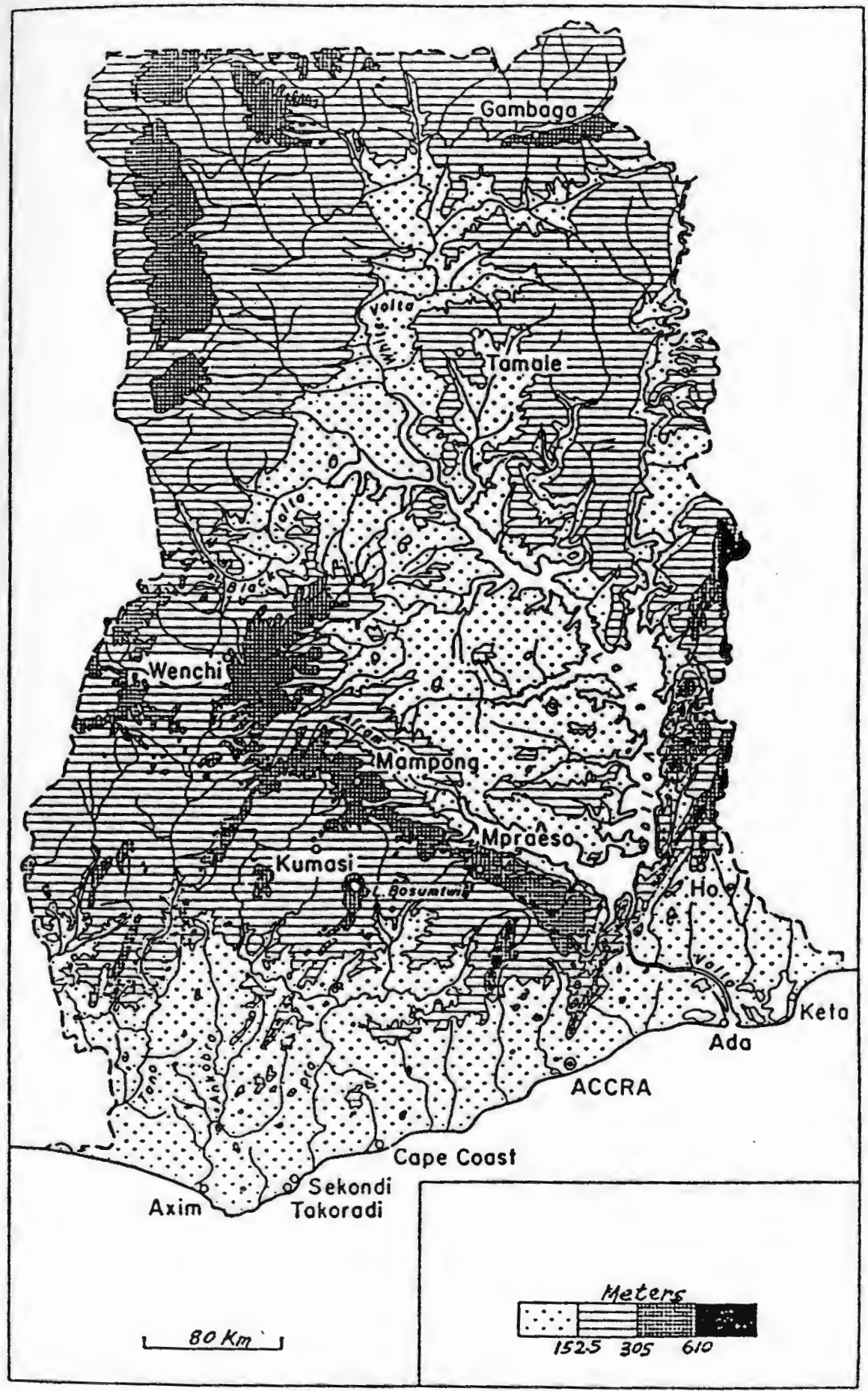




\section{FIGURE 3}

VEGETATION ZONES OF GHANA

(ADAPTED FROM ADAMS, (1960)) 


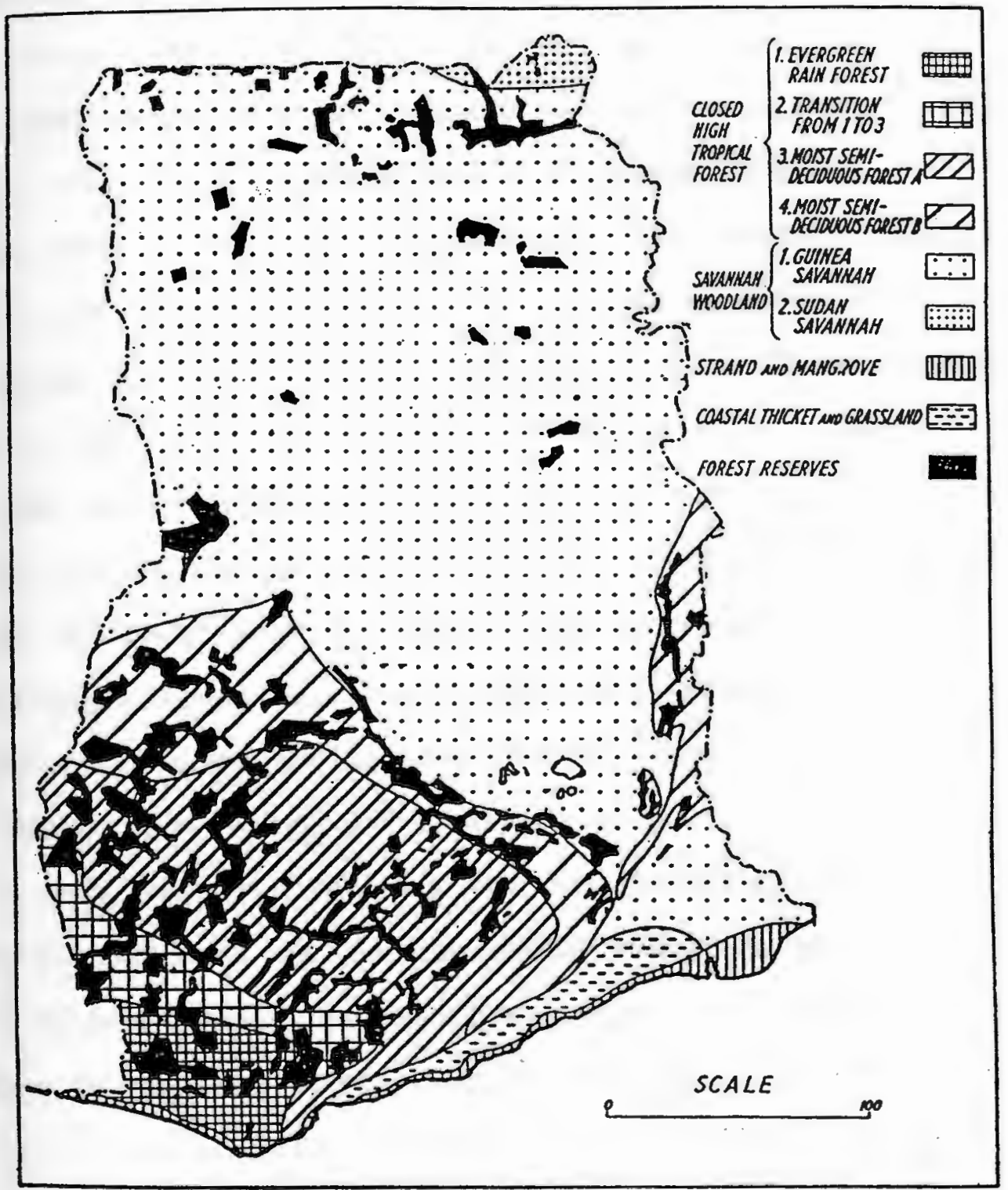

Vegetation zones of Ghana. 
The area where collections were made are characterized predominantly by Pre-Cambrian rocks and intruding granites referred to as the Birrimian and the Tarkwaian (Boateng, 1967). This indicates the absence of major carbonate sediments such as limestone and dolomites.

The region between the Kwahu-Wenchi plateau and the Gulf of Guinea is a gentle slope from the scarplands to the coastal plains. In this region, one finds ridges and valleys of Rivers Pra, Ankobra, Tano, Amisa and Densu. River Pra has its source close to Mpraeso in the Kwahu scarp with its tributary rivers like offin, the Anum, and the Birim, it is the largest river system in the southwest of Ghana. It joins the sea near Shama in the Western Region with rapids at Krobo. River Densu derives its source from the Akwapim-Togo Ranges. The soils at the three sites are forest ochrosols which are usually red or reddish brown on the summits and upper slopes of hills, orange brown or brown on the middle slopes, and yellow-brown on the lower slopes. They are better drained and less acidic than the oxysols. (Boateng, 1967)

The lower valleys experience the same rainfall pattern as the Kwahu Plateau except in the western section near Axim and Half Assini where the maximum rainfall in the country occurs and therefore is the wettest area in the Ghana, with permanent equatorial rainforest. (Figure 3) The eastern section which includes Achimota in Accra has very little rainfall between September and November and, therefore, lies in the dry part of Ghana with coastal thicket and grassland. Vegetative cover at both Sunyani and Krobo consists of moist semi-deciduous forest which forms a transition zone between the evergreen rainforest and the 
savannah. This area is very humid with tall trees creating a "canopy" effect which decreases gradually away from the evergreen to the savannah grassland. In some of the moist areas, ferns and orchids grow on the branches of trees and some swamps harbour raffia and oil palms, mahogany, and ebony. Other crops that fluorish in this type of vegetation are cocoa, cocoyam, plantain, maize and sugarcane. (Varley and White, 1958). Maize (Zea mays) and sugercane (Saccharum sp.) are $C_{4}$ plants (Van der Merwe, 1982) whereas most of the vegetation in these lowland areas is of the $C_{3}$ type. The $\delta^{13} \mathrm{C}$ values of the plants in this region may be of significance in the interpretation of the shell $\delta^{13} \mathrm{C}$ values.

\section{CLIMATIC AND WEATHER PATTERNS IN SOUTHERN GHANA}

There are two dry seasons (Dec.-Feb. and Aug.-Sep.) and two wet seasons (Mar.-Jul. and Sep.-Nov.) in the yearly climatic sequence of Ghana (Oboli, 1963). These episodes are characterized as follows:

Dec. - Feb. Dry, "Harmattan" winds off Sahara desert, Temperatures range from $25^{\circ} \mathrm{C}$ to $32^{\circ} \mathrm{C}$ with high evaporation in day, strong radiational cooling at night. Rainfall is lowest.

Mar. - Jul. Principal rainfall with maximum in June or July Cloudy. Maximum average temperature, $33^{\circ} \mathrm{C}$, may be in March, April, or May.

Aug. - Sep. The Benguella current brings cold waters closer to the Guinea coast. It is cloudy and lowest average day temp., $27^{\circ} \mathrm{C}$, is recorded in August. Rainfall is abated. 
et. - Nov. Subsidiary rainfall with temperatures around $29^{\circ} \mathrm{C}$. Humidity is high.

COLLECTION PROTOCOL

Live gastropods of the species, Melanoides tuberculata were collected at monthly intervals from a tributary of the River Pra at Krobo, $5.2^{\circ} \mathrm{N}, 1.7^{\circ} \mathrm{W}$ in the Western Region, from River Densu at Achimota a suburb of Accra, $5.7^{\circ} \mathrm{N}, 0.3^{\circ} \mathrm{W}$ in the Greater Accra Region, and from a Stream at Sunyani, $\quad 7^{\circ} 22^{\prime} \mathrm{N}, 2^{\circ} 20^{\prime} \mathrm{W}$ in the Brong-Ahafo Region, and analyzed for carbon and oxygen isotope ratios together with water samples collected at the same time and location from the host body of water in which the gastropods lived.

Water samples, freshwater gastropods and data on prevailing climatic conditions were collected at monthly intervals from November 1985 to November 1986. The gastropods were collected at shallow (1 meter) depth, and were thus growing in water that was well-mixed, neither deep nor stagnant. Approximately 10 gastropods were collected each month from the bottom of the river (usually in a cluster), allowed to die and then dried before shipping to the laboratory. The water sample was collected in a $25 \mathrm{~mL}$ septum capped vial, which was lowered down into the river at the proximity of the gastropods and then opened to fill up. It was recapped, labeled and kept sealed for analysis in the laboratory. Water temperatures were also measured monthly over the same period at the collection site.

Individual gastropods from the set of 10 collected each month at the three sites were accepted as representative. We had already 
established (unpublished data) that all individual gastropods, from the same site record the same $\delta^{18} 0$. For uniformity purposes and comparison in this work all the samples are Melanoides tuberculata. Their ubiquity in Africa, and sturdy, robust characteristics make them ideal species for our study. See Brown, (1980) for distributions of this species throughout Africa.

\section{EXPERIMENTAL}

The processing of the freshwater gastropod shells for the purpose of evolving their $\mathrm{CO}_{2}$ content into ampoules for stable isotope ratio determination was by the procedure of Abell (1985). This involved longitudinal sectioning of a whole shell with a low speed diamond wafering saw in such a way that if a shell has 6 to 8 whorls in the growth spiral, sampling from opposite edges of each whorl $\left(180^{\circ}\right)$ in the sectioned shell would give 12 to 16 samples. (Figure $3 b$ ) The samples of a fractional milligram size were baked under vacuum at $400^{\circ} \mathrm{C}$ for approximately 4 hrs to destroy all organic matter. For the monthly analyses the milligram size fraction comes from the apertures of the Melanoides shells. The $\mathrm{CO}_{2}$ samples were prepared on a vacuum line by solution of shell fragments in $100 \%$ phosphoric acid at $55^{\circ} \mathrm{C}$. The evolved $\mathrm{CO}_{2}$ samples were sealed off in ampoules for isotopic ratio analysis on a V.G. Micromass 602-D mass spectrometer.

The results were corrected to $25^{\circ} \mathrm{C}$, the temperature usually used for reporting isotope ratio results and recalculated to the PDB standard. Since all the samples analyzed were aragonitic, $0.6 \%$ was subtracted from the values to compensate for the difference between 
FIGURE 3B

SECTIONING PROCEDURE OF MOLLUSCS 


\section{SECTIONING PROCEDURE OF MOLLUSCS}
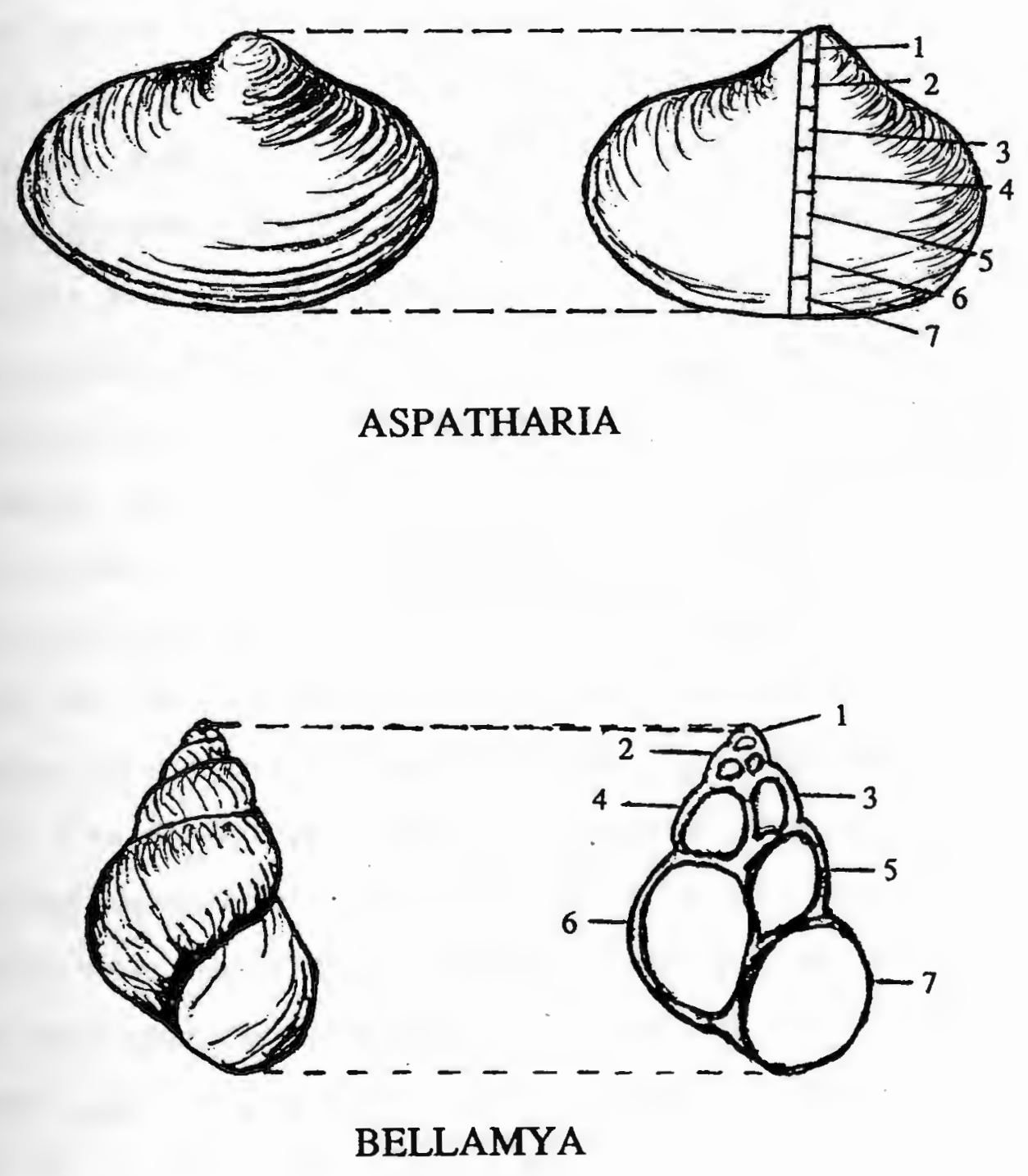
calcite and aragonite (Grossman, 1962).

Monthly water samples were analyzed according to the procedure of Epstein and Mayeda (1953). This involved the equilibration of approximately $24 \mathrm{cc}$ (STP) of $\mathrm{CO}_{2}$ with $2.5 \mathrm{~g}$ of water in a thermostated bath for approximately 7 days and the analysis of approximately $3 \mathrm{cc}$ aliquot of the gas on a V. G. Micromass 602-D mass spectrometer. To facilitate rapid equilibration the $\mathrm{pH}$ may be adjusted to 6 or lower (Mills and Urey, 1940). The water sample was inserted into a $25 \mathrm{cc}$ round bottom flask provided with ground glass joints and a stopcock so as to be connectable to a vacuum manifold. The water was frozen in liquid nitrogen-2-propanol slush bath and the air quickly pumped away. The ice was melted and warmed to room temperature to release gas which was trapped during the initial freezing. The water was then refrozen and pumped for a minute to remove the remaining non-condensible gases. The ice was melted again and commercial cylinder $\mathrm{CO}_{2}, 99.8 \%$ purity, was introduced into the flask to a pressure of about $73.5 \mathrm{~cm} \mathrm{Hg}$. After equilibration in a bath thermostated at $31^{\circ} \mathrm{C}$ for 7 days with frequent shaking, a $3 \mathrm{cc}$ aliquot of the $\mathrm{CO}_{2}$ was withdrawn on a vacuum line by freezing into ampoules and analyzed on the V. G. Micromass 602-D mass spectrometer using the method described by McKinney et al. (1950).

All mass spectrometric analyses were reported relative to the PDB $\mathrm{CO}_{2}$ standard gas. The probable error was $\pm 0.01 \%$. Replicate samples measured on the same day were usually reproducible to $\pm 0.05 \%$. Standards (usually NBS-20), were always run the same day as any unknowns were run. 
RESULTS

As part of the procedure for sampling, sample collectors at the sites were asked to furnish information on environmental changes especially at the habitat of the freshwater gastropods. We summarize the collector's notes below:

\section{ry of Collectors Notes}

\section{Sunyani Site}

Shells of Melanoides tuberculata were collected from November 29, 1985 to 0ctober 29, 1986. Water samples were collected for the same period, but the 0ctober 29, 1986 sample was lost in the mail. Water temperatures are recorded in Figure 4. The following are observations recorded verbatum from the collector's notes:

Sample \#1 0ct. 29, 1985 - Sample collected by Leo Amegashitsi. Heavy dew.

Sample \#2 Dec. 29, 1985 - Harmattan season; there was heavy dew. No rain since the first week of December.

Sample \#3 Jan. 29, 1986 - Slightly overcast. Harmattan- No rain the whole month.

Sample \#4 Feb. 28, 1986 - Rain the night'before- Rains were just beginning.

Sample \#5 Apr. 2, 1986 - Rains are upon us.

Sample \#6 Apr. 29, 1986 - Rained the day before and in the evening.

Sample \#7 May 28, 1986 - Rained at the weekend and tuesday (May 27). Rains started early this year and they have been good.

Sample \#8 Jun. 28, 1986 - Specimen collected by Ms. Margaret Mary 
Nimo. Rainy season.

Sample \#9 Jul. 28, 1986 - Collected by M. M. Nimo. Rains are still on. Sample \#10 Aug. 28, 1986 - Collected by Bro. Joe, C.S.C. Rains are still on.

Sample \#11 Sep. 28, 1986 - Collected by Bro. Joe CSC. Regular rains. Sample \#12 Sep. 29, 1986 - Lost in the mail.

\section{Krobo Site}

Table 1 gives the days and rainfall amounts during the period of collection at an airforce meteorological station at Takoradi. The rainfall pattern at this station is representative of rainfall in Southern Ghana within which all the collection sites fall except that the amount of rainfall will be slightly lower at Sunyani and Achimota.

Melanoides tuberculata and Bellamya unicolor shells were collected from December 9, 1985 to 0ctober 12, 1986. Water samples were also collected at the same period. The water temperatures are summarized in Figure 4. The following are comments recorded verbatum from the collector's notes: Sample \#1 Dec. 9, 1985 - Dry and cool, Harmattan blowing.

Sample \#2 Jan. 6, 1986 - Dry \& cool, river drying up.

Sample \#3 Feb. 3, 1986 - Extremely dry, Harmattan still blowing. River almost dried up.

Sample \#4 Mar. 2, 1986 - Light rainy season. River filling up.

Sample \#5 Mar. 30, 1986 - Same as \#4.

Sample \#6 Apr. 27, 1986 - Bright sunny weather, river level normal but flowing faster due to onset of rains.

Sample \#7 May 27, 1986 - Only M. tuberculata species was available due to rains and river flooding. 
Sample \#8 Jun. 22, 1986 - River completely flooded due to rains.

Gastropods swept from natural habitat (rocks).

Sample \#9 Jul. 21, 1986 - Rainy season - River still in flood. Only $\underline{M}$ tuberculata species was collected.

Sample \#10 Aug. 17, 1986 - Major rainy season over. Weather cool, but bright.

Sample \#11 Sep. 13, 1986 - September rains - river flooding again.

Sample \#12 0ct. 12, 1986 - River completely flooded due to rains.

\section{Achimota}

The Achimota Melanoides tuberculata shells were collected monthly between Nov. 22, 1985- Nov. 16, 1986, with the exception of Jan. 1986 when collection was not possible. Water samples were also collected for the same period. Water temperatures are summarized in Figure 4 . The following recorded verbatum comments are from the collector's notes:

Sample \#1 Nov. 22, 1985 - Heavy rainfall at the weekend. Collection made by Leo and Ben.

Sample \#2 Dec. 8, 1985 - Cool and dry.

Sample \#3 Feb. 16, 1986 - Very dry.

Sample \#4 Mar. 16, 1986 - Onset of the rainy season.

Sample \#5 Apr. 16, 1986 - Bright and sunny.

Sample \#6 May 6, 1986 - More rains.

Sample \#7 May 30, 1986 - Very heavy rains.

Sample \#8 Jun. 22, 1986 - Same as \#7.

Sample \#9 Jul. 16, 1986 - Light rains.

Sample \#10 Aug. 16, 1986 - Rain has abated. Weather is cool. 
Sample \#11 Sep. 16, 1986 - Very light rain.

Sample \#12 0ct. 16, 1986 - Same as \#11. 


\section{FIGURE 4}

PLOTS OF MONTHLY WATER TEMPERATURES

RECORDED DURING SAMPLING (NOV.1985-

NOV.1986) FROM ACHIMOTA, SUNYANI AND

KROBO. 


\section{WATER TEMPERATURES ${ }^{\circ} \mathrm{C}$ COMPARED}

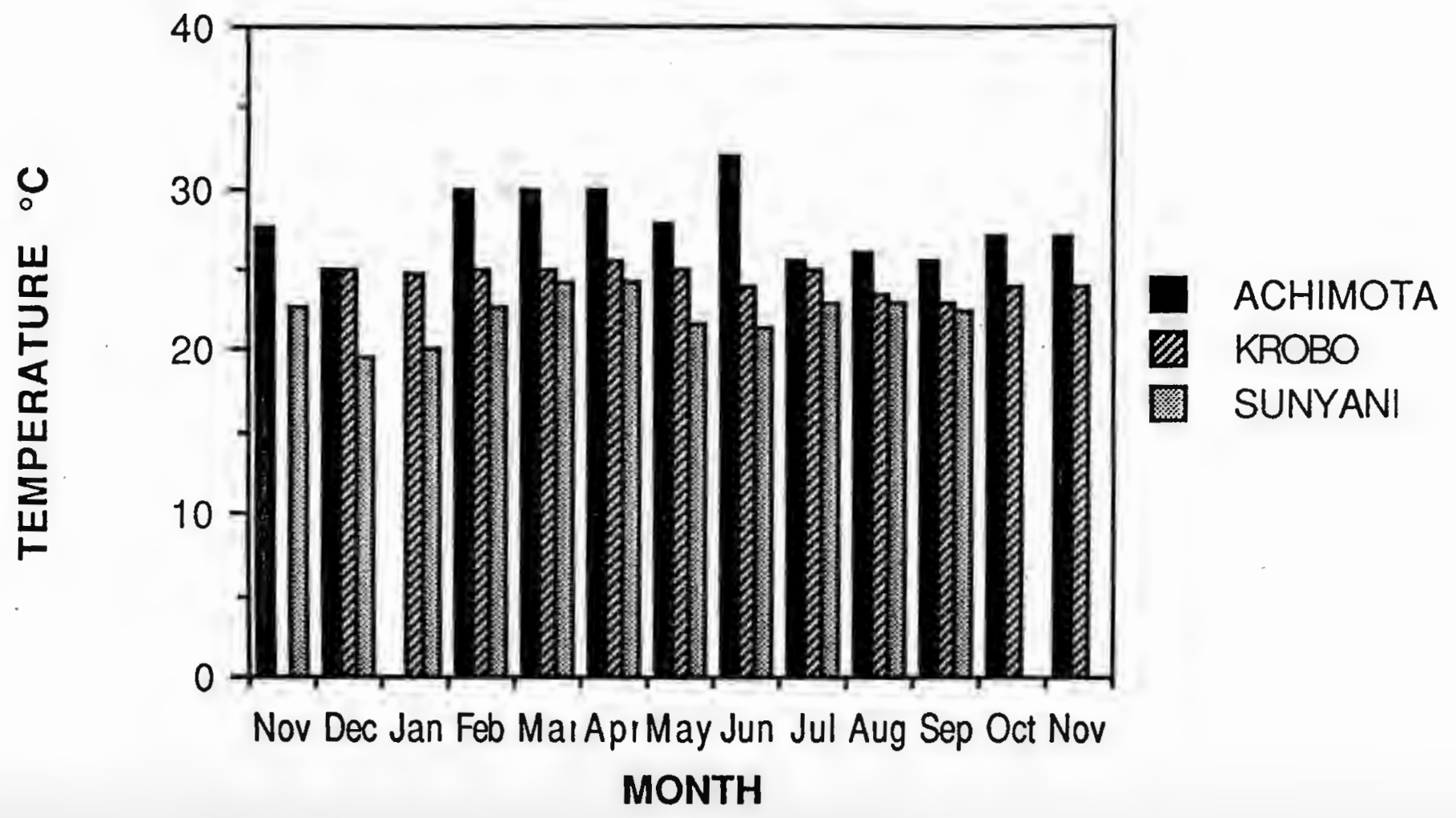


FIGURE 5

AVERAGE MONTHLY RELATIVE HUMIDITIES

AT NOON IN GHANA. 


\section{AVERAGE MONTHLY RELATIVE HUMIDITY AT NOON IN GHANA}

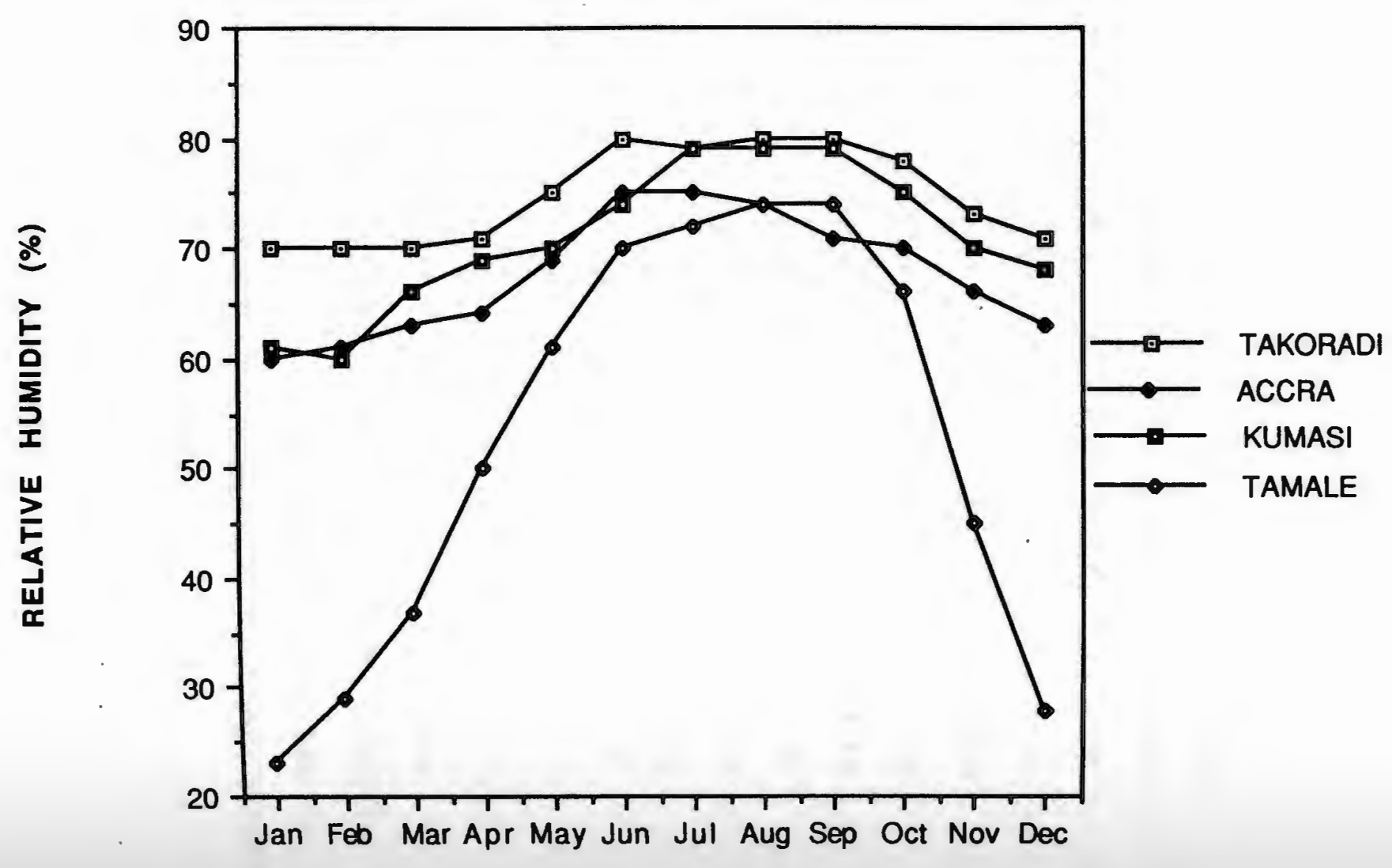




\section{TABLE 1}

\section{MOOGICAL DATA FROM THE AIRFORCE BASE AT TAKORADI}

PERIOD : OCTOBER 1985 - NOVEMBER 1986.

MONTH RAINFALL (mm) NO. OF DAYS MEAN TEMP. ${ }^{\circ} \mathrm{C}$

$\begin{array}{lrrr}\text { OCT. } & 64.8 & 3 & 29.7 \\ \text { NOV. } & 111.8 & 6 & 31.5 \\ \text { DEC. } & 0.0 & - & 31.3 \\ \text { JAN. } & 0.0 & - & 31.5 \\ \text { FEB. } & 62.3 & 7 & 31.6 \\ \text { MAR. } & 20.0 & 4 & 31.6 \\ \text { APR. } & 50.4 & 6 & 32.3 \\ \text { MAY. } & 99.4 & 16 & 31.6 \\ \text { JUN. } & 185.2 & 17 & 29.5 \\ \text { JUL. } & 163.6 & 12 & 28.2 \\ \text { AUG. } & 21.3 & 4 & 27.7 \\ \text { SEP. } & 18.5 & 8 & 28.3 \\ \text { OCT. } & 51.9 & 8 & 29.0 \\ \text { NOV. } & 61.4 & 6 & 28.2\end{array}$


Figures 6 and 7 summarize the oxygen isotope ratio information on the water samples and the freshwater gastropod shells (aperture) respectively. The plotted $\delta^{18} 0$ values are from the raw oxygen isotope ratio values which were corrected to $\mathrm{PDB}$ by adding $0.84 \%$ 。 to correct to the PDB standard from the Graduate School of Oceanography, University of Rhode Island, substandard and then subtracting $0.60 \%$ as an aragonitic correction factor. Since $\delta^{18} 0$ values with reference to the PDB is reported at $25^{\circ} \mathrm{C}$, the $\mathrm{PDB}$ values were corrected to $25^{\circ} \mathrm{C}$ by adding or subtracting $0.18 \%$ for each $1^{\circ} \mathrm{C}$ of temperature change. The application of the $0.18 \%$ to bring the shell and water samples to $25^{\circ} \mathrm{C}$ is to make the values comparable and also to correct for ambient temperature deviations in Ghana. In addition to the above corrections carried out on the raw $\delta^{18} 0$ values for the water samples, the bath temperature which was equilibrated at $31^{\circ} \mathrm{C}$ was also corrected to $25^{\circ} \mathrm{C}$ to determine the final $\delta^{18} 0$ values plotted in Figures 6 and 7 .

Figure 8 summarizes the $\delta^{13} \mathrm{C}$ of the 3 sites. The average $\delta^{13} \mathrm{C}$ of Sunyani and Achimota is -11 while that of Krobo is -14 . The point sandwiched between the dotted lines is an interpolation. Figures 9, 10 and 11 give plots of $\delta^{18} 0$ of both shell and water at each of the sites. The usefulness of this plot is that any correlation which exits between the water and shell $\delta^{18} 0$ would be obvious from the plots. Plots of $\delta^{18} 0$ of water and shell of each of the sites are shown in Figures 9, 10 and 11. The carbon and oxygen plots are shown in Figures 12, 13 and 14 . The $\delta^{13} \mathrm{C}$ and $\delta^{18} 0$ values from sequential analysis of shells from the three sites in December 1985, February 1986, and April 1986 are plotted in Figures 15, 16, and 17 respectively. 


\section{FIGURE 6}

PLOTS OF WATER $\delta^{18} 0$

FROM SUNYANI, KROBO

AND ACHIMOTA. 


\section{GHANA WATER 0-18 COMPARED}

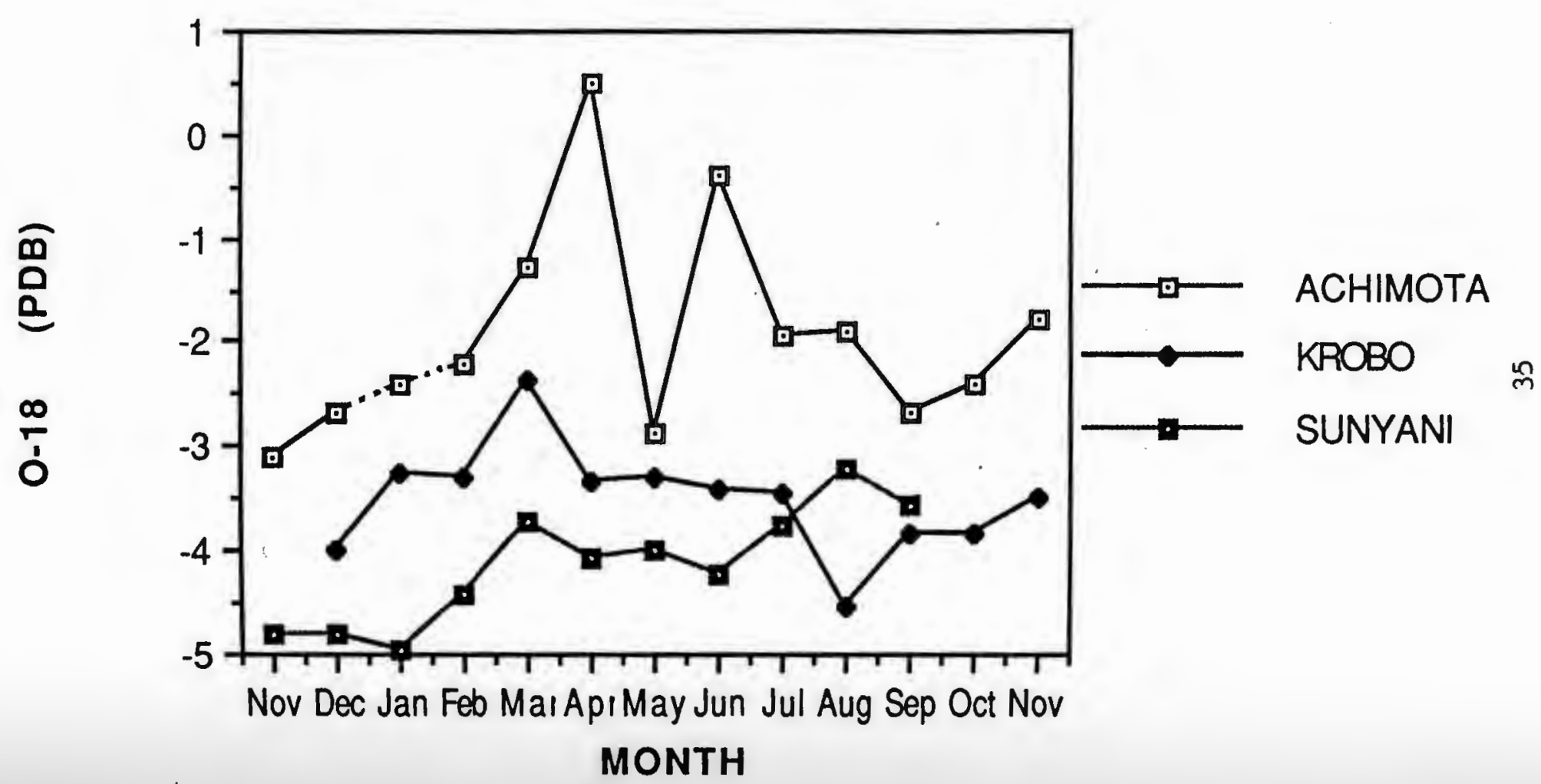


FIGURE 7

PLOTS OF $M$. TUBERCULATA $\delta^{18} 0$

FROM SUNYANI, KROBO AND ACHIMOTA. 


\section{GHANA SHELL 0-18 COMPARED}

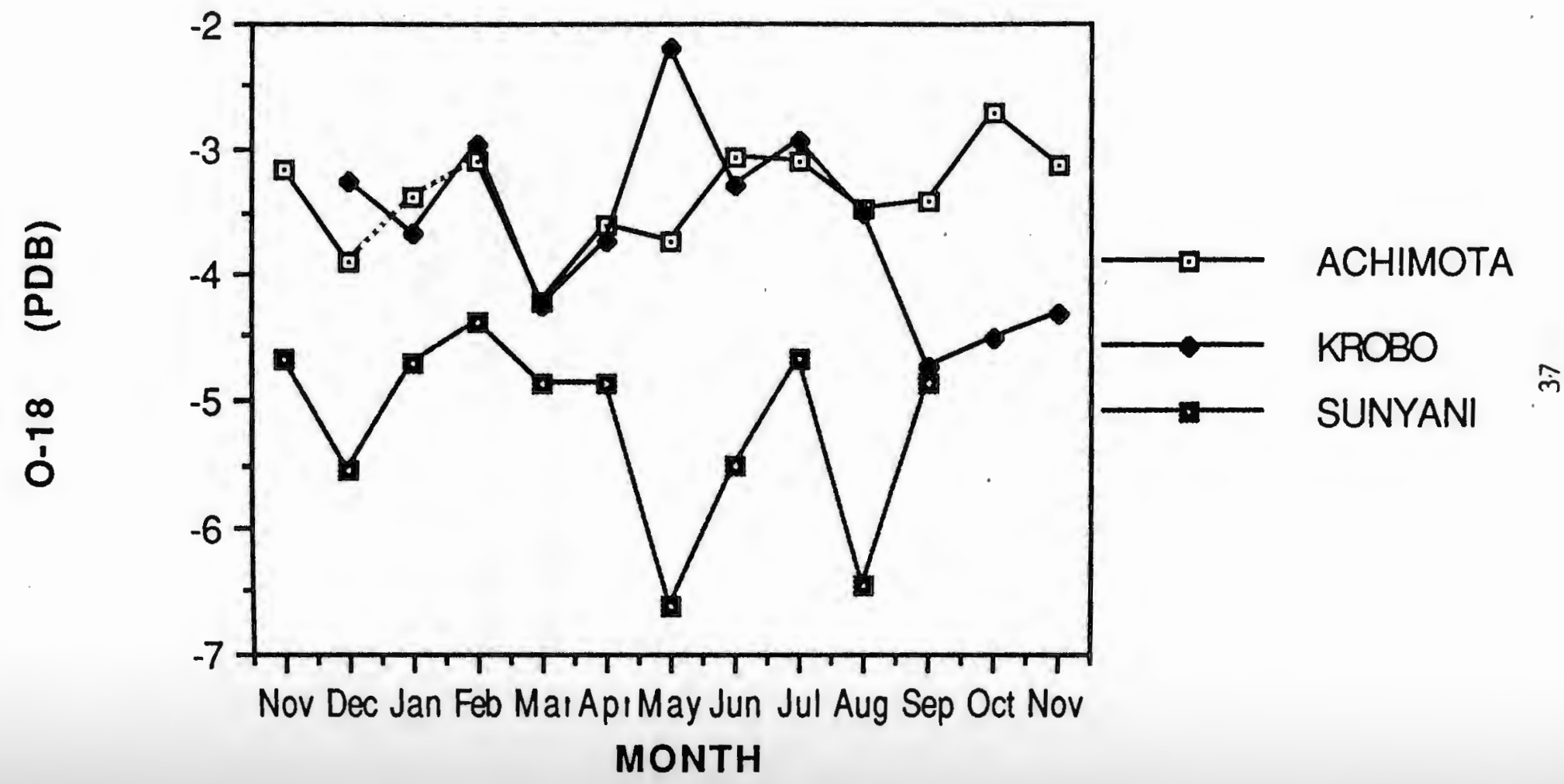


FIGURE 8

PLOTS OF MELANOIDES TUBERCULATA $\delta^{13} \mathrm{C}$

FROM SUNYANI, KROBO AND ACHIMOTA. 


\section{GHANA SHELL C-13 COMPARED}

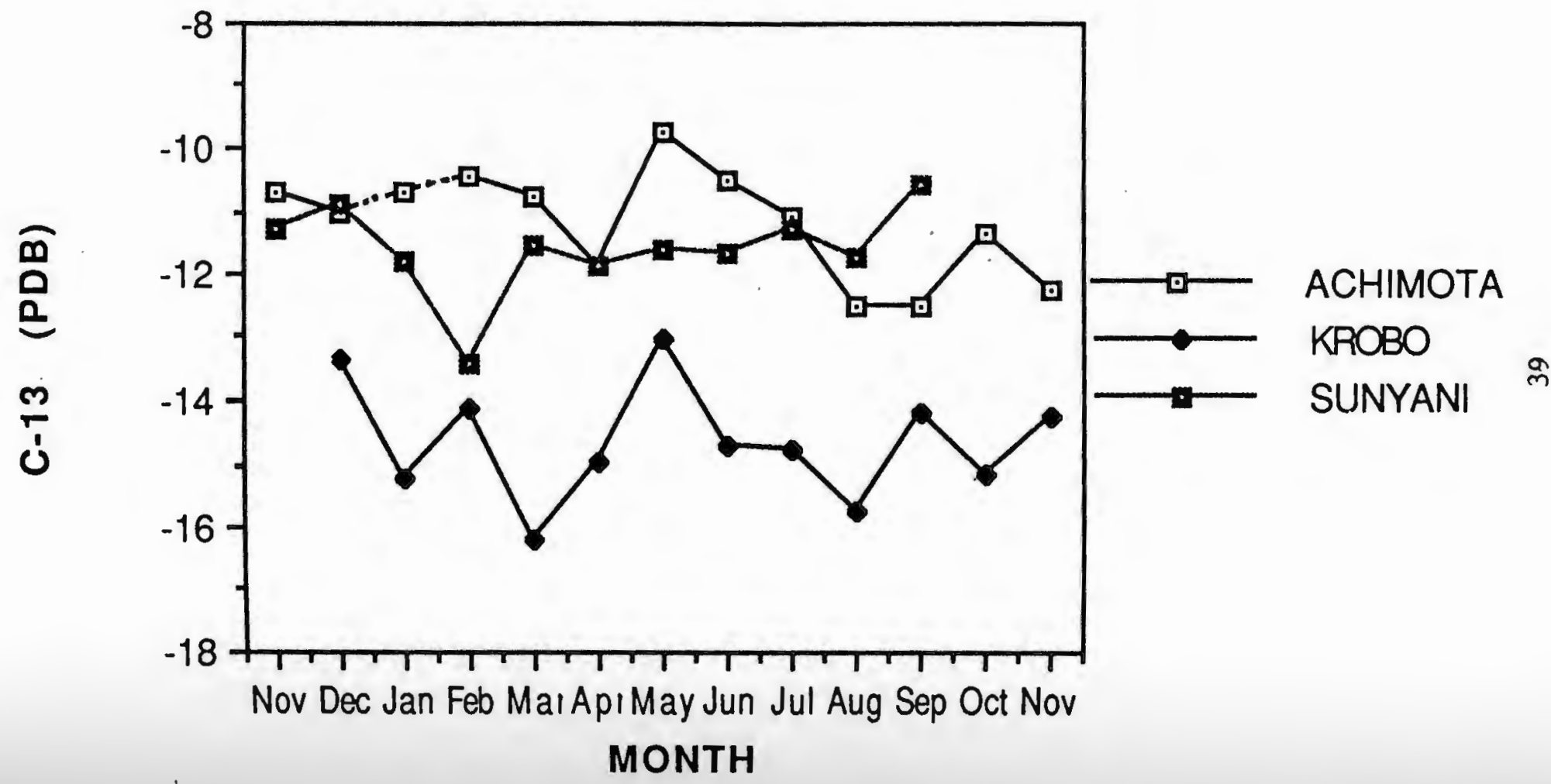


FIGURE 9

PLOTS OF WATER AND MELANOIDES $\delta^{18} 0$ FROM KROBO. 


\section{WATER AND SHELL O-18 FROM KROBO-GHANA}

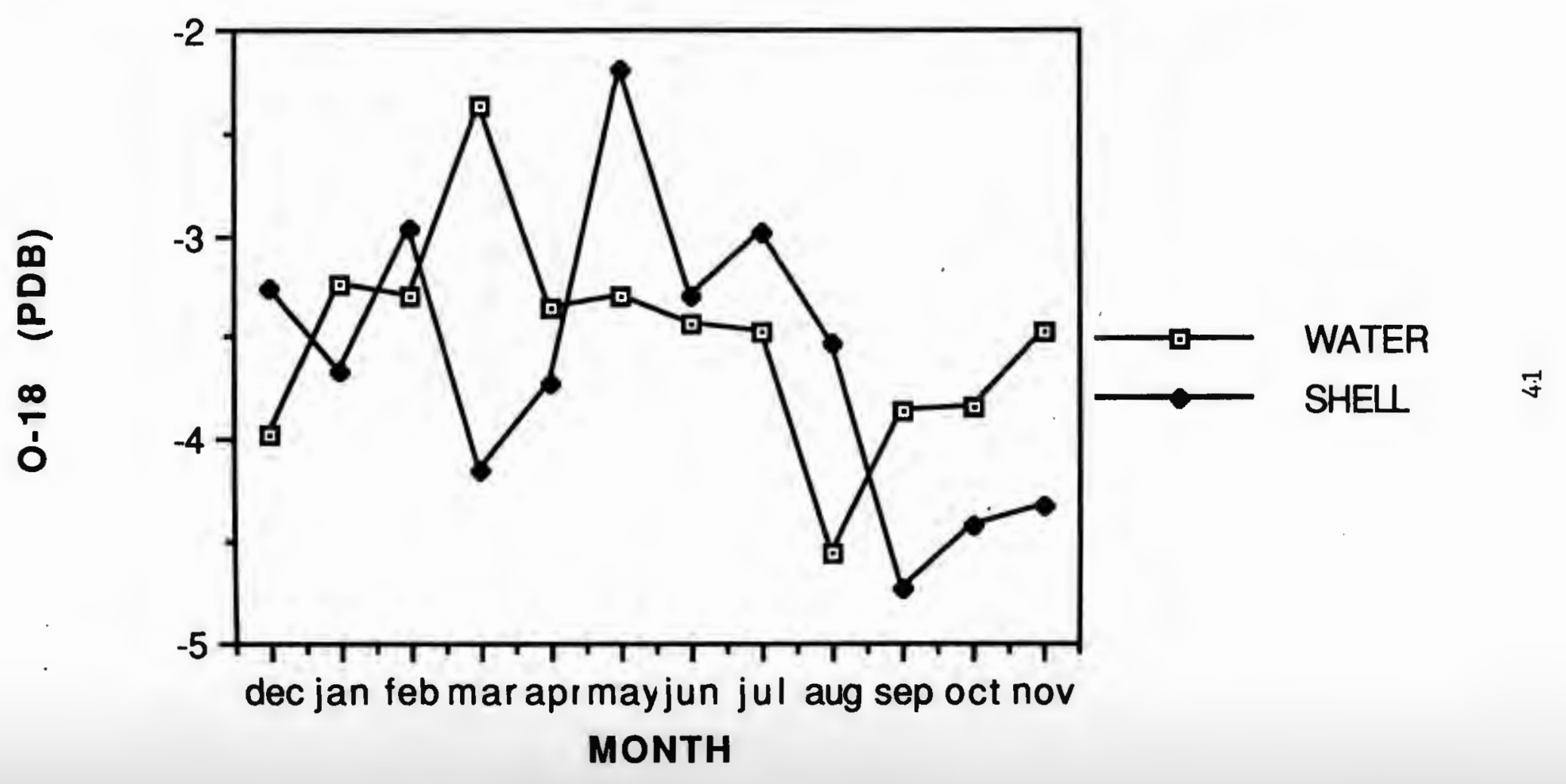


FIGURE 10

PLOTS OF WATER AND MELANOIDES $\delta^{18} 0$

FROM ACHIMOTA. 


\section{WATER AND SHELL 0-18 AT RIVER DENSU, ACHIMOTA}

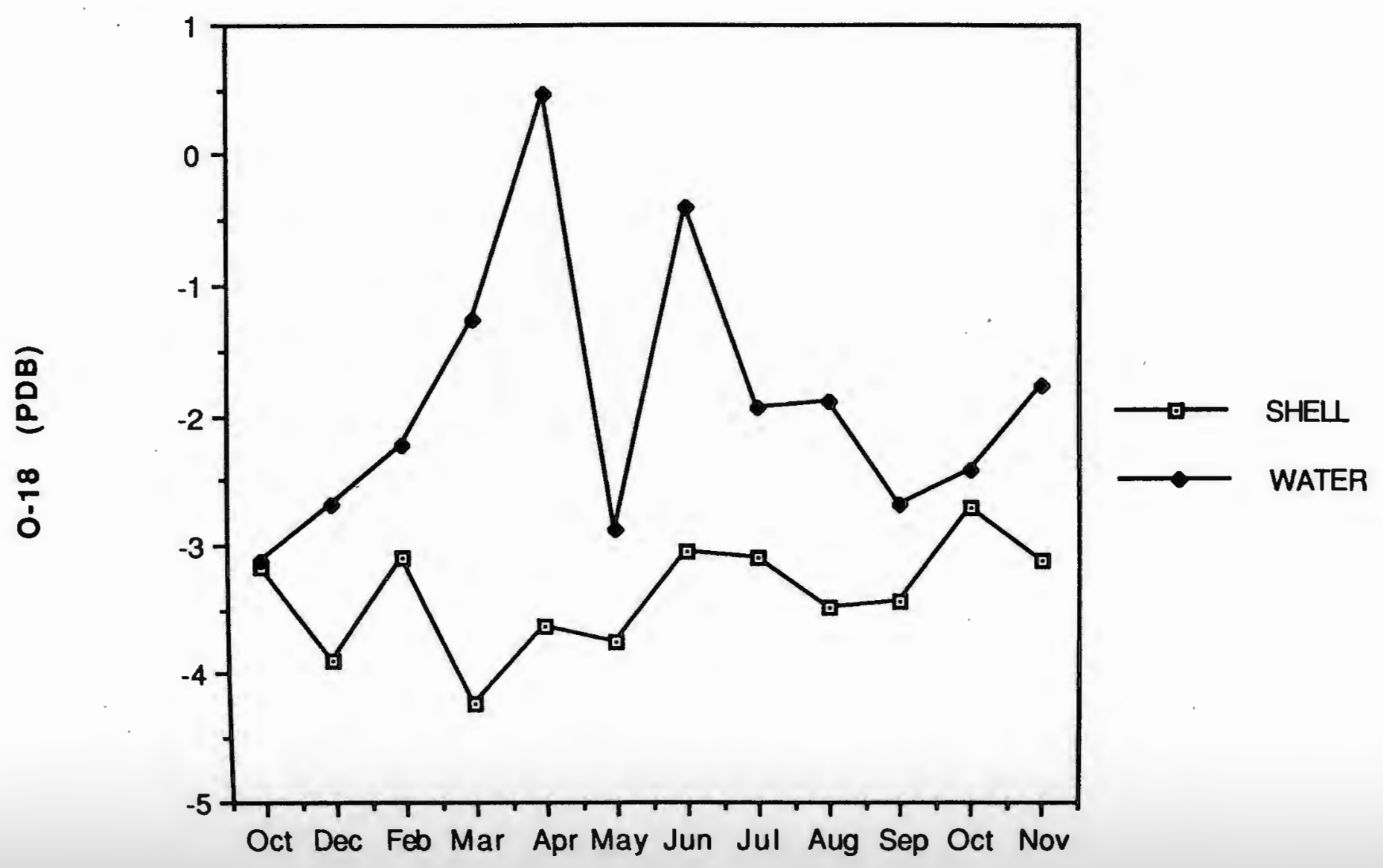




\section{FIGURE 11}

PLOTS OF WATER AND MELANOIDES $\delta^{18} 0$

FROM SUNYANI. 
WATER AND SHELL 0-18 AT SUNYANI STREAM

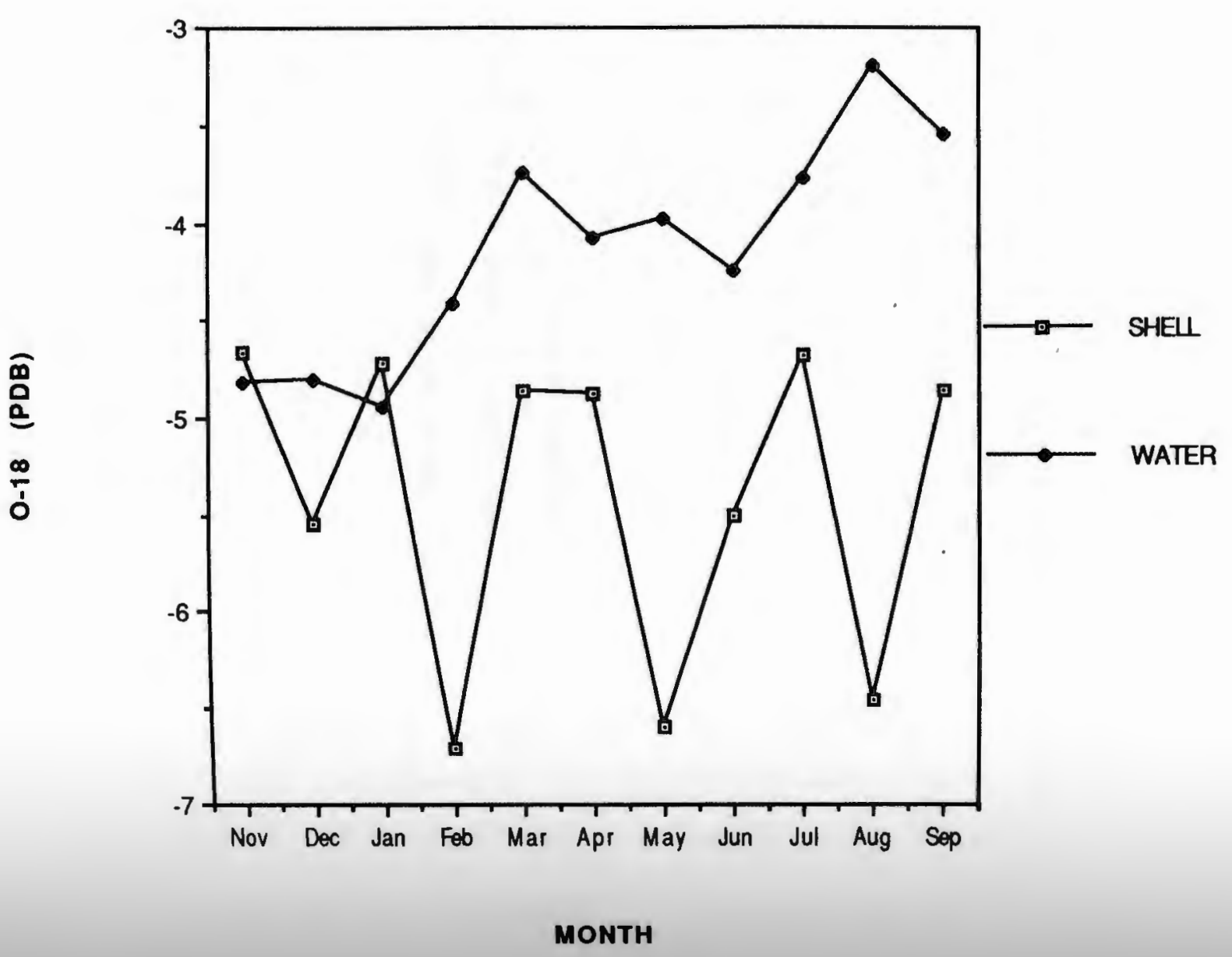




\section{FIGURE 12}

PLOTS OF KROBO WATER AND MELANOIDES

$\delta^{18} 0$. THE WATER ISOTOPE RATIOS ARE SHIFTED BY ONE MONTH. 


\section{0-18 OF WATER AND SHELLS FROM R. PRA,}

KROBO - GHANA (one month shift)

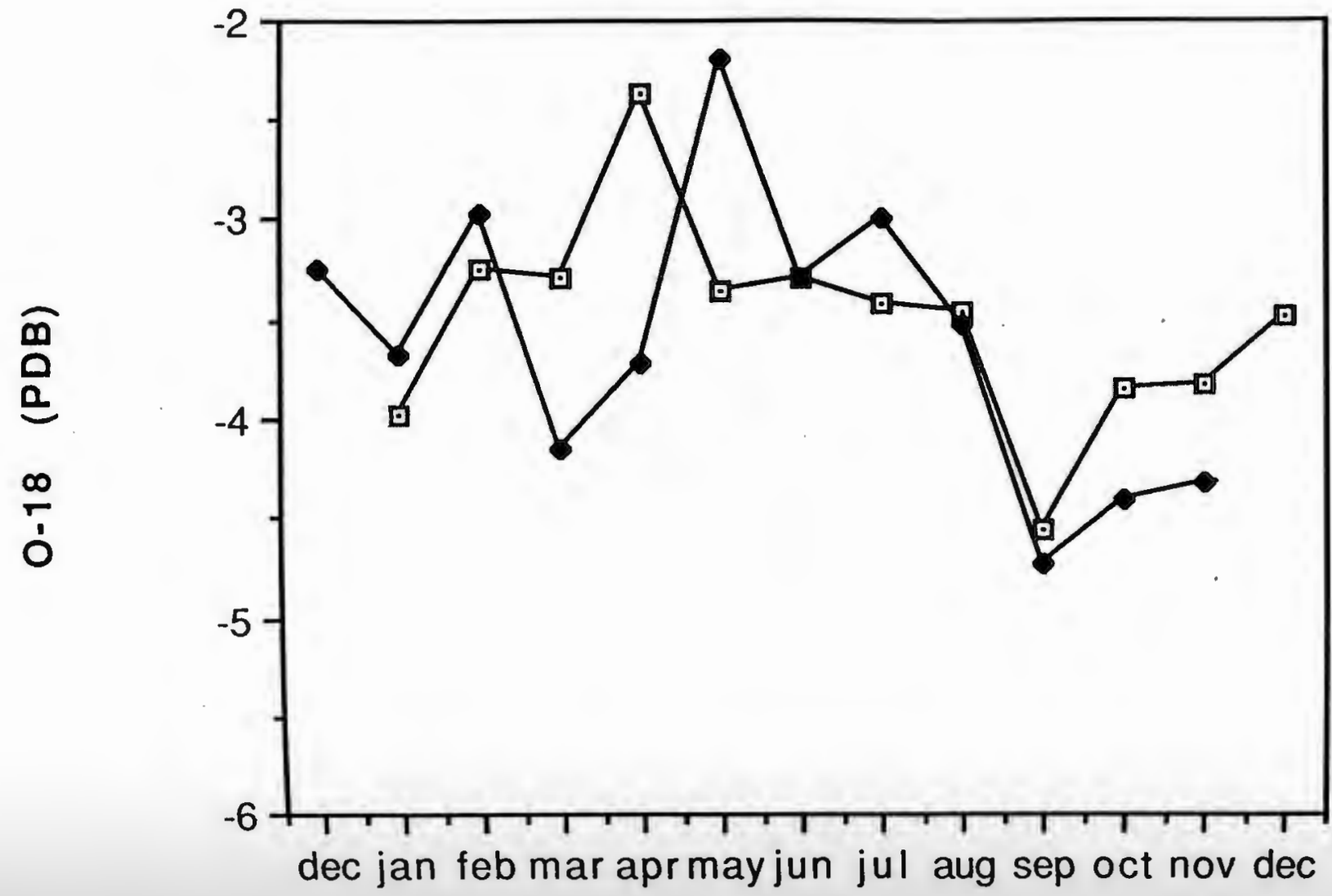

$\longrightarrow$ WATER

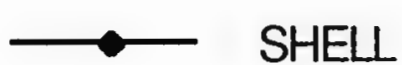


FIGURE 13

PLOTS OF ACHIMOTA WATER AND MELANOIDES

$\delta^{18} 0$ WITH THE WATER ISOTOPE RATIOS SHIFTED

BY ONE MONTH. 
0-18 OF WATER AND SHELL FROM R. DENSU, ACHIMOTA - GHANA (one month shift)

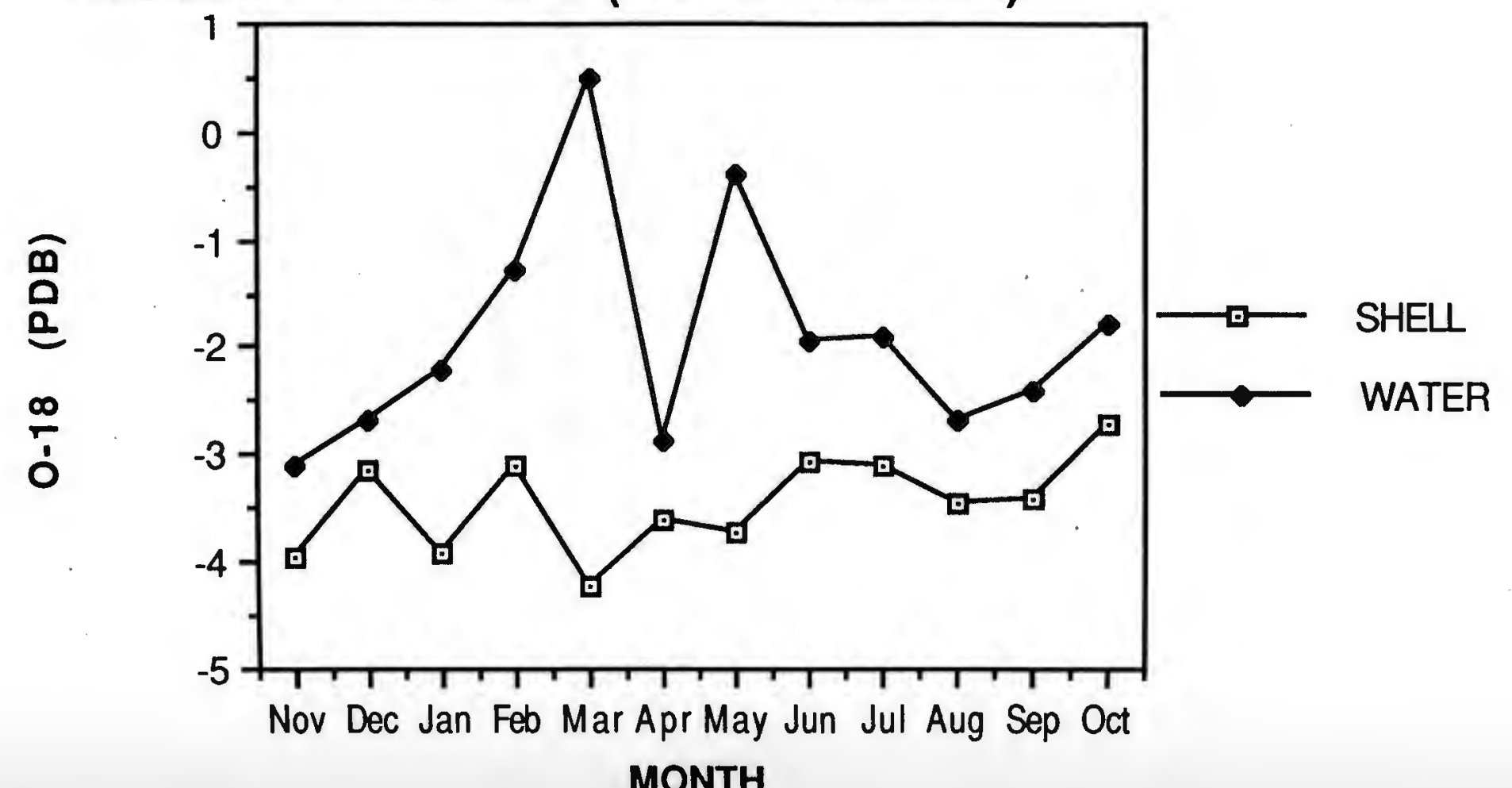


FIGURE 14

PLOTS OF SUNYANI WATER AND MELANOIDES

$\delta^{18} 0$ WITH THE WATER ISOTOPE RATIOS

SHIFTED BY ONE MONTH. 


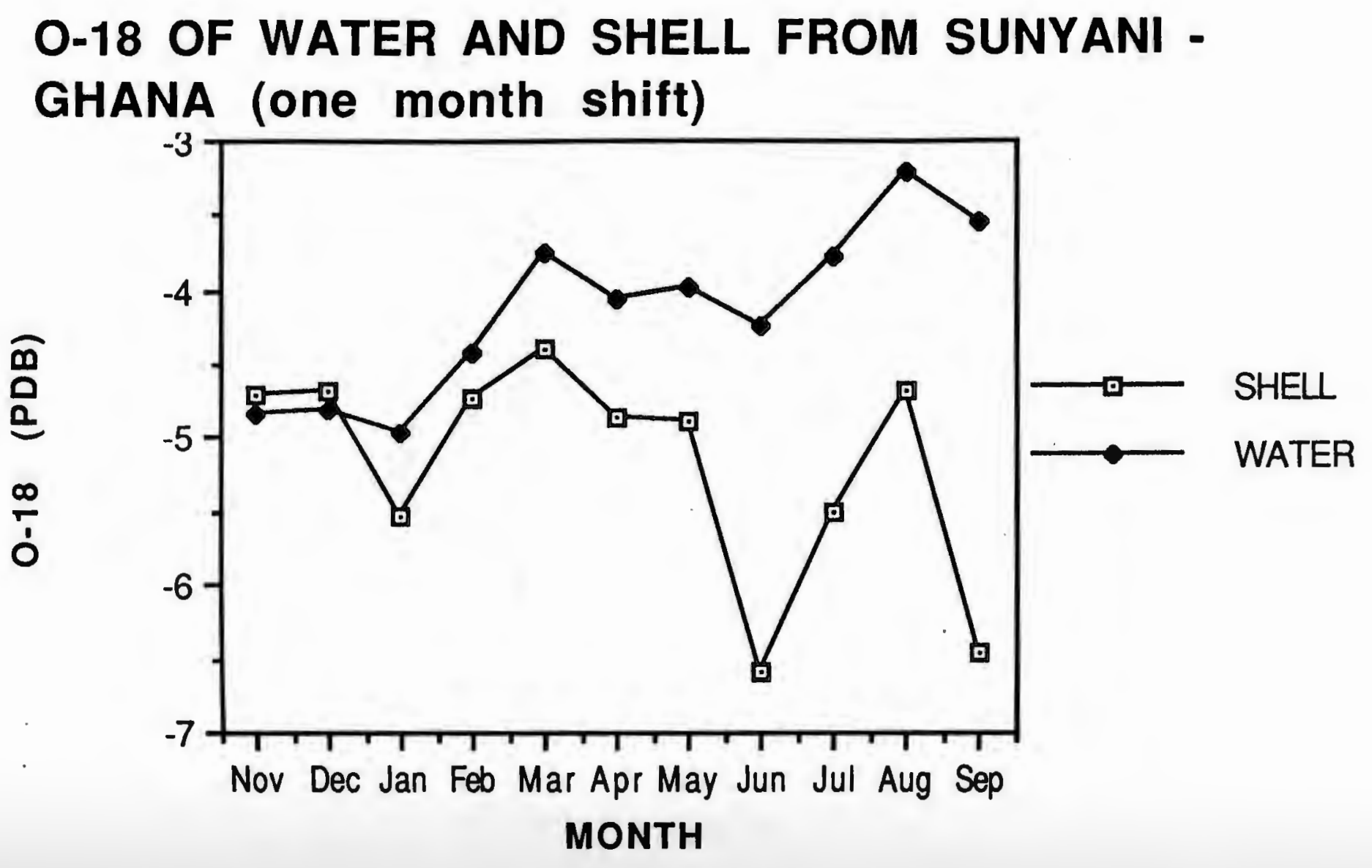


FIGURE 15

PLOTS OF APRIL SEQUENTIAL MELANOIDES

$\delta^{18} 0$ FROM SUNYANI, KROBO AND ACHIMOTA. 


\section{APR.'86 GHANA M. TUBERCULATA 0-18}

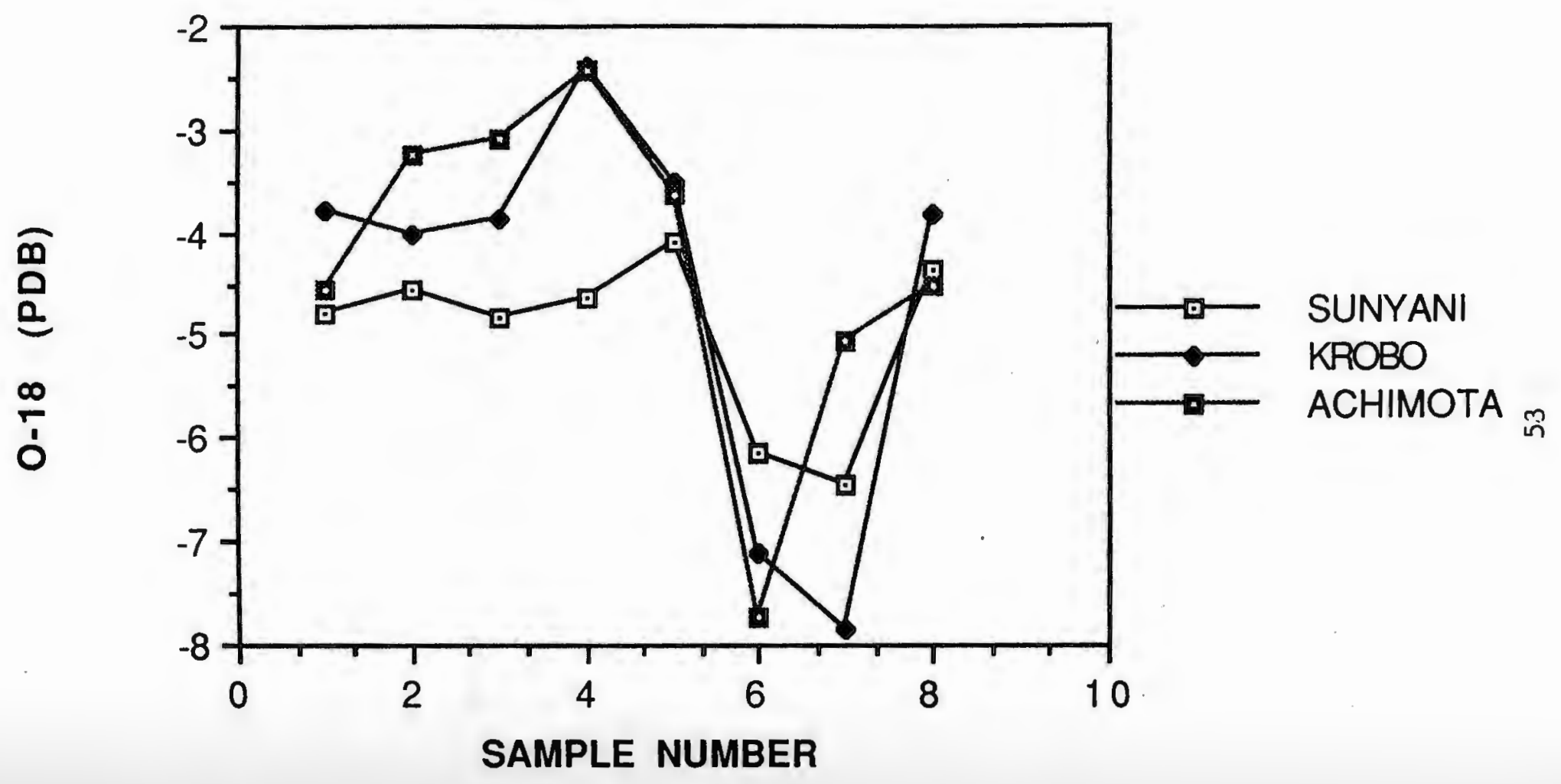




\section{FIGURE 16}

PLOTS OF APRIL SEQUENTIAL MELANOIDES

$\delta^{13} \mathrm{C}$ FROM SUNYANI, KROBO AND ACHIMOTA. 


\section{APR.'86 GHANA M. TUBERCULATA C-13}

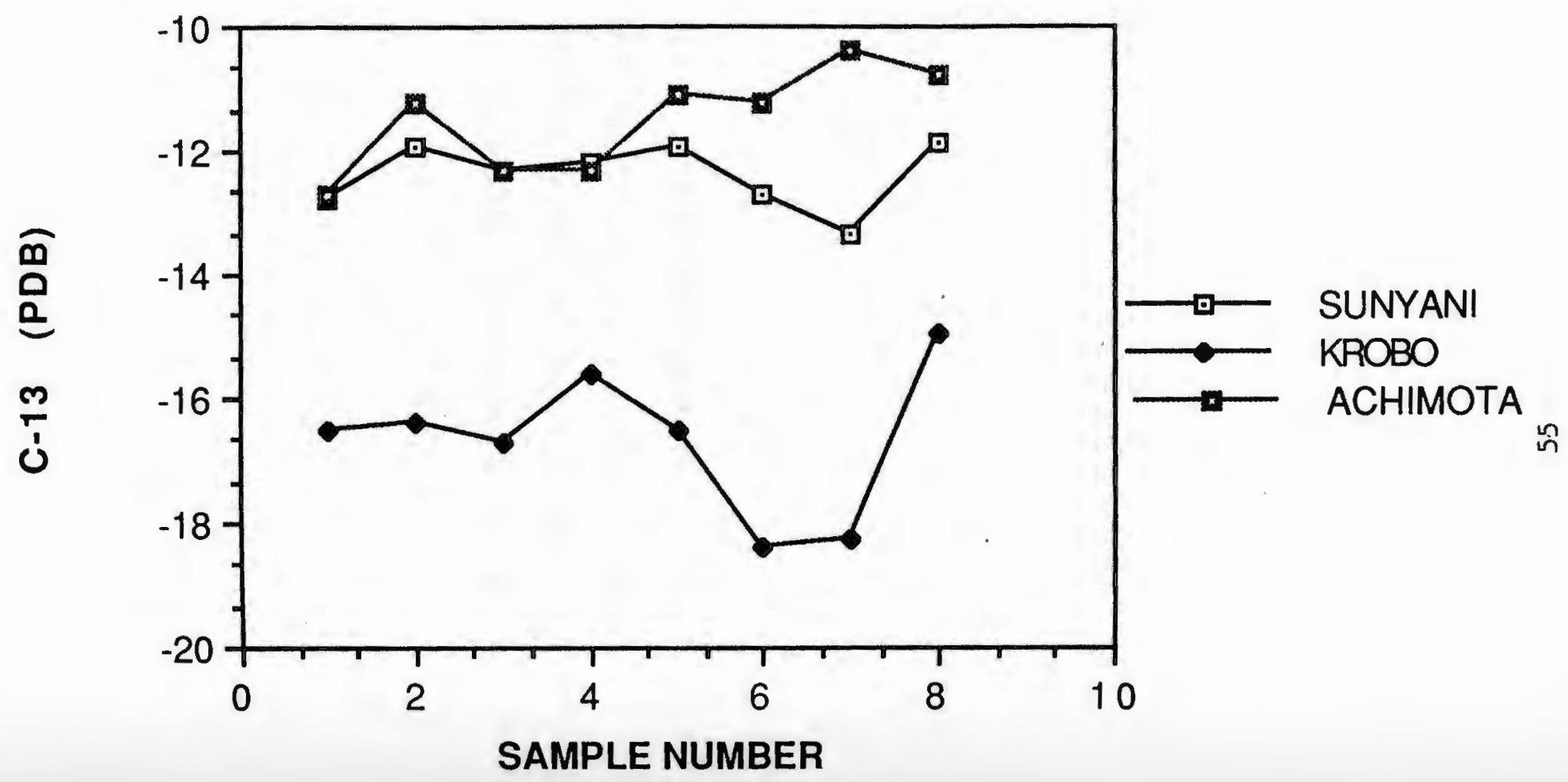




\section{FIGURE 17}

\section{PLOTS OF DECEMBER 1985 MELANOIDES \\ $\delta^{13} \mathrm{C}$ AND $\delta^{18} 0$ FROM SEQUENTIAL ANALYSIS \\ OF FOUR WHORLS. THE SAMPLES ARE FROM \\ SUNYANI, KROBO AND ACHIMOTA.}




\section{DEC.'85 GHANA M. TUBERCULATA RATIOS}

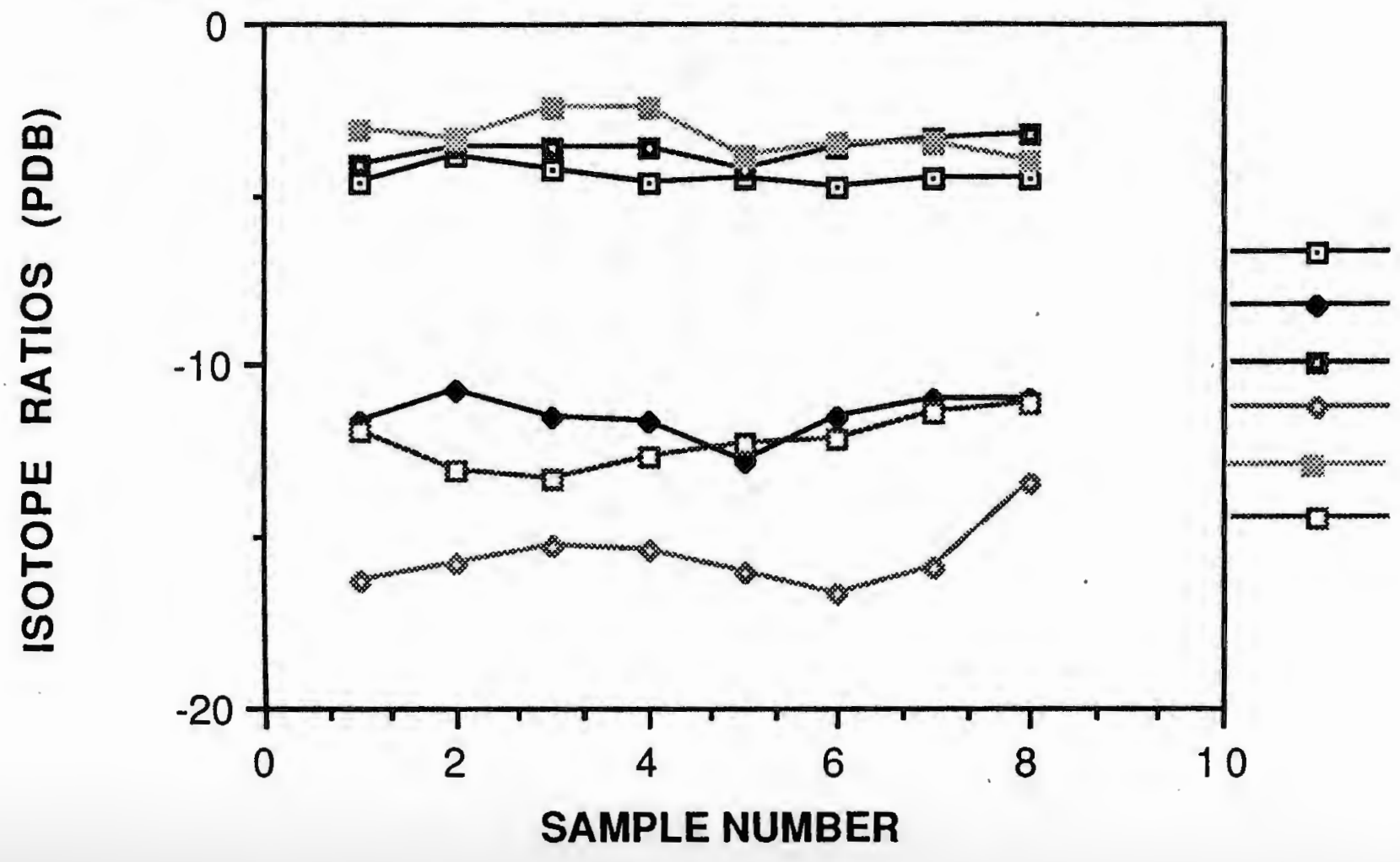

SUNYANI 0-18 SUNYANI C-13

KROBO 0-18

KROBO C-13 ACHIMOTA 0-18 ACHIMOTA C-13 


\section{FIGURE 18}

PLOTS OF FEBRUARY 1986 MELANOIDES

$\delta^{13} \mathrm{C}$ AND $\delta^{18} 0$ FROM SEQUENTIAL ANALYSIS

OF FOUR WHORLS. THE SAMPLES ARE FROM

SUNYANI, KROBO AND ACHIMOTA. 


\section{FEB.'86 GHANA M. TUBERCULATA RATIOS}

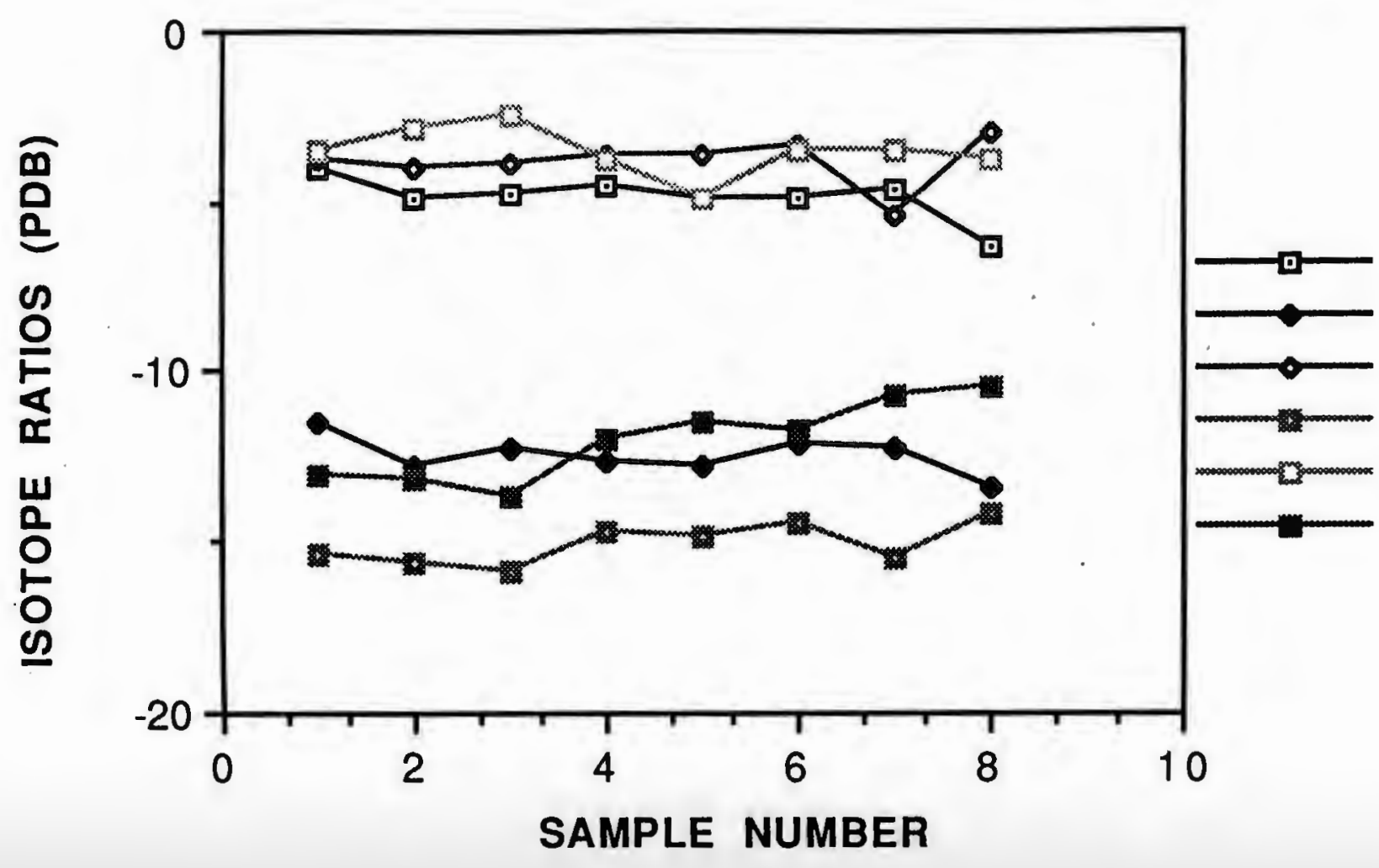

SUNYANI 0-18 SUNYANI C-13 KROBO 0-18 $\mathrm{KROBO} \mathrm{C}-13$ in ACHIMOTA 0-18 ACHIMOTA C-13 
FIGURE 19

PLOTS OF APRIL 1986 MELANOIDES

$\delta^{13} \mathrm{C}$ AND $\delta^{18} 0$ FROM SEQUENTIAL ANALYSIS

OF FOUR WHORLS. THE SAMPLES ARE FROM

SUNYANI, KROBO AND ACHIMOTA. 


\section{APR.'86 GHANA M. TUBERCULATA RATIOS}

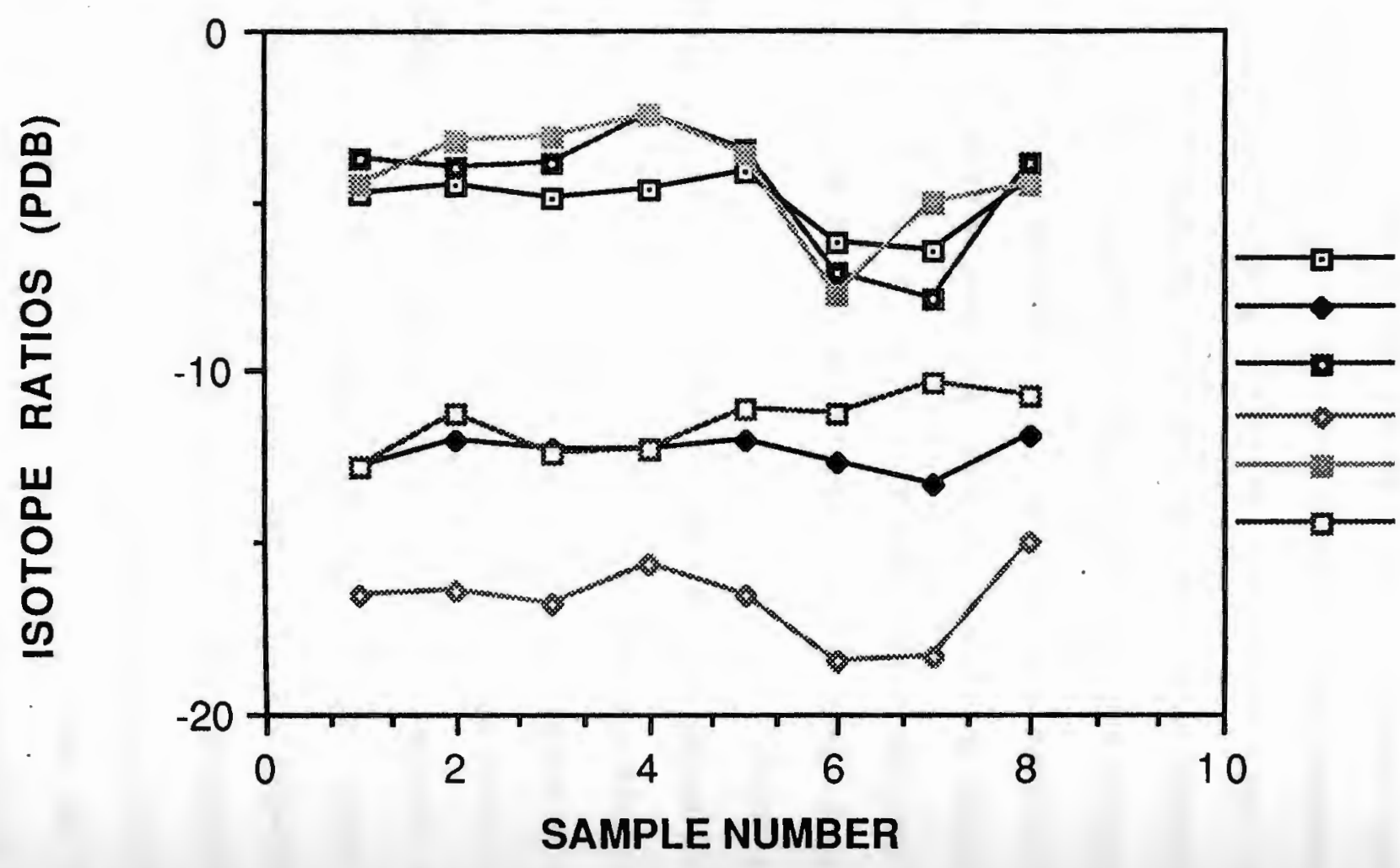

SUNYANI 0-18 SUNYANI C-13 KROBO 0-18 KROBO C-13 ACHIMOTA 0-18 ACHIMOTA C-13 


\section{USSION OF RESULTS}

A good understanding of the information gathered from the three sites require the examination of those factors in the environment that may influence the $\delta^{18} 0$ and the $\delta^{13} \mathrm{C}$.

That Influence The 0xygen Isotope Ratios In Shells And Water

The following factors have been identified as influencing the water and shell oxygen isotope ratios : latitude, altitude, precipitation (amount effect), and temperature ( evaporation and humidity). Altitude effect is brought about as a result of fractionation gradient at different elevations. It is known that fractionation of precipitation is very significant at higher elevations. The latitude at which the rain fell should influence the oxygen isotope ratios significantly.

Temperature plays a very vital role in the determination of the $\delta^{18} 0$ of both the shells and the water in which they grew. Just as air temperature alters the oxygen isotope ratios of precipitation so do air and water temperature influence the precipitation of aragonitic shells. The paleoclimatic scale of Craig (1965) is based on this principle. In most modern environments studied, the air temperatures correlate in parallel with the water temperatures. Evaporation which is also temperature dependent and engendered by dry wind may concentrate a body of water thereby, enriching its isotope ratios as well as that of the molluscs. In environments with high humidity, rainfall and moderating temperatures, evaporation is reduced and therefore, the oxygen isotope ratios of the gastropod shells are less enriched. 
Gastropods, sampling the oxygen isotope ratios in that rainwater in their host body of water, will generally provide a faithful record of that isotope ratio, particulary if the gastropods lived in large deep bodies of water, resistant to evaporative changes or in areas where rainfall is persistent through much of the year and humidity is high enough to discourage evaporative fractionation. The deep lakes, Ianganyika and Malawi, are the obvious examples of those bodies of water large enough to resist short term evaporative change, while the rivers and lakes in the tropical forest of Central and West Africa are going to be characterized by low evaporation (Abell, 1985). On the other hand, there are a number of areas where control of $\delta^{18} 0$ will be largely by evaporation. The shallower East African and Southern Saharan lakes will be maintained by seasonal rainfall in their source areas, but will be subject to continuous high evaporation rates. Lake Turkana, for example, fed largely $(80 \%)$ by seasonal rainfall in the highlands of Ethiopia, has a climate of relatively unchanging temperature, but the lake level, and the $\delta^{18} 0$ of the gastropod shells oscillates with this seasonal imput. In all these arid locations, the average value of $\delta^{18} 0$ will be positive, reflecting the prevailing evaporative condition.

The combination of temperature and evaporation are enough to offset the latitudinal effects of several permil. These general climatic trends and their manifestation in the oxygen isotope ratios of gastropod shells has been reported by Abell (1985). Latitudinal effects produce $\delta^{18} 0$ values near -4 to $-5 \%$ at the equator, and extending to 8 to $-9 \%$ at the northern and southern extremes of Africa. Evaporative situations in East Africa are clearly delineated with $\delta^{18} 0$ values near 
+1 to $+2 \%$. The regional anomaly in the Transvaal area of South Africa is also obvious. Abell's isotopic ratio map supplies the norms for isotope ratios and climatic patterns of modern Africa, but it also supplies examples of regional effects which can be used for the interpretation of paleo-isotope ratios. Some general observations have emerged from the recent studies of $\delta^{18} 0$ values and their correlation with environmental conditions. One of such observations is that in cool, high and regular rainfall areas, where $\delta^{18} 0$ of shell is -3 to $5 \%$, in situ evaporation is probably much less important than temperature in controlling $\delta^{18} 0$. But where rainfall is light, and conditions are arid and hot, in most circumstances temperature variation is small, and the $\delta^{18} 0$ values are predominantly governed by evaporation. For example, at both Lake Malawi and Lake Victoria (Winam Gulf) there is minimal temperature change with the seasons, but $\delta^{18} 0$ of the shells varies considerably (Amegashitsi, Abell \& Ochumba, unpublished). There will be exceptions to these generalities, but they make a starting point.

In an attempt to apply these interpretations to paleoclimates we must not lose sight of the importance of the correlation between amount effect or rainfall and vegetation. The amount effect which according to Dansgaard (1964) is engendered by the deep cooling of air in heavy frequent rainfall, with minimum possible post-precipitation enrichments through evaporation, has been found to correlate well with vegetation cover (Tucker et al., 1985, Abell, 1985). With respect to the African climate, it has been found that areas with enough rainfall, and rainfall sufficiently well distributed throughout the year to ensure permanent 
vegetation cover, show $\delta^{18} 0$ values ranging from -3.5 to $-0.9 \%$ or lower. West African and Central African gastropods fall in this category of depleted $\delta^{18} 0$, an indication of amount effect overwhelming latitudinal effect. Similar effect may be applicable in the coastal regions of East Africa, Malagasy and South Africa where latitudinal effect is masked by amount effect. By these observations, vegetational cover maps could be used to correlate $\delta^{18} 0$ values of shells and environments because they integrate over time the effects of rainfall and provide topographically continuous information. In applying $\delta^{18} 0$ values of gastropod shells to estimate paleoclimate, negative values of $\delta^{18} 0$ will indicate environments of substantial rainfall while very positive $\delta^{18} 0$ values will give an indication of areas of evaporative control of the oxygen isotope ratios taking into consideration predicted latitudinal isotope ratio values.

\section{That Influence Carbon Isotope Ratios}

If all the carbon in the molluscan shells was derived from dissolved inorganic carbon, the expected range of $\delta^{13} C_{s h e 11}$ would be near $0 \%$, but if all were metabolic carbon, then the expected range would be anywhere from -30 to $-9 \%$. The $\delta^{13} \mathrm{C}$ values for molluscan species collected from most of the African lakes are within -9 to $+2 \%$ 。 range (Abell, 1982, 1985; Abell and Nyamweru, 1988; Abell and Williams, 1989).

The above factors that influence the $\delta^{18} 0$ in shells will not affect the $\delta^{13} \mathrm{C}$ in the same way as they do the $\delta^{18} 0$, due to the various sources of carbon available to the molluscs. Changes in $\delta^{13} \mathrm{C}$ may be 
attributed to varying utilization of DIC or changes in the photosynthetic activity, both of which may be associated with. temperature changes (Stuiver, 1970). There are other factors which also contribute to the changes in $\delta^{13} \mathrm{C}$ and limit the use of $\delta^{13} \mathrm{C}$ as a climatic indicator. Carbon in shells of freshwater systems may come from dissolved inorganic carbon or allochthonous and autochthonous organic matter. They can also ingest limestone particles but the major species has been observed to be bicarbonate ion (Hem, 1970). 0ther species that are present in water in relative amounts are $\mathrm{CO}_{2}(\mathrm{aq}), \mathrm{HCO}_{3}^{-}$ and $\mathrm{CO}_{2}{ }^{2-}$ (Hitchon and Krouse 1972). Their concentrations in a given system vary with temperature, $\mathrm{pH}$ and $\mathrm{P}_{\mathrm{CO} 2}$ of the atmosphere.

We know that long residence time of rainfall in a given body of water could cause enrichment in the ${ }^{13} \mathrm{C}$ through exchange with atmospheric $\mathrm{CO}_{2}$. However, experimental observations of Deuser and Degens (1967) suggest that there is no ${ }^{13} \mathrm{C}$ fractionation in $\mathrm{CO}_{2}(\mathrm{~g})$ through the air-water interface in a $\mathrm{CO}_{2}(\mathrm{~g})-\mathrm{CO}_{2}(\mathrm{aq})-\mathrm{HCO}_{3}{ }^{-}(\mathrm{aq})$ system. Wendt (1968) has reported a negligible difference of $-0.56 \%$, in the $\mathrm{CO}_{2}(\mathrm{~g})-\mathrm{CO}_{2}(\mathrm{aq})$ phase and a temperature dependent fractionation.

In the study of the stable isotope mass-balance of DIC during blue-green algae bloom in a softwater lake, Herczeg and Fairbanks (1987) have found an enrichment factor of $13 \%$, for $\mathrm{HCO}_{3}^{-}$with respect to $\mathrm{CO}_{2}(\mathrm{~g})$ for a solution at $\mathrm{pH} 9.5$ and suggested that a chemical enhancement of $\mathrm{CO}_{2}(\mathrm{~g})$ at high $\mathrm{pH}$ may also cause enrichment close to this value. They have attributed the anomalous $\delta^{13} \mathrm{C}$ they were reporting in the softwater lake to the fractionation induced by photosynthetic algae when dissolved $\mathrm{CO}_{2}$ concentration is high in surface freshwater. The $\delta^{13} \mathrm{C}$ of the algae 
is depleted by $13 \%$ with respect to the aqueous $\mathrm{CO}_{2}$ when its concentration is above that of $P_{\text {atm }}$ and $u p$ to $20 \%$ when the concentration of aqueous $\mathrm{CO}_{2}$ is far greater than that of the atmosphere (Rau, 1978; Herczeg and Fairbanks, 1987). In another recent development, Tanaka et $\underline{\text { al. }}$ (1986) have found that a large percentage of carbon in calcereous tests from New Haven Harbor, Connecticut in the Long Island Sound is metabolic. Their results of shell $\delta^{13} \mathrm{C}$ show that without metabolic carbon incorporation, the values should be approximately $2 \%$ o heavier than the $\delta^{13} \mathrm{C}$ of dissolved inorganic carbon while with about $50 \%$ incorporation of metabolic carbon the values could vary anywhere from 0.3 to $7.5 \%$ lighter, with the actual value determined by $\delta^{13} \mathrm{C}$ of the food source.

Cerling et al.(1989) have observed a $\delta^{13} \mathrm{C}$ difference of $14-16 \%$ 。 between modern soil carbonate and an undisturbed coexisting organic matter. An identical difference was observed between the $\delta^{13} \mathrm{C}$ of organic matter and pedogenic carbonate from palaeosols of Pleistocene to late Miocene age in Northern Pakistan. These findings are in agreement with isotopic equilibrium between $\mathrm{CO}_{2}(\mathrm{~g}), \mathrm{HCO}_{3}{ }^{-}(\mathrm{aq}), \mathrm{CO}_{2}{ }^{2-}$ and aqueous and solid carbonate species in a soil system controlled by diffusive mass transfer of soil $\mathrm{CO}_{2}$ derived from irreversible oxidation of soil organic matter. An enrichment of up to $2 \%$ of the $\delta^{13} \mathrm{C}$ of soil carbonate in low respiration rate soils at a depth of $50 \mathrm{~cm}$ has been reported by Quade et al.(1989). This enrichment has been attributed to diffusional mixing of atmospheric $\mathrm{CO}_{2}$ and plant derived $\mathrm{CO}_{2}$. The $\delta^{13} \mathrm{C}$ and $\delta^{18} 0$ of the Miocene Siwalik Group sediments in Northern Pakistan show a dramatic ecological shift from $C_{3}$ to $C_{4}$ dominated flood plain 
biomass. As a result of fractionation effect, the $\mathrm{C}_{3}$ and $\mathrm{C}_{4}$ biomass in soil carbonate would have -12 and $2 \%$ repectively at $25^{\circ} \mathrm{C}$.

It has been observed by Abell (1989) that shells with depleted values of $\delta^{13} \mathrm{C}$, will indicate incorporation of substantial fraction of carbon derived from photosynthetically produced organic material such as algae or plant detritus. Parallelism observed between carbon and oxygen In most of the analyses may reflect changing organic productivity with the changing supply of nutrients introduced by fresh water imput.

\section{TON OF ENVIRONMENTAL CHANGES IN SHELL AND WATER ISOTOPE RATIOS}

The plots in Figures 6 , and 7 show $\delta^{18} 0$ values for both shells (aperture samples) and water corrected to PDB and temperature corrected to $25^{\circ} \mathrm{C}$. It can be observed that there is a correlation between the $\delta^{18} 0$ values of the gastropod shells and those of the water samples, and that the shell isotope ratios lag behind water isotope ratios by about 1 month. Deviations from an exact correlation are to be expected, given that an instantaneous sampling of a constantly changing water supply may deviate from the time-averaged isotope ratio of a finite shell aperturegrowth that may have taken place over several weeks. The parallelism between the $\delta^{18} 0$ plots of the water and the shells, which is a good indicator as to the possibility of applying oxygen isotope ratios in paleoclimatology, is in accordance with an earlier observation by Epstein et al. (1953) that the oxygen isotope constant of calcite is dependent on both the $\delta^{18} 0$ and temperature of ambient water.

At Krobo, the Collector's monthly remarks on water level of the River Pra which were requested as part of this research project, and the 
prevailing climatic conditions during the period of water and gastropod collection correspond very well with the mean monthly rainfall values tabulated in Table 1 and also plotted in Figure 17 (Griffiths, 1972). In West and Central Equatorial Africa where rainfall is high and well spread out over the year, such that there is permanent vegetative cover, $\delta^{18} 0$ values in gastropod shells have been observed to be between -3.5 to -0.9 per mil (Abell, 1985). Our values fall close to this range with the average monthly $\delta^{18} 0$ for the one year period being -3.51 for the water samples and -3.60 for the gastropod shells, giving a 0.11 per mil average difference between the shells and the water samples. Without any fractionation associated with land masses, the expected values of the $\delta^{18} 0$ at this latitude should have been approximately -1.0 or -2.0 (Abell, 1985). Here, this difference is attributable to an amount effect, which is substantiated by the $\delta_{s}-\delta_{w}$ values of -0.52 from the water and -0.54 from the shell. This is in consonance with the observation of Tucker et al., (1985) and Abell (1985) that the latitudinal effect is overwhelmed by the amount effect in tropical rainforests. (Figure 3) The seasonality information summarized in Table 2 can assist in the separation of the amount effect from the temperature effect in the tropics. This is accomplished by taking the difference between $\delta_{s}$, the unweighted mean $\delta$ value for summer and $\delta_{w}$, the unweighted mean $\delta$ value for winter. A negative $\delta_{s}-\delta_{w}$ indicates the predominance of amount effect in the tropics.

Shifting the $\delta^{18} 0$ plot of the water by one month gives a good correlation of the $\delta^{18} 0$ plots of water and shells as shown in Figures 12, 13 and 14. Both water values and shell values give a fairly good 
picture of changing climatic conditions, allowing for the lag in shell 1sotope ratios. The $\delta^{18} 0$ values of the water samples fall within a narrow range $-3 \%$ to $-4 \%$, except for March and August when $\delta^{18} 0$ values of -2.36 and -4.55 were recorded respectively. The high value recorded for March coincides with the month of maximum temperature. The low August $\delta^{18} 0$ value, on the contrary, corresponds well with the period of low temperature, high rainfall and the flooding of the River Pra. Similar correspondence is observed for the shell $\delta^{18} 0$ values plotted in Figure 9 except for the 1 month's slippage of the maximum $\delta^{18} 0$ from March to May and the minimum $\delta^{18} 0$ slipping from August to September. In general, the $\delta^{18} 0$ results are nearly constant except for a rise of $0.5 \%$ 。 in 0ctober for the shell and in December for the water samples. We attribute this general constancy to normal constancy of rainfall and temperature, and the one excursion as a consequence of the yearly arrival of the Harmattan.

Figure 4 shows the temperature profile of all the three sites during the sampling period of November 29, 1985 to October 15, 1986. The maximum, minimum, temperature range and average temperatures extracted from Collector's notes are summarized in Table 3 . The average temperature recorded in Table 3 was determined by the simple mean over 12 months period. Average summer and winter temperatures were obtained over 6 months period with summer in the Northern hemisphere defined by the months between May and october and winter months from November to April. Ambient temperature difference $\left(5^{\circ} \mathrm{C}\right)$ over the period of collection is twice that of the water temperature difference $\left(2.5^{\circ} \mathrm{C}\right)$ over the same period. The average summer temperature is lower than the 
average winter temperature.

Table 4 summarizes the correlation between water temperature, air temperature, precipitation and the oxygen isotope ratio values of both the water and the shell. The correlation factors for the water temperature values and the oxygen isotope ratios of the shell and water are 0.75 and 0.74 respectively. This correlation is further improved from 0.75 to 0.81 by shifting the oxygen isotope ratios of the shell one month to adjust for the lag in the $\delta^{18} 0$ incorporation into the gastropods.

\section{TABLE 2}

\section{SEASONALITY AND $\delta^{18} 0$ VALUES}

COLLECTION PERIOD : October 1985 - November 1986

$$
\underline{\delta^{18} 0 \text { OF WATER }}
$$

\section{Achimota Krobo Sunyani $\underline{\text { Achimota }}$ Krobo $\underline{\text { Sunyani }}$}

$\begin{array}{lllllll}\delta_{w} & -1.77 & -3.25 & -4.46 & -3.60 & -3.33 & -4.85 \\ \delta_{s} & -2.03 & -3.77 & -3.75 & -3.25 & -3.87 & -5.62 \\ \delta_{s}-\delta_{w} & -0.26 & -0.52 & 0.71 & 0.35 & -0.54 & -0.77\end{array}$

$\delta_{w}=$ Vinter oxygen isotope ratio

$\delta_{\mathbf{s}} \quad=$ Summer oxygen isotope ratio

Northern Hemisphere Summer Months : May - October.

Northern Hemisphere Winter Months : November - April. 


\section{TABLE 3}

MAXIMA, MINIMA AND AVERAGE TEMPERATURES ${ }^{\circ} \mathrm{C}$

SITE : Southern Ghana sites

COLLECTION PERIOD : October 1985- November 1986.

$\underline{\text { ACHIMOTA }} \underline{\text { KROBO }}$ SUNYANI AMBIENT (KROBO)

$\begin{array}{lllll}\text { Maximum Temperature } & 32.0 & 25.5 & 24.3 & 31.0\end{array}$

$\begin{array}{lllll}\text { Minimum Temperature } & 25.0 & 23.0 & 19.5 & 26.0\end{array}$

$\begin{array}{lllll}\text { Average Temperature } & 27.8 & 24.5 & 22.3 & 27.5\end{array}$

$\begin{array}{lllll}\text { Average Summer Temp. } & 27.3 & 23.9 & 22.4 & 26.9\end{array}$

Average Winter Temp. $\quad 28.3 \quad 25.1 \quad 22.2 \quad 28.0$

$\begin{array}{lllll}\text { Temperature Fluctuation } & 7.0 & 2.5 & 4.8 & 5.0\end{array}$ 
TABLE 4

SUMMARY OF CORRELATION VALUES

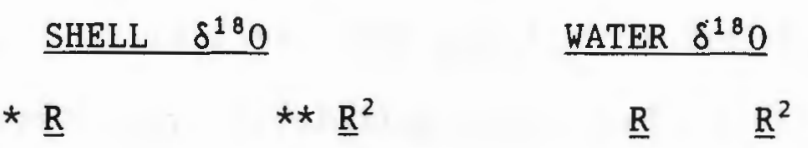

KROBO

Water Temperature

$0.74(0.81) \quad 0.55(0.65)$

$0.75 \quad 0.56$

Air Temperature

$0.67(0.33) \quad 0.45(0.11)$

$0.44 \quad 0.20$

Precipitation

$0.66(0.62) \quad 0.44(0.39)$

$0.42 \quad 0.18$

shell $\delta^{18} 0$

$0.68 \quad 0.47$

shell $\delta^{13} \mathrm{C}$

0.48

0.23

ACHIMOTA

Vater Temperature

0.54

0.29

$0.65 \quad 0.47$

Air Temperature

Relative Humidity

0.49

0.24

$0.13 \quad 0.13$

Shell $\delta^{18} 0$

$0.25 \quad 0.06$

Shell $\delta^{13} \mathrm{C}$

0.22

0.05

SUNYANI

Water Temperature

0.62

0.39

$0.57 \quad 0.32$

Air Temperature

0.46

0.21

$0.20 \quad 0.04$

Precipitation

0.45

0.20

$0.14 \quad 0.02$

Shell $\delta^{18} 0$

$0.14 \quad 0.02$

Shell $\delta^{13} \mathrm{C}$

0.55

0.30

$* \mathrm{R}=$ Coefficient of correlation $\quad * * \mathrm{R}^{2}=$ Coefficient of determination Correlation coefficients of one month slippage are in brackets. 
The correlation of precipitation with shell oxygen isotope ratios, 0.66 , and with water oxygen isotope ratios, 0.42 , are good, however, the shell $\delta^{18} 0$ values correlate better with precipitation than the water $\delta^{18} 0$ values. Air temperature correlations with shell $\delta^{18} 0$ and water $\delta^{18} 0$ are as good as the precipitation correlation with shell $\delta^{18} 0$ and water $\delta^{18} 0$. The correlation between the shell oxygen isotope ratio values and the water oxygen isotope ratios, 0.68 , is also listed in Table 4 .

The climatic conditions prevailing in the Southern rainforest region of Ghana consist of two rainy periods in March-July and Aptember-October. The September-0ctober rains in Ghana are followed by the Harmattan winds from the Sahara desert, which are characterized by high daytime temperatures with low humidity and dry cool nights. The Harmattan is usually intense during December and January (Beadle, 1974) however, during the sampling period, the highest intensity of the Harmattan winds was recorded in January and February. The highest $\delta^{18} 0$ value of -2.36 for the water was recorded in March, one of the months of high temperatures, which was reflected in the shell value as -2.20 in May, a lag of approximately 2 months. The Harmattan winds are comparatively less powerful than the Southeasterlies in August but because of their dryness they accelerate evaporation at the surface of standing waters and also provide the necessary energy for stirring. (Beadle, 1974) A lag of 1 month is observed between the $\delta^{18} 0$ values of the shells and that of the water. A low $\delta^{18} 0$ value of -4.55 is recorded in the $\mathrm{H}_{2} \mathrm{O}$ in August, while a low of -4.55 is recorded in the shell in September. The difference between the maximum and minimum $\delta^{18} 0$ for the 
water is -2.19 per mil while that of the shell is -2.53 per mil. In general $\delta^{18} 0$ results are nearly constant except for a rise of about 0.5\% in October for the shells and in December for the water samples. We attribute this general constancy to normal constancy of rainfall and temperature, and the one excursion as the consequence of the yearly arrival of the Harmattan.

The temperature effect is clearly demonstrated by the parallelism that exists between the $\delta^{18} 0$ plot of the water, the shell and the monthly temperature plot. The maximum ambient temperature, $31^{\circ} \mathrm{C}$, and the maximum water temperature, $25.5^{\circ} \mathrm{C}$, were both recorded in April while the minimum ambient temperature, $26.0^{\circ} \mathrm{C}$, and the minimum water temperature, $23.0^{\circ} \mathrm{C}$, were recorded for the month of August. The average monthly water temperature of $24.5^{\circ} \mathrm{C}$ was calculated for the collection period. The maximum and minimum $\delta^{18} 0$ values recorded by both shell and water correspond very well with the months for which maximum and minimum temperatures were recorded. The average ambient temperature was $3.0^{\circ} \mathrm{C}$ higher. The water temperature fluctuation was $2.5^{\circ} \mathrm{C}$ while the air temperature fluctuated by $5.0^{\circ} \mathrm{C}$ during the collection period. The average summer temperature is lower than the average winter temperature. A negative difference is obtained when the average winter temperture is subtracted from the average summer temperature. The conversion of this temperature difference to $\delta^{18} 0$ gives a negative $\delta^{18} 0$ value which substantiates the amount effect obtained by the difference between $\delta_{s}$ $\delta_{w} \cdot$

The amount effect is further substantiated by the correlation between precipitation and $\delta^{18} 0$ of both the water $(0.42)$ and the shells 
(0.66). By these correlation values it is observed that approximately $18 \%$ of the variations in the water $\delta^{18} 0$ values at the River Pra is due to the amount effect while approximately $44 \%$ of the variations in the shell $\delta^{18} \dot{0}$ values is attributable to the amount effect (Table 4). Significant correlations exist between shell $\delta^{18} 0$ and water $\delta^{18} 0$, air temperature and precipitation, however, the correlation between shell $\delta^{18} 0$ and water temperature is even better $(0.74)$. This is understandable because the microenvironment of the gastropod is greatly Influenced by the water temperature. For all practical purposes, the correlation between water $\delta^{18} 0$, shell $\delta^{18} 0$ and water temperature are the same 0.75. Since it does not rain heavily all year round, the precipitation influences the $\delta^{18} 0$ variation by approximately $44 \%$ leaving the major influence, $55 \%$, of the $\delta^{18} 0$ values to water temperature variation which improves considerably with the slippage (65\%).

SUNYANI

The water $\delta^{18} 0$ was responsive to the effect of temperature as can be seen in Figure 6 . At a temperature of about $20^{\circ} \mathrm{C}$ during the Harmattan months (Nov-Jan) $\delta^{18} 0$ of the water was $-5 \%$ 。 but became enriched by $1 \%$, with a $2^{\circ} \mathrm{C}$ increase in temperature. The oxygen isotope ratios remained almost constant until a further temperature increase in July and August, when it was enriched by another $1 \%$. Therefore, for a temperature range of $3^{\circ} \mathrm{C}$, a $2 \%$ e enrichment was observed. A poor correlation exists between the water $\delta^{18} 0$ and shell $\delta^{18} 0$ (Figure 11). It should be noted that this collection site was in a fast flowing body of water and in this high rainfall region, changes in $\delta^{18} 0_{\mathrm{H} 2 \mathrm{O}}$ may occur too rapidly to be recorded by slow shell accretion. The robust shells, 
however, recorded a $\delta^{18} 0$ range of $2 \%$ throughout the collection period. According to Dansgaard (1964) a one degree change in temperature should bring an average change in the oxygen isotope ratio of $0.7 \%$ of water.

The shell oxygen isotope ratios predicted for this general area according to Abell (1985) is recorded as -4 while at this location we find an average shell isotope ratio of -5.4 . The depletion may be attributed to altitudinal effect and limited evaporation due to vegetation cover at the collection site. According to Dansgaard (1964) and Yurtsever (1975) the altitudinal effect will cause a depletion in the $\delta^{18} 0$ and it should be noted that Sunyani is at an altitude of $310 \mathrm{~m}$. A lapse rate of $0.5 \%$, per $3^{\circ} \mathrm{C}$ is reported (Abell, 1989) for changes in $\delta^{18} 0$ with altitude difference of $500 \mathrm{~m}$ between Lake Besaka and Aladi Springs.

Although the shell $\delta^{18} 0$ values at Sunyani do not correlate well with temperature and the $\delta^{18} 0$ of the water, there is a fair amount of inverse correlation with the relative humidity of Kumasi meteorological station which can be taken to be representative of this area in general. There appears to be no correlation between the $\delta^{13} \mathrm{C}$ and the $\delta^{18} 0$ of the shell.

The influence of water temperature on shell $\delta^{18} 0$ (39\%) is greater than on water $\delta^{18} 0(32 \%)$. Air temperature and precipitation have similar influence on the $\delta^{18} 0$ of both shell and water. Both influence the shell $\delta^{18} 0$ by approximately $20 \%$ and the water by a negligible $2 \%$. This may be attributed to altitudinal influence, a predominant factor at Sunyani which was not incorporated as a variable in the regression plot. We know that Sunyani is at an altitude of $310 \mathrm{~m}$ and there is "canopy 
effect" of the forest at the sampling site inhibiting evaporation. This may account for the depletion of the $\delta^{18} 0$ at this site compared with that of Krobo and Achimota. The amount effect is recorded in the shell $\delta^{18} 0$ as shown in Table 2 .

We notice that there is less correlation between shell $\delta^{18} 0$ and water $\delta^{18} 0$. The $\delta^{18} 0$ values reflect the latitudinal effect and values normal for a very wet and humid tropical rainforest area. 0xygen isotope ratios of the water correlate well with temperature. The $\delta^{13} \mathrm{C}$ values range from -11 to $-16 \%$. This indicates incorporation of considerable quantities of metabolic carbon into the shells.

\section{ACHIMOTA}

We see the demonstration of seasonality in the Achimota samples, because the $\delta^{18} 0$ of the shells correlate with $\delta^{18} 0$ of water fairly well. The $\delta^{13} \mathrm{C}$ values of the shells range from -10 to $-13 \%$, an indication of a metabolic carbon contribution. Evaporative effects of the Harmattan are clearly recorded in the $\delta^{18} 0$ of the water.

Water $\delta^{18} 0$ correlates fairly well with temperature in Accra except for the effect of Harmattan which is very pronounced in the water oxygen isotope ratios. There is an inverse relationship between the relative humidity plot and the $\delta^{18} 0$ of the River Densu except for the slight deviation in May. This deviation is not as pronouced in the shell. The shell aperture carbonate isotope measurement gives information integrated over some considerable period of time about the $\delta^{18} 0$ of the water resident in the vicinity of the gastropod during shell growth. There appears to be no correlation between the $\delta^{13} \mathrm{C}$ and the $\delta^{18} 0$ of the shell. The average $\delta^{13} \mathrm{C}$ value of $-11.6 \%$, in the gastropod shell may be 
a reflection of an incorporation of bicarbonate (from atmospheric $\mathrm{CO}_{2}$ $(-7 \%))$ and metabolic carbon of $\mathrm{C}_{3}$ or $\mathrm{C}_{4}$ plants. If the latter is the case, then the shell isotope ratio is a result of a mass balance between bicarbonate at $(\sim 0 \%)$ and $\mathrm{C}_{3}\left(\sim-26.5 \%\right.$ ) or $\mathrm{C}_{4}(\sim-12.5 \%)$ (Vogel et al., 1978) plants. Of the two possible explanations, the latter is tenable based on results of aquaria experiments in our laboratory. In aquaria exposed to atmospheric $\mathrm{CO}_{2}$ and gastropods fed on fish food, with $\delta^{13} \mathrm{C}$ of $-20 \%$ for a month, we have observed that the $\delta^{13} \mathrm{C}$ incorporated into the shell was $-9.1 \%$.

\section{Table 5}

Aquaria Experiment

\section{Species : Melanoides tuberculata}

squarium No.

1.

2.

1.

Fish Food

$$
\text { Sampling Date }
$$

April 18, 1987

April 18, 1987

May 27,1987 $\underline{\delta^{18} 0}$

$-8.76$

$-8.82$

$-9.96$ $\delta^{13} \mathrm{C}$

$-8.83$

$-10 \cdot 34$

$-7.70$

$-20.20$

From the correlation table, we estimate that about $47 \%$ of the $\delta^{18} 0$ of the water is influenced by the water temperature and $13 \%$ by relative humidity. The other $40 \%$ might have been influenced by evaporation and altitude. The shell $\delta^{18} 0$ was $30 \%$ influenced by the water temperature and $24 \%$ by relative humidity. The reason why the influence of water temperature on the water $\delta^{18} 0$ is not as high may be attributed to the verwhelming effect of the amount effect as indicated in Table 2 . There appears to be an unaccountable factor influencing the $\delta^{18} 0$ of the shells 
and water at Achimota (Figure 13). Amount effect is recorded by the water $\delta^{18} 0$.

Sequential analyses of whole Melanoides tuberculata shells from each of the sites collected in December 1985, February 1986 and April 1986 show how major seasonal changes like the peak of the rainy season and the drought periods are preserved in the oxygen isotope ratios of the shells (Figures 15-19).

In December 1985 shells (Figure 17) from the 3 sites all recorded $\delta^{18} 0$ of $-4 \%$. which is the expected value for this area according to Abell (1985). Interestingly enough, the $\delta^{13} \mathrm{C}$ values parallel the $\delta^{18} 0$ values as the latter respond to the evaporative effect of this time of the year. At the time of collection of the December 1985 samples, the whole region was experiencing a very warm humid climate with the Harmattan just beginning. The April shell samples (Figures 15 and 19) show the effects of March rains and the temporary reprieve which is manifested as an enrichment of the isotopic ratios at the time of sampling. The reason why River Densu samples seem to be recording events slightly ahead of the other sites may be traced to the actual date in the month the samples were collected. (See comments in the next paragraph.) Krobo samples show an amount effect but Sunyani and Achimota do not. This may be due to similarity in precipitation of the two sites and their distance from Axim $\left(4^{\circ} 52^{\prime} \mathrm{N}\right)$ a tropical rainforest area. It should be noted that rainfall decreases eastward from Axim. The nearness of Pra to the tropical rainforest may account for its conformity with an amount effect.

For better correlation, samples from a bigger body of water may 
be required or a relatively stable body of water like a pond. Differences in water movement may account for some of the lag observed between $\delta^{18} 0_{\text {water }}$ and $\delta^{18} 0_{\text {shel1 }}$

Although the sequential shell analyses data from the three sites (Pigures 15, 17, 18 and 19) are compared for the following months, December 1985, February 1986 and April 1986, it should be noted that the samples being compared within a given month were not collected on the same day. In some cases, they were collected approximately two or three weeks apart. Despite this discrepancy, shells collected within a given month from the three sites all do record the climatic changes prior to the time of sampling. The $\delta^{18} 0$ and $\delta^{13} \mathrm{C}$ of the December, Pebruary and April samples plotted in Figures 15, 16 and 17 show a parallelism between the carbon and the oxygen, especially for the Krobo and Sunyani samples. By comparing rainfall and temperature information given in Figures 4 and 5 with the isotope ratios plotted in Figures 15, 16 and 17 we estimate that the molluscs must have lived for a period of approximately four to five months. This is corroborated by comparison with monthly aperture isotope ratios plotted in Figures 9, 10 and 11 .

Since the shell $\delta^{13} \mathrm{C}$ values reflect the $\delta^{13} \mathrm{C}$ of the plants that thrive in this region, we suggest that a great portion of the shell $\delta^{13} \mathrm{C}$ is derived from the plant $\delta^{13} \mathrm{C}$. The carbon and oxygen scatter diagram suggests seasonality conditions which introduces fresh imput of carbon and oxygen coupled with temperature variation. A plot of these seasonality conditions would be shown as points outside the tight groupings of the $\delta^{13} \mathrm{C}$ and the $\delta^{18} 0$. For example, the River Pra points vould be more negative in both $\delta^{13} \mathrm{C}$ and $\delta^{18} 0$. 
In summary, the monthly $\delta^{18} 0_{\text {shell }}$ and $\delta^{18} 0_{\text {water }}$ from a tributary of the River Pra at Krobo, in the Western region of Ghana, the River Densu at Achimota, in the Greater-Accra region and the Sunyani Stream, in the yong-Ahafo region, approximately $700 \mathrm{~km}$ from the Sahel, have responded to heavy rainfall, variations in temperature and evaporative effects. Good parallelism between the $\delta^{18} 0$ plots of the shells, water and temperature was observed. The $\delta^{18} 0$ values were in agreement with vegetative cover maps of Ghana and Africa. Seasonality was also recorded by the isotope ratios of the shells of the gastropods. These results seem to pave the way for the application of $\delta^{18} 0$ of shells in deciphering past climatic conditions, which may be expected to have application in paleoclimatology. Similar investigations like this one carried out in different bodies of water, and at sites with different vegetative cover in Africa would contribute to the data base upon which the application of $\delta^{18} 0$ values in the study of past climates could be based.

However the application of these techniques to the study of fossil mollusc shells must be carried out with caution as several other factors may come into play and must be taken into consideration in the interpretation of $\delta^{18} 0$ ratios of fossil gastropod shells. Some of the factors that must be considered include reliability of dating, longevity of gastropods and some knowledge of the hydrological regime from which the mollusc shell was collected. For example, the ancient site from where the shell is collected should be well documented as to size and stability of the water body and knowledge of the longevity of the individual species of gastropods must be known if seasonality is to be 
deduced. It is highly desirable to know the age of the shell in order to correlate it with other historical environmental information. Fossil shells may undergo recrystallization from aragonite to calcite, a process engendered by local weathering conditions. In order to extract veasonality information from a fossil shell, a sequential sampling along the accretionary growth pattern of the individual shells is necessary, while the average oxygen isotope ratios of whole shells will be useful in the characterization of major regional climatic trends.

In addition to shell isotope data, some environmental information (which can be acquired by other geological techniques) has to be provided before applying oxygen isotope ratio values to the interpretation of paleoclimates. Among these are latitudinal, altitudinal, and hydrological information. For example, the $\delta^{18} 0$ values of shells collected from a location where an ancient transient stream existed would be more difficult to interpret compared with a location where a permanent body of water existed. Molluscs in areas with low rainfall and transient streams risk undergoing estivation which in turn will give only fragmentary seasonal information. Molluscan shells collected from areas where there was permanent vegetative cover, permanent lakes or tropical rainforest areas with rainfall all year round will give interpretable results. Latitudinal and altitudinal information would also be useful in data interpretation. The geographical conditions of past water basins may be deciphered from remote sensing by the Shuttle Imaging Radar (SIR), Landsat images and Satellite navigation systems. For example, Kerr (1986) has reported that McCauley (1986) and coworkers have applied SIR, Landsat images and 
Satellite navigation systems in their study of Miocene-Pliocene drainage system in Saharan Africa. Freshwater bivalves and gastropods were recovered at several points along the ancient waterways which crossed the Sahara during the late Miocene and early Pliocene period, and could prove useful in characterizing that climatic episode.

\section{CONCLUSIONS}

Upon completion of this study, the following observation were made:

1. Freshwater molluscan shells can be useful proxies of the prevailing climatic conditions during the life span of the molluscs.

2. Evaporative effects, temperature effects, and amount effects can be determined using the $\delta^{18} 0$ of shells and water.

3. A time lag was observed between the $\delta^{18} 0$ values of shell and the $\delta^{18} 0$ values of the water. The shell values lag the water values.

4. $\delta^{18} 0$ values of shells and the water correlate well with vegetation cover maps of Ghana and other sites in Africa.

5. Seasonality was recorded in the $\delta^{18} 0$ values of the shell and the water.

6. Information on the general character of the body of water is needed to apply shell oxygen isotope ratios as proxies in paleoclimatology.

7. $\delta^{13} \mathrm{C}$ can give clues as to the extent of seasonality and variability of carbon input.

8. Melanoides tuberculata from different bodies of water in southern Ghana all record the same environmental changes.

9. Seasonality, affecting the $\delta^{18} 0$ values of water and shell, can be used to estimate the life span of the gastropod. 
Acknowledgement

We thank the National Science Foundation for financial support and the Graduate School of Oceanography, University of Rhode Island for the use of the mass spectrometer. We also acknowledge the dedication of the following Ghanaian collectors, which made this study possible : Rev. Brother Joseph Tsiquaye and Sister Margaret Mary Nimo, Sunyani; Mr. Leonard Amegashitsi and Mr. Oscar Fynn, Sekondi-Takoradi; Mr. Ben. K. Amegashitsi, Achimota; and Peter Adodo, Accra. 


\section{REFERENCES}

Abe11, P. I., (1982) Paleoclimates at Lake Turkana, Kenya, from oxygen 1sotope ratios of gastropod shells. Nature, 297, 321-323

Abell, P. I., (1985). Oxygen Isotope Ratios in Modern African Gastropod Shells : A data base for Paleoclimatology. Chemical Geology, 58, 183193

Abell, P. I., and Nyanmweru, C., (1988). Paleoenvironments in the Chalbi Basin of Kenya. Isotope Geosci., 72, 283-291.

Abell, P. I., and Williams, M. A. J.,(1989). 0xygen and carbon isotope ratios in gastropod shells as indicators of paleoenvironments in the Afar region of Ethiopia. Palaeogeogr., Palaeoclimatol., Palaeoecol., 74, 265-278.

Adams, D. T. (1960). A Ghana Geography Second edition, University of London Press Ltd. p.

Arthur, M. A., Williams, D. F. and Jones, D. S. (1983). Seasonal temperature-salinity changes and thermocline development in the midAtlantic Bight as recorded by the isotopic composition of bivalves. Geology, 11, 655-659

Barnett, T. P., (1978). The role of the oceans in the global climate system, in Climatic Change, ed. J. Gribben, University of Cambridge 
Press, Cambridge, England, pp157-177

Beadle, L. C., (1974). The Inland Waters of Tropical Africa- An introduction to Tropical Limnology. Longman Group Limited, p.32

Boateng, E. A., (1967). A Geography of Ghana, Cambridge University Press, Second edition.

Brown, D. S., (1980). Freshwater Snails of Africa and Their Medical Importance. Taylor and Francis, London, pp 487

Budyko, M. I., (1978). The heat balance of the earth. In Climatic Change, ed. J. Gribben, University of Cambridge Press, Cambridge, England. pp85-113.

Cerling, T. E., Quade, J., Wang, Y. \& Bowman, J. R. (1989). Carbon isotopes in soils and palaeosols as ecology and palaeoecology Indicators. Nature, $341,138-139$.

Craig, H., (1961). Standard for reporting concentrations of deuterium and oxygen-18 in natural waters. Science, 133, 1833-1834

Dansgaard, W., (1964). Stable isotopes in precipitation. Tellus, $\underline{16}, 436-468$

Deuser, W. G., and Degens, E. T., (1967). Carbon isotope fractionation 
in the system $\mathrm{CO}_{2 \text { (gas) }}-\mathrm{CO}_{2 \text { (aqueous) }}-\mathrm{HCO}_{3}$-(aqueous) . Nature $\underline{215}, 1033-1035$.

Dobzhansky, T., (1962). Mankind evolving. Yale University Press, New Haven, Conn.

Bhhalt, D., et al. (1963). Deuterium and oxygen-18 in rain water. Journ. Geophys. Research, $\underline{68}$, pp 3775-80

Epstein, S., Buchsbaum, R., Lowenstam, H. A. and Urey, H. C. (1951). Carbonate-water isotopic temperature scale. Geol. Soc. Amer. Bull., $\underline{62}$, $417-426$

Epstein, S., Buchsbaum, R., Lowemstam, H. A. and Urey, H. C., (1953). Revised carbonate water isotopic temperature scale. Geol. Soc. Amer. Bull., 64, 1315-1326

Epstein, S. and Lowenstam, H. A., (1953). Temperatue-shell growth relations of recent and interglacial Pleistocene shoal-water biota from Bermuda. J. Geol., 61, (5), 424-438

Epstein, S. and Mayeda, T., (1953). Variation of ${ }^{18} 0$ content of waters from natural sources. Geochim. et Cosmochimica Acta, 4, 213-224.

Epstein, S., (1956). Variations of the ${ }^{18} 0 /{ }^{16} 0$ ratios of freshwater and ice. Nat. Acad. Sci., Nucl. Sci. Ser., Rep. No.19, pp20-25 
Briksson, E., (1964). The history of the major pulses of tritium in the stratosphere. Tellus, $\underline{16}$

Priedman, I., Machta, L., and Soller, R., (1962). Water vapor exchange between a water droplet and its environment. Journ. Geophys. Res., 67, pp $2761-70$.

Friedman, I. and 0'Niel, J. R., (1977). Compilation of stable isotope fractionation factors of geochemical interest. Geol. Sur. Prof. Paper 440-kk. U. S. Gov. Printing office, Washington, D. C.

Fritz, P. and Poplawski, S., (1974) ${ }^{18} 0$ and ${ }^{13} \mathrm{C}$ in the shells of freshwater mollusks and their environments. Earth Planet. Sci. Lett., 24: $91-98$

Griffiths, J. F., ed. (1972). World Survey of climatology, Vol. 10, Climates of Africa. Elsevier Publ. Co., Amsterdam, pp 604

Grossman, E., (1982). Stable isotopes in live benthic foraminifera from the southern California Borderland. Ph. D. Dissertation, University of Southern California, Los Angeles, Calif.

Grossman, E. L., (1987). Stable isotopes in modern benthic foraminifera: A Study of Vital Effect. Journal of Foraminiferal Research, 17, 48-61 
Hem, J. D. (1970). Study and interpretation of the chemical characteristics of natural water. U. S. Geol. Surv. Water-Supply Paper 1473.

Herczeg, A. L. and Fairbanks, R. G. (1987). Anomalous carbon isotope fractionation between atmospheric $\mathrm{CO}_{2}$ and dissolved inorganic carbon induced by intense photosynthesis. Geochim. et Cosmochim. Acta $\underline{51}$ 895899.

Hitchon, B. and Krouse, H. R., (1972). Hydrogeochemistry of the surface waters of the MacKenzie River drainage basin, Canada, III. Stable isotopes of oxygen, carbon and sulfur. Geochim. Cosmochim. Acta, 36: $1337-1357$

Keith, M. L. and Weber, J. N., (1964). Carbon and oxygen isotope composition of selected limestones and fossils. Geochim. Cosmochim. Acta, $\underline{28}, 1787-1816$

Kerr, R. A. (1986). Ancient River System Across Africa Proposed. Science 233,940 .

Lévêque, C., (1973). Dynamique des peuplements biologie, et estimation de la production des mollusques benthique du Lac Chad. Cah. Off. Rech. Sci. Tech. Outre-Mer, ser. Hydrobiol. I, 117-147.

McCauley, J., et al., (1986). Paleodrainages of eastern Sahara - The 
radar rivers revisited, IEEE Trans. Geoscience GE-2 24624 .

Hckinney, C. R., McCrea, J. M., Epstein, S., Allen, H. A. and Urey, H. C. (1950). Improvements in mass spectrometers for the measurement of small differences in isotope abundance ratios. Rev. Sci. Insr. 21, 724730.

Mills, G. A., and Urey, H. C. (1940). The Kinetics Of Isotopic Exchange Between Carbon Dioxide, Bicarbonate Ion, Carbonate Ion and Water. Journ. Amer. Chem. Soc. $\underline{62}$, 1019-1026.

oboli, H. O. N. (1963). An Outline Geography of West Africa. $3^{\text {rd }}$ edition, George G. Harrap \& Co. Ltd. London.

Quade, J., Cerling, T. E. and Bowman, J. R. (1989). Development of Asian monsoon revealed by marked ecological shift during the latest Miocene in northern Pakistan. Nature $\underline{342}, 163-166$.

Rau, G., (1978). Carbon-13 depletion in a subalpine lake: Carbon flow implications. Science 201, 901-902.

Schneider S. H. and Londer R., (1984). The Coevolution of Climate and Life. Sierra-Club Books. San Francisco. p45.

Siegenthaler, U and Deschger, H. (1980). Correlation of ${ }^{18} 0$ in precipitation with temperature and altitude. Nature Vol 285 314-317 
Stuiver, M., (1970). Oxygen and Carbon Isotope Ratios of Fresh-Water Carbonates as Climatic Indicators. Journ. of Geophysical Research $\underline{75}$, $5247-5257$.

Tanaka, N., Monaghan, M. C., and Rye, D. M., (1986). Contribution of netabolic carbon to mollusc and barnacle shell carbonate. Nature $\underline{320}$, 520-523.

Tucker, C. J., Townshend, J. R. G. and Goff, T. E., (1985). African land-cover classification using satellite data. Science, 227, 369-375

Urey, H. C., (1947). The thermodynamic properties of isotopic substances. J. Chem. Soc., pt. 1. p562-581

Van der Merwe, N. J. (1982). Carbon isotopes, photosynthesis and archaeology. Amer. Scientist, 70, 596-606.

Varley, W. J. \& White, H. P. (1958). The Geography of Ghana. 1st edition, Longmans, Green and Co. Ltd. London.

Vogel, J. C., Fuls, A. and Ellis, R. P. (1978). The geographical distribution of Kranz species in southern Africa. South Afr. J. Sci. 75, 209-15.

Wendt, I., (1968). Fractionation of carbon isotopes and its temperature 
dependence in the system $\mathrm{CO}_{2}-$ gas $-\mathrm{CO}_{2}$ in solution and $\mathrm{HCO}_{3}-\mathrm{CO}_{2}$ in solution. Earth Planet. Sci. Letters 4, 64-68.

Iurtsever, Y., (1975). Worldwide survery of stable isotopes in precipitation. I. A. E. A. (Int. At. Energy. Agency), Vienna, Rep., report, Sect. Isot. Hydrol., pp 53. 
MANUSCRIPT 2 
VARYING ISOTOPIC RESPONSE OF FRESHWATER MOLLUSCAN SPECIES TO IRONMENTAL CHANGE: LAKE VICTORIA.

\author{
BY \\ LEO L. AMEGASHITSI, PAUL I. ABELL \\ Department of Chemistry \\ The University of Rhode Island \\ Kingston, Rhode Island, 02881
}

and

PETER OCHUMBA

Kenya Marine and Fisheries Research Institute

Kisumu Laboratory, P. 0. Box 1881

Kisumu, Kenya. 
VARYING

ISOTOPIC RESPONSE OF

NIRONMENTAL CHANGE; LAKE VICTORIA.

\section{TNTRODUCTION}

As part of ongoing investigations into the usefulness of stable isotope ratios in freshwater mollusc shells as proxies for paleoclimates and paleoenvironments, we have included the examination, in detail, of the isotope ratios of shells of living molluscs collected from several modern sites to aid in our understanding of ratios of ancient shells. In these studies we wanted to be sure we understood the correlations between the oxygen isotope ratios of the shells and the isotope ratios of the host body of water, and climatic factors such as rainfall and the water temperature, and to understand the correlations between the carbon isotope ratios of the shells and the availability of dissolved inorganic carbon. One of the sites selected for these studies of modern shells was the Winam Gulf (formerly the Kavirondo Gulf) of Lake Victoria. The most common species of gastropod in the waters of the Winam Gulf is Bellamya unicolor, an oviperous gastropod which achieves a normal adult size of about $20 \mathrm{~mm}$ from apex to aperture. The other molluscan species sampled were Corbicula, Mutela, and Aspatharia, all of them bivalves. Monthly collections of the molluscs were made along the northeast shore of the Winam Gulf, a few kilometers west of Kisumu (Figures 1 \& 2), together with water samples and water temperature measurements. Limited information is available in the malacological literature on the growth habits of these molluscs, and we initially assumed that they had a life 


\section{FIGURE 1}

MAP OF EAST AFRICA SHOWING MAJOR

PALEOANTHROPOLOGICAL SITES. 


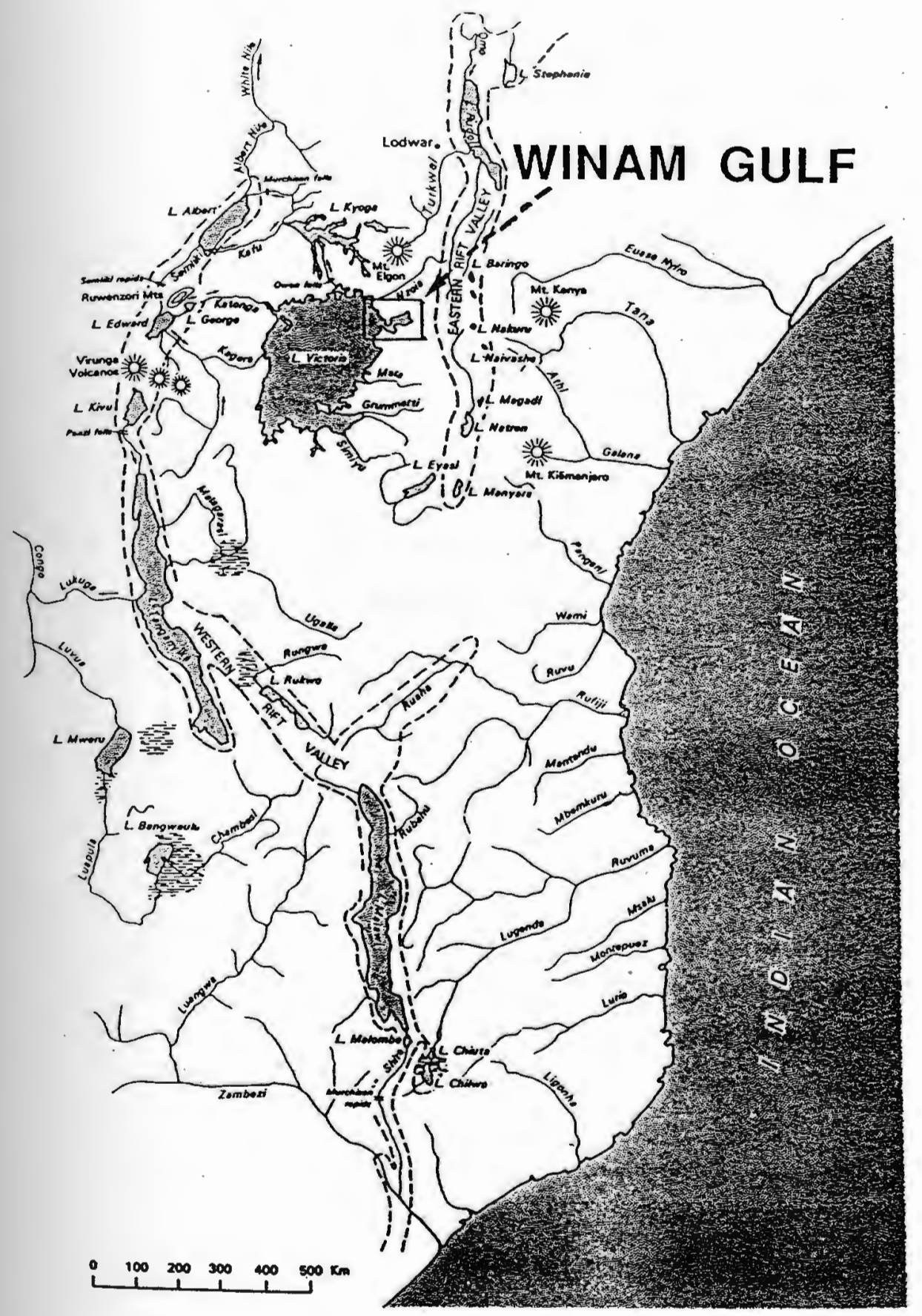

Eastern tropical Africa showing courses of the two Rift Valleys and the water systems 
FIGURE 2

MAP OF LAKE VICTORIA SHOWING WINAM GULF AND KISUMU WHERE MOLLUSCS WERE SAMPLED. 


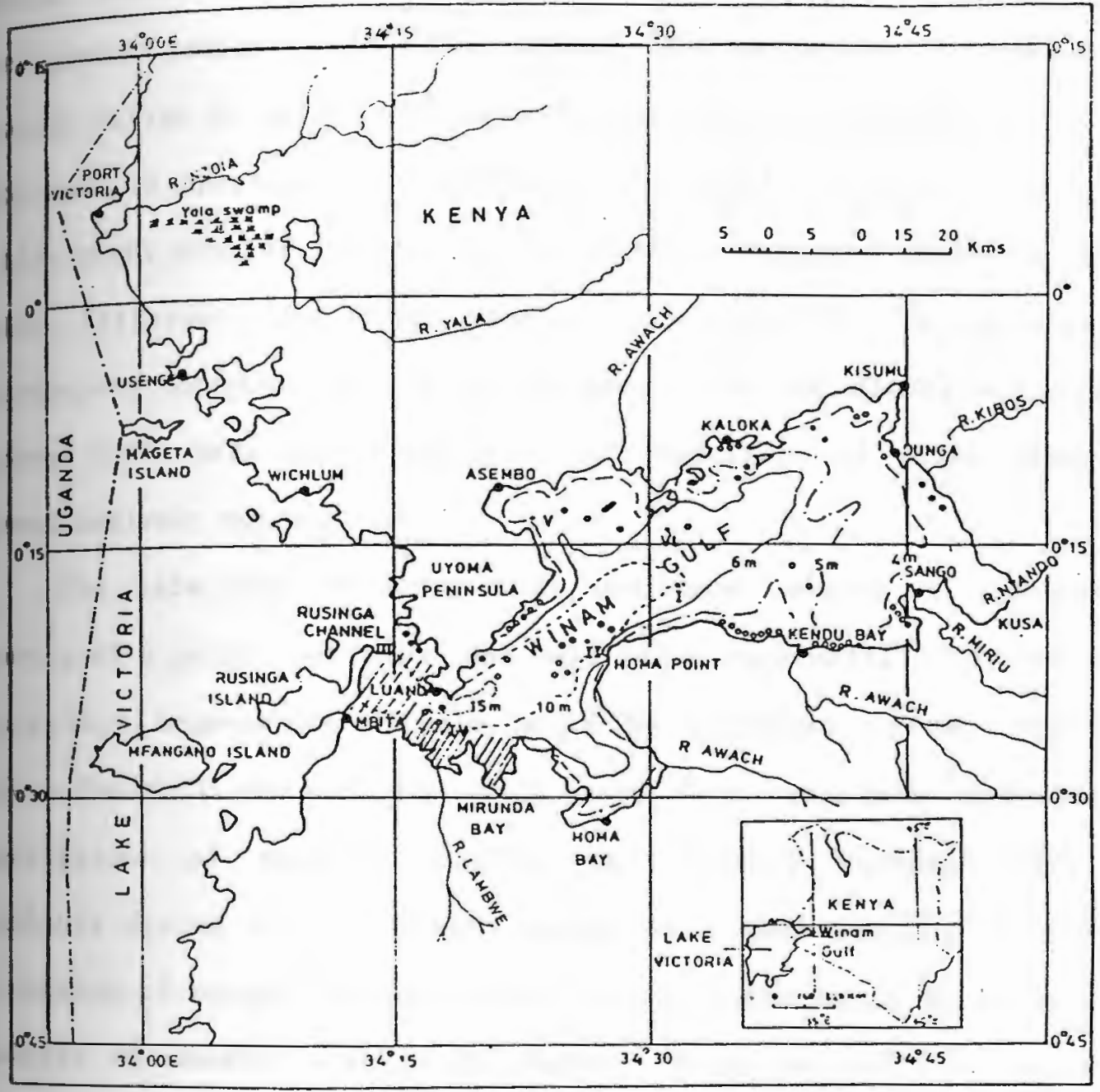


span ranging from several months upwards to a year (Lévêque, 1968). Taking monthly samples, we hoped that they would provide us with overlapping sequences of environmental information as we analyzed for isotope ratios of carbon and oxygen along the growth spiral of the shell from apex to aperture. Furthermore, we assumed that the carbon isotope ratios might provide information on the existence of "vital effects", in which different gastropod species may possibly be expected to Incorporate varying amounts of metabolic versus dissolved inorganic carbon (DIC) into their shells. The magnitude of vital effects is almost entirely unknown.

The selection of Vinam Gulf was made because it provides an example of a large, permanent and well mixed equatorial lake, and on the basis that temperature effects would be minimized at this equatorial site. Rainfall patterns were well known from long term meteorological observations at Entebbe, Uganda, and monthly rainfall data were available during the collection period in Kisumu itself. Evaporative alteration of oxygen isotope ratios in the water could be monitored by analysis of monthly samples of water. Thus, we felt we had a good natural laboratory, and the presence of a biological station (The Kisumu station of the Kenya Marine and Fisheries Research Institute (Figure 2)) with permanent personel ensured that an adequate sampling program would be possible.

\section{BACRGROUND}

Preliminary investigations of molluscs as possible carbonate sources, whose carbon and oxygen isotope ratios bear the potentiality of 
paleotemperature calculations, were carried out by Keith et al ( 1960 , 1964, 1965) after such a suggestion by Urey (1947). This technique has been applied by other workers (Epstein et al., 1951, 1953; Mook, 1971, 1977; Burchardt, 1977) and it has been established that both marine and freshwater molluscs form their shells at, or close to, oxygen isotope equilibrium with the water in which they dwell (Epstein et al., 1951; Fritz and Poplawski, 1974). Lee (1979) has demonstrated that seasonal temperatures are recorded in the growth bands of both modern and fossil clams by carrying out an oxygen isotope study of the Pismo clam (Tivela tultorem) of the coast of California. A micro-sampling technique along a section cut from the shell was employed in this study. Similarly, Jones et al., (1983) and Arthur et al., (1983) have employed the oxygen isotope technique in the study of the Atlantic surf clam, Spisula solidissima) and observed a record of environmental change in the shell growth increments. By studying carbonates and molluscs from sediments from four lakes in the United States, Stuiver (1970) observed the extent to which $\delta^{13} \mathrm{C}$ and $\delta^{18} 0$ of freshwater carbonates could be utilized as climatic indicators. He observed only small variations in the $\delta^{18} 0$ in shells of different species of gastropods and pelecypods grown at the same locality, however, the $\delta^{13} \mathrm{C}$ variations were rather more substantial (up to 4\%). Grossman (1987) studied "vital effects" using stable 1sotope ratios in modern benthic foraminifera.

The investigation of the isotope ratios of the shells of African freshwater molluscs as proxies of past climates was initiated several years ago with the examination of whole shell oxygen isotope ratios of the "fossil" molluscs of Lake Turkana (Abell, 1982). This was followed 
by an examination of whole shell oxygen isotope ratios of gastropod shells from some 80 sites covering much of Africa (Abell, 1985). Since then, stable isotope ratios in the shells of the freshwater gastropod Velanoides tuberculata, collected from Holocene sites in the Chalbi Basin of north-central Kenya, have been applied in a study of the nature of paleo Lake Chalbi. (Abell and Nyamweru, 1988) In a recent development, carbon and oxygen isotope ratios of ancient freshwater gastropod shells collected from the Afar region of Ethiopia have been utilized in studying the paleoenvironments of that region. (Abell and Villiams, 1989) It was evident from these investigations that much more detailed isotope studies were needed to understand the forces producing the isotope ratios. Shells from natural sites with sequential analyses along the growth spirals and bands of the molluscan shells might be expected to give short sequences which would be interpreted in terms of past environmental events, the temporal length of the sequence depending upon the life span of the mollusc being sampled. This paper reports on one of the first of these studies on molluscs collected at regular intervals from a natural site - the Winam Gulf of Lake Victoria.

\section{iription of Site and Environment}

Lake Victoria is one of the largest lakes in the world with a surface area of $75,000 \mathrm{~km}^{2}$ at an altitude of $1240 \mathrm{~m}$. It lies across the equator between latitudes $0^{\circ} 30^{\prime} \mathrm{N}$ and $2^{\circ} 50^{\prime} \mathrm{S}$. The lake is shallow with a maximum depth of $79 \mathrm{~m}$ and an average depth of $40 \mathrm{~m}$. Water levels are altered by changes both in rainfall and temperature. The Winam Gulf has an average depth of less than $20 \mathrm{~m}$. 
Lake Victoria is bound along the southern, northwestern and northern shores by shallow bays most of which lie in the branch valleys of the pre-lake river system, which provides good conditions for vegetative growth (macrophytes). (Beadle, 1974)

The lake is fed largely by the Kagera River which drains the high tainfall area of the Ruanda and Kigezi Highlands bordering the Western Rift, but it is also fed by the Nzoia River in the northeast which has its source in the Kenya Highlands, specifically Mount Elgon and the cherangani hills. Smaller seasonal rivers come in from the south and the east while northern and northwestern inflows are mainly from slow flowing swamps. Lake Victoria flows out into Lake Kyoga in the north.

There is little seasonal change in water temperature compared with temperature changes in lakes in the temperate zones. Surface and bottom temperatures differ by not more than about $2^{\circ} \mathrm{C}$. The lowering of water temperature between May and July is attributed to the Southeast trade winds which might affect evaporative cooling of the lake, as the intensity and duration of insolation is nearly constant. Relatively clear skies, and radiational cooling in the night is accountable for the lowering of temperatures between May and July, and surface cooling during this period is believed to provide energy for lake mixing. From Pebruary to May, the bottom water fluctuates little and becomes slightly acidic due to an increase of dissolved $\mathrm{CO}_{2}$. (Talling, 1964; Beadle, 1974) The frequency of violent storms, coupled with temperature and oxygen data gathered at the center of lake (sampling depth $60 \mathrm{~cm}$ ) during one of such storms by Kitaka (1971), suggest the drawing of lower water to the surface by a cyclonic swirl in the center of the depression. 
The climate of Lake Victoria, like most of East Africa, is Iuenced by subtropical high pressure areas situated North and South of the equator. The subtropical air masses move north during northern summer and south during southern summers. The south-east trades from the Indian Ocean dominate the air mass over East Africa in July (See Hamilton (1982) pp12). Rainfall occurs as a result of the convergence of the northeastlies and the southeastlies at the inter-tropical convergence zone (ITCZ). (Boucher, 1975; Hamilton, 1982) September is the driest month of the year while April is the wettest over the East African region. The northern and western margins of Lake Victoria oxperience heavy rain brought about by the presence of the lake itself. The vegetative cover around Lake Victoria is mainly moist savannah composed of fairly closely spaced trees with relatively large leaves, and a herbaceous stratum of tall, narrow-leaved grasses. The soil is deep yellow or red and sandier than forest soils. (Hamilton, 1982)

\section{EXPERIMENTAL}

An opportunity to examine critically the relationship between isotope ratios and lake environment is made possible by an extensive collection of a number of species of molluscs in East Africa, at the Vinam Gulf of Lake Victoria. The following molluscan species were collected at monthly intervals together with water samples at Kisumu, Kenya between December 1985 and January 1987 : Bellamya, Corbicula, Mutela, and Aspatharia. Identification of molluscan species was provided by Dr. Pieter Kat of the National Museum of Kenya. Detailed teorological data covering this period were also obtained from the 
treorological station in Kisumu. The $\delta^{18} \mathrm{O}$ and $\delta^{13} \mathrm{C}$ of the above colluscan bivalves species were determined by sampling across the growth increments. The gastropods to be analyzed were sectioned longitudinally with a low speed diamond wafering saw in such a way that if a shell has 6 to 8 complete turns in the growth spiral, sampling from opposite edges of each turn $\left(180^{\circ}\right)$ in the sectioned shell gave 12 to 16 milligram-size samples. In the bivalves, samples were taken at short intervals along the increments of the growth bands (Figure 3). For the monthly analyses, the milligram size samples came from the apertures of the molluscan shells.

The samples of a fractional milligram size were baked under vacuum at $400^{\circ} \mathrm{C}$ to destroy all organic matter. The carbon dioxide samples were prepared on a vacuum line by solution of shell fragments in $100 \%$ phosphoric acid, at $55^{\circ} \mathrm{C}$. The evolved $\mathrm{CO}_{2}$ samples were sealed off in ampoules for isotopic ratio analysis on a V. G. Micromass 602-D mass spectrometer in the Graduate School of Oceanography at the University of Rhode Island.

The results were corrected to $25^{\circ} \mathrm{C}$, and recalculated to the PDB standard. Since all the samples analyzed were aragonitic, $0.6 \%$, was subtracted from the values to compensate for the difference between calcite and aragonite (Grossman, 1962).

Water samples were analyzed according to the procedure of Epstein and Mayeda (1953). This involved the equilibration of approximately 24 cc (STP) of $\mathrm{CO}_{2}$ with $2.5 \mathrm{~g}$ of water in a thermostated bath for approximately 7 days and the analysis of a $3 \mathrm{cc}$ aliquot of the gas on a V. G. Micromass 602-D mass spectrometer. To facilitate rapid 
equilibration the $\mathrm{pH}$ may be adjusted to 6 or lower (Mills and Urey, 1940). The water samples were placed in a $25 \mathrm{cc}$ round bottom flask which could be connected to a vacuum manifold. The water was frozen in a liquid nitrogen-2-propanol slush bath and the air quickly pumped away. The ice was melted and warmed to room temperature to release any gas trapped during the initial freezing. The water was then refrozen and pumped for a minute to remove the remaining non-condensible gases. The ice was melted again and commercial cylinder $\mathrm{CO}_{2}, 99.8 \%$ purity, was introduced into the flask to a pressure of about $73.5 \mathrm{~cm} \mathrm{Hg}$. After equilibration in a bath thermostated at $31^{\circ} \mathrm{C}$ for 7 days with frequent shaking, an $3 \mathrm{cc}$ aliquot of the $\mathrm{CO}_{2}$ was withdrawn on a vacuum line by freezing into ampoules and analyzed on the V. G. Micromass 602-D mass spectrometer using the method described by McKinney et al. (1950).

All mass spectrometric analyses are reported relative to the PDB $\mathrm{CO}_{2}$ standard gas. The analyses were calculated from the formula :

$$
\delta=\left[\left(R_{x} / R_{s t d}\right)-1\right] 1000
$$

The probable error is $\pm 0.01 \%$. Replicate samples measured on the same day are usually reproducible to $\pm 0.05 \%$. Standards (usually NBS-20), were always run the same day as the unknowns.

\section{RESULTS}

The results of this study have been summarized in Figures 4-26. Pigure 4 shows the air and water temperatures at Winam Gulf. The water temperatures are for the period of December, 1985 through January, 1987 
and were taken at the same time and location as the gastropod collection near Kisumu. Air temperatures are means over a 32 year compilation of weather data at Kisumu. Rainfall plot at Winam Gulf during the collection period is plotted in Figure 5. Figures 6 through 11 summarize the $\delta^{13} \mathrm{C}$ and the $\delta^{18} 0$ plots of the Winam Gulf mulluscan species and the surrounding water at the time of collection. The carbon and oxygen isotope ratios were obtained by analyzing the apertures of Aspatharia, Bellamya, Corbicula, and Mutela shells. The aperture $\delta^{18} 0$ plots of the molluscan species are compared in Figure 10 while the aperture $\delta^{13} \mathrm{C}$ plots of the molluscan species are compared in Figure 11. Plots of carbon and oxygen isotope ratio from sequential analyses of the different molluscan species are summarized in Figures 12 through 26. Carbon and oxygen isotope ratio plots of detailed sequential analyses of 0ctober, 1986 Mutela is shown in Figures 12. The oxygen isotope ratio plots from sequential analyses of the Winam Gulf molluscan species collected between March, 1986 and September, 1986 are summarized in Figures 13 through 19 . The carbon analogues are plotted in Figures 20 through 26. 


\section{FIGURE 3}

MAP OF EAST AFRICA SHOWING TYPES OF VEGETATION. (FROM HAMILTON, 1982). 


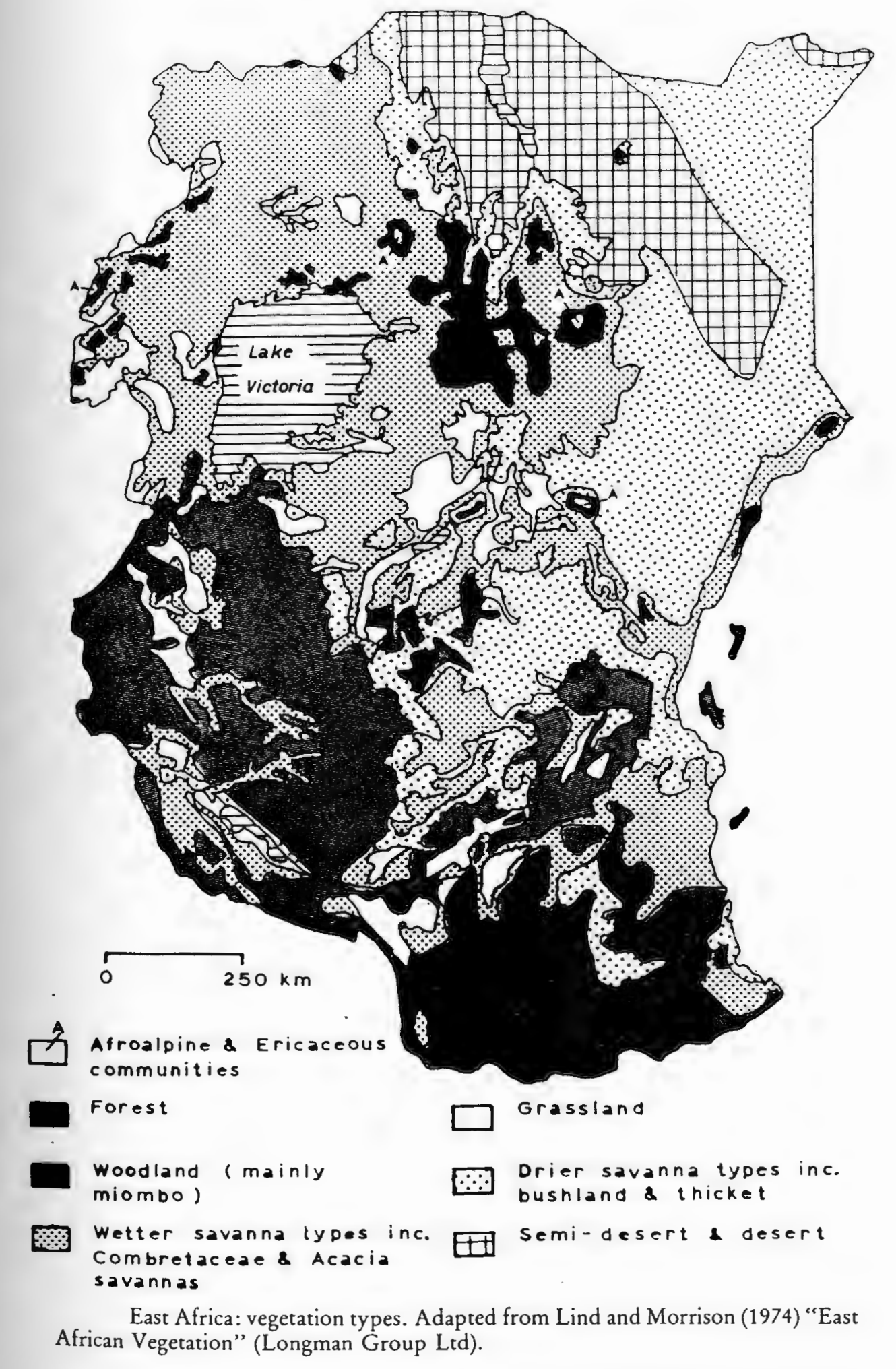


FIGURE 4

WINAM GULF AIR AND WATER TEMPERATURES

DURING SAMPLING PERIOD. 


\section{WINAM GULF AIR AND WATER TEMP.}

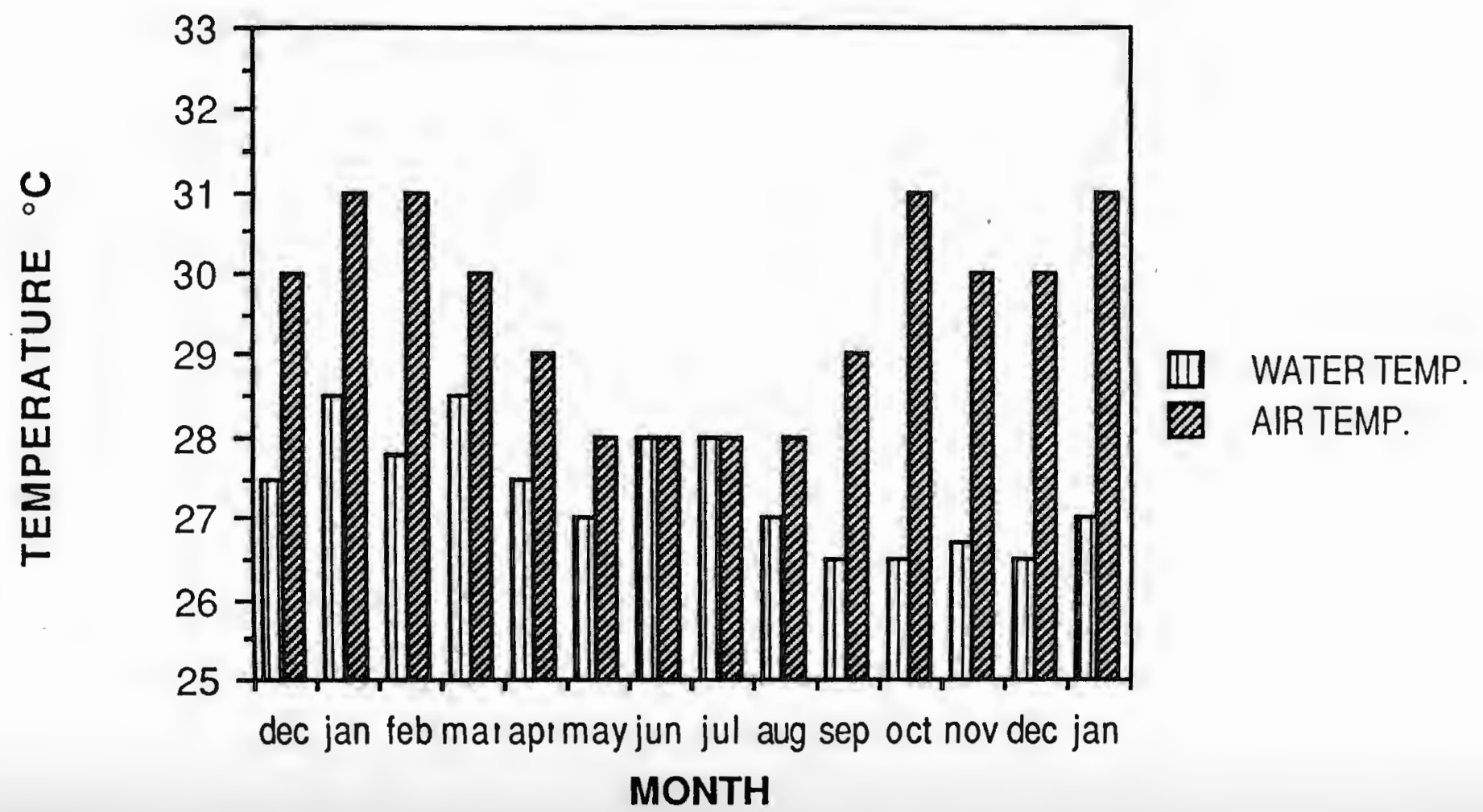


FIGURE 5

RAINFALL (MM) AT WINAM GULF DURING

SAMPLING . 
RAINFALL (MM)

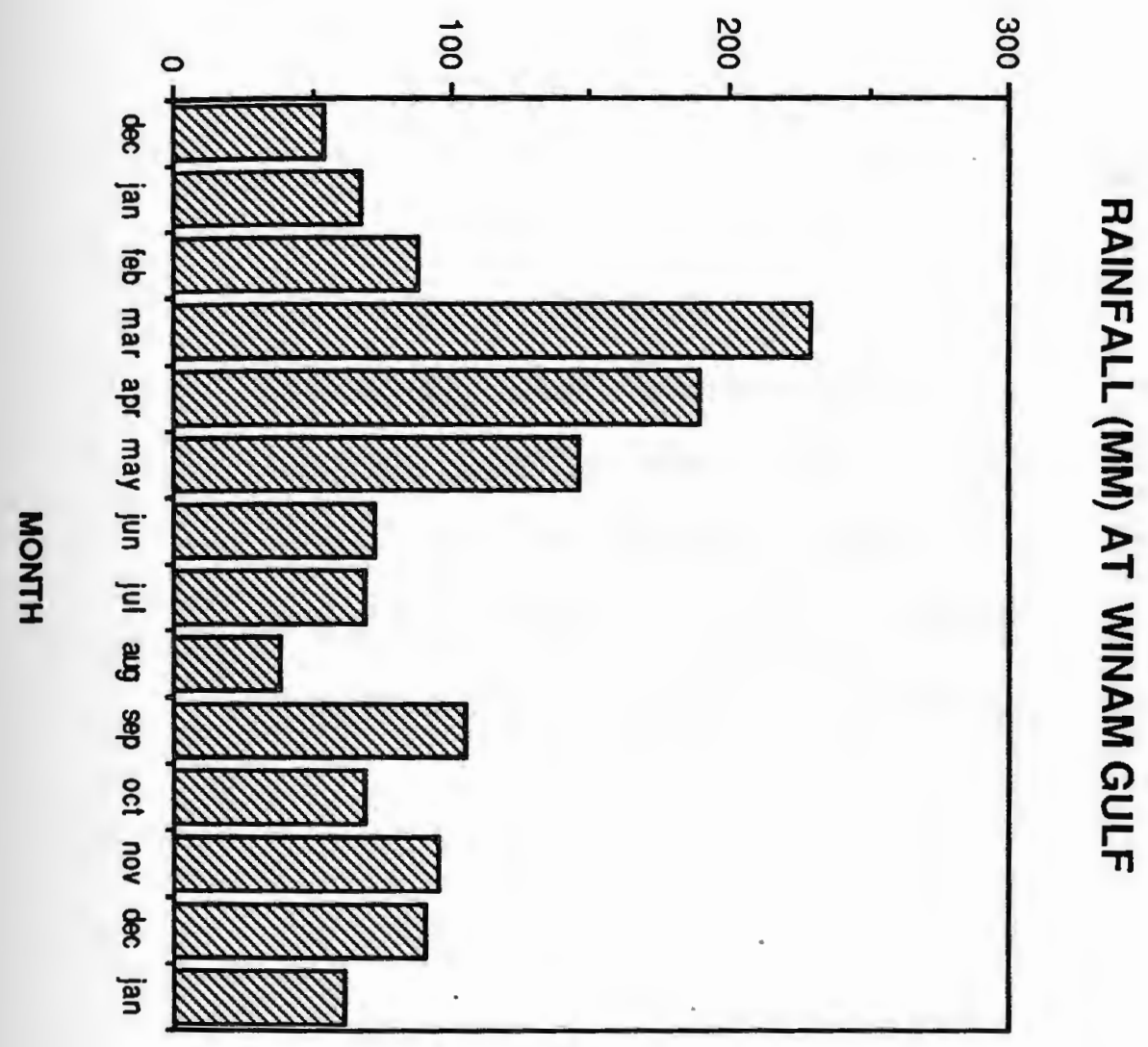




\section{FIGURE 6}

OXYGEN AND CARBON ISOTOPE RATIO PLOTS

FROM THE APERTURE ANALYSES OF BELLAMYA

SHELLS COLLECTED BETWEEN DECEMBER, 1985

AND JANUARY, 1987. THE DOTTED LINE IS A

PLOT OF WATER $\delta^{18} 0$ SHIFTED ONE MONTH. 


\section{WATER AND BELLAMYA ISOTOPE RATIOS}

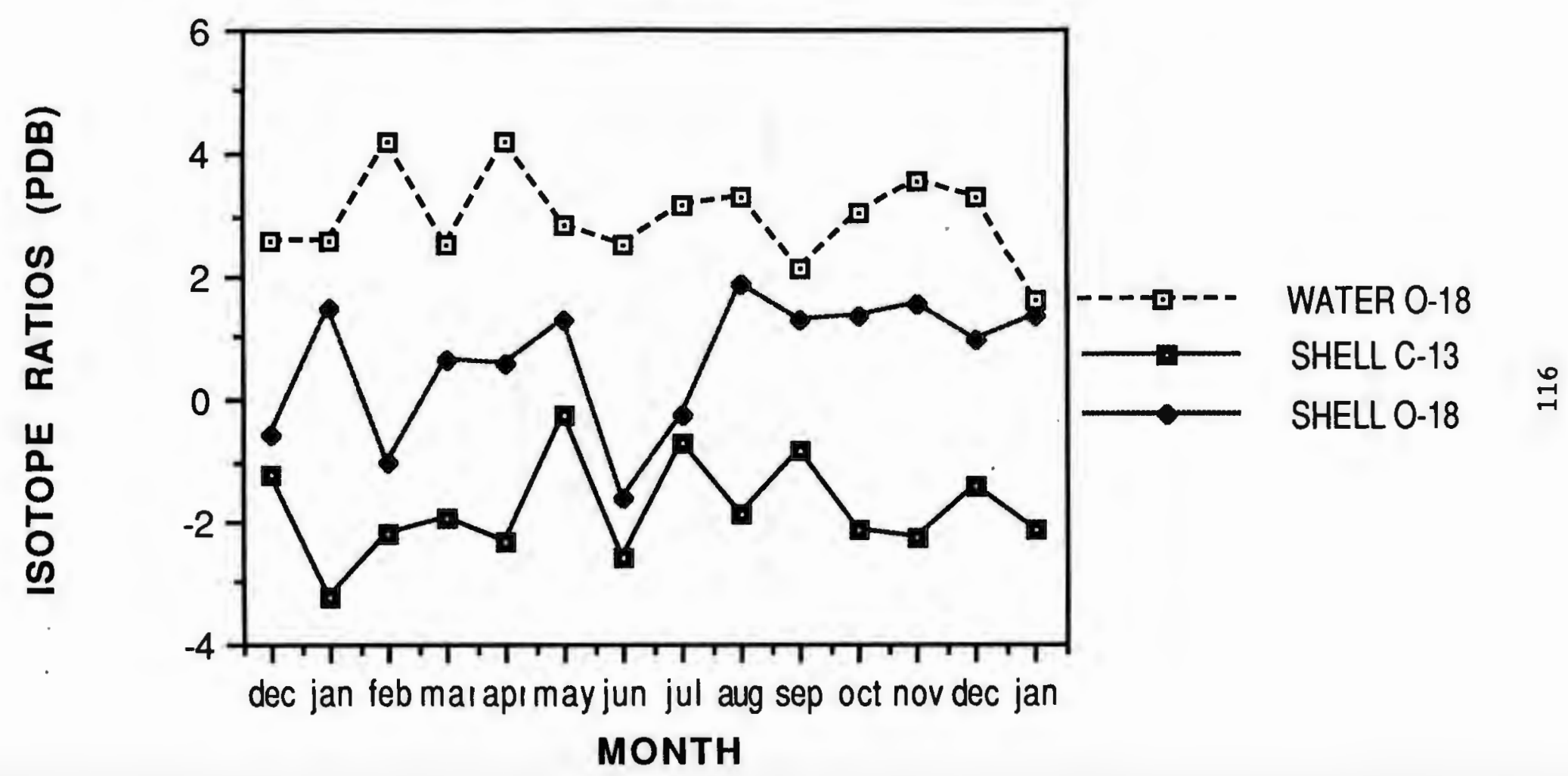


FIGURE 7

OXYGEN AND CARBON ISOTOPE RATIO PLOTS

FROM THE APERTURE ANALYSES OF CORBICULA

SHELLS COLLECTED BETWEEN DECEMBER, 1985

AND JANUANRY, 1987. THE DOTTED LINE IS

THE WATER $\delta^{18} 0$ SHIFTED ONE MONTH. 


\section{WATER AND CORBICULA ISOTOPE RATIOS}

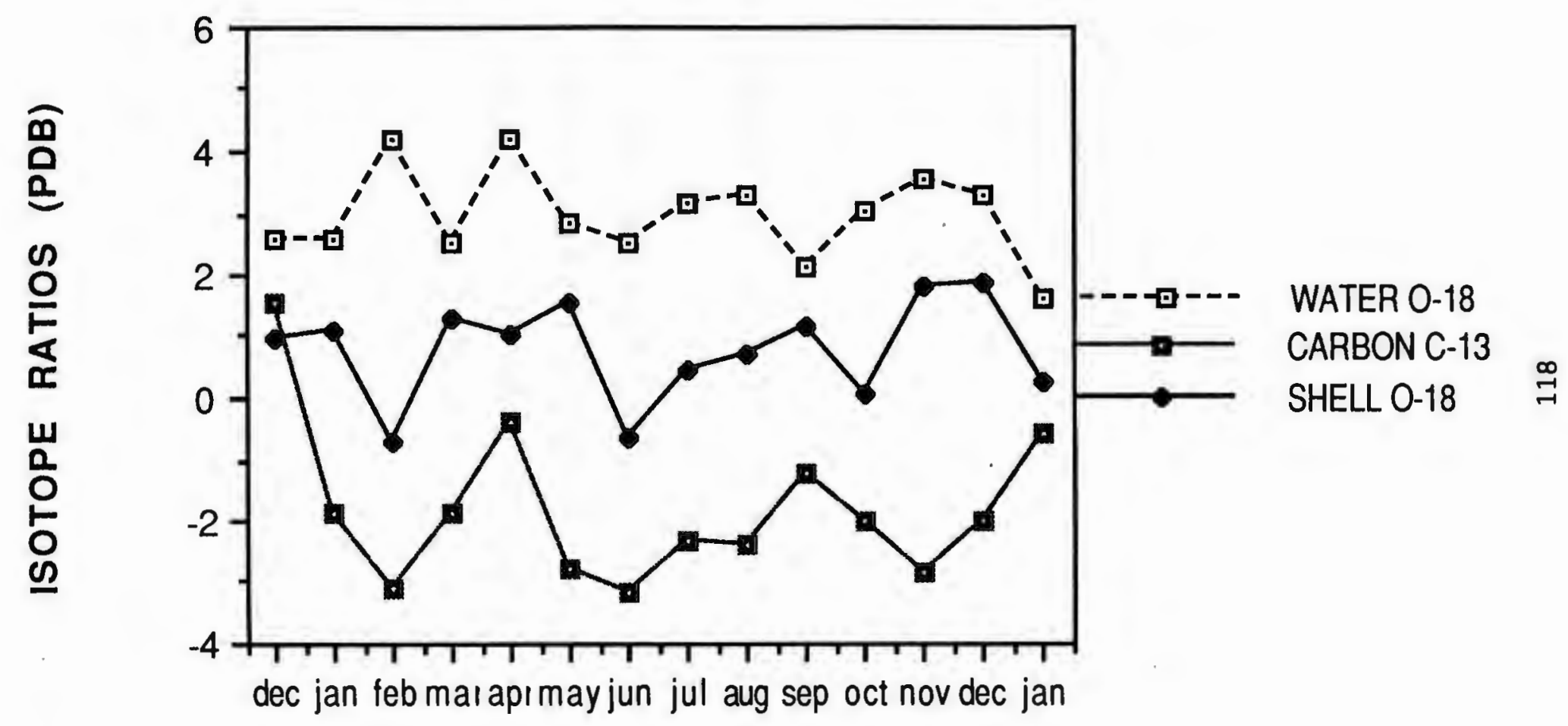

MONTH 
FIGURE 8

OXYGEN AND CARBON ISOTOPE RATIO PLOTS

FROM THE APERTURE ANALYSES OF MUTELA

SHELLS COLLECTED BETWEEEN MARCH, 1986

AND OCTOBER, 1986. THE DOTTED LINE IS A

PLOT OF WATER $\delta^{18} 0$ SHIFTED ONE MONTH. 


\section{WATER AND MUTELA ISOTOPE RATIOS}

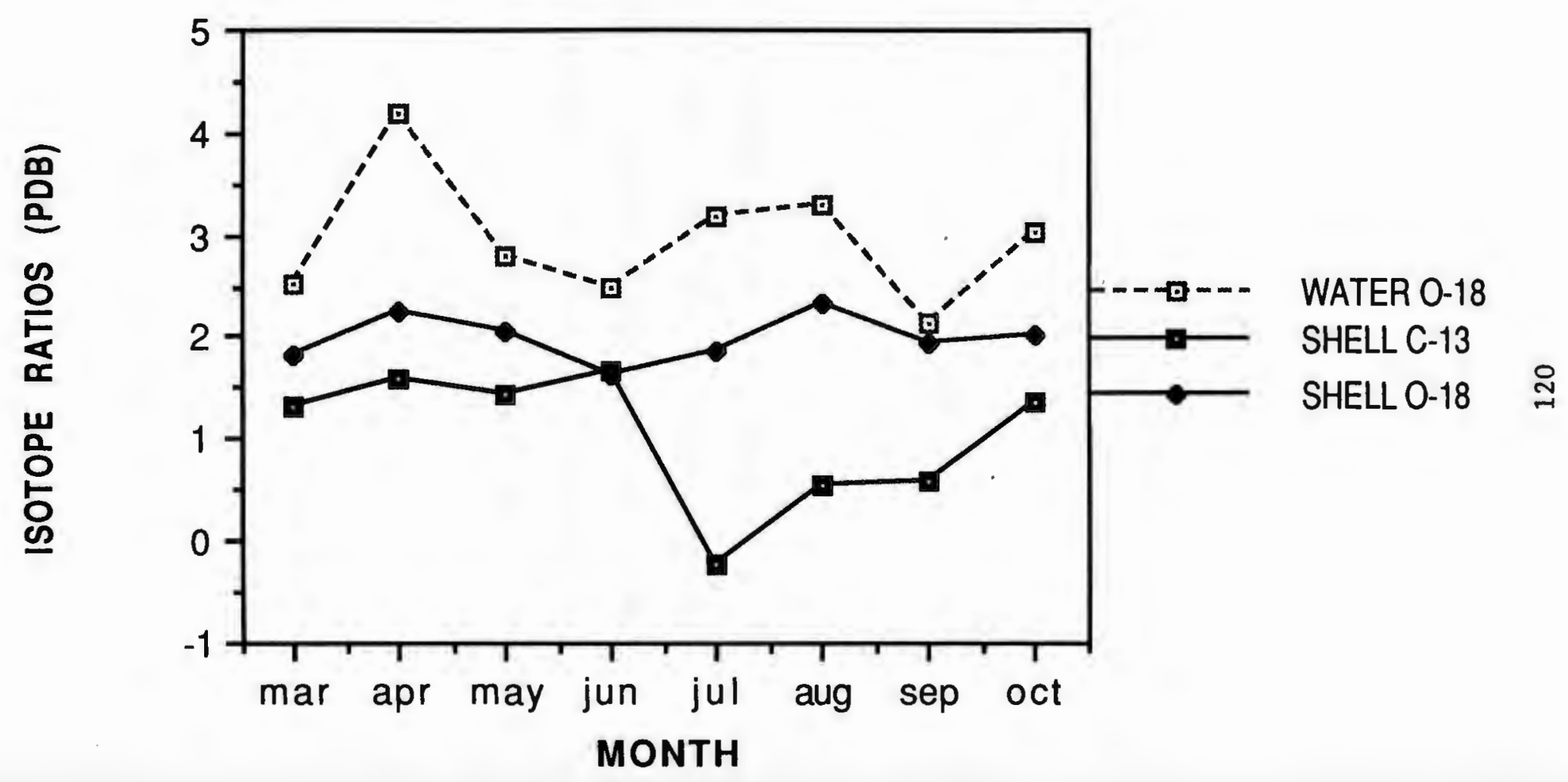




\section{FIGURE 9}

OXYGEN AND CARBON ISOTOPE RATIO PLOTS

FROM THE APERTURE ANALYSES OF ASPATHARIA

SHELLS COLLECTED BETWEEN DECEMBER, 1985

AND OCTOBER, 1986. THE DOTTED LINE IS A

PLOT OF WATER $\delta^{18} 0$ SHIFTED ONE MONTH. 


\section{WATER AND ASPATHARIA ISOTOPE RATIOS}

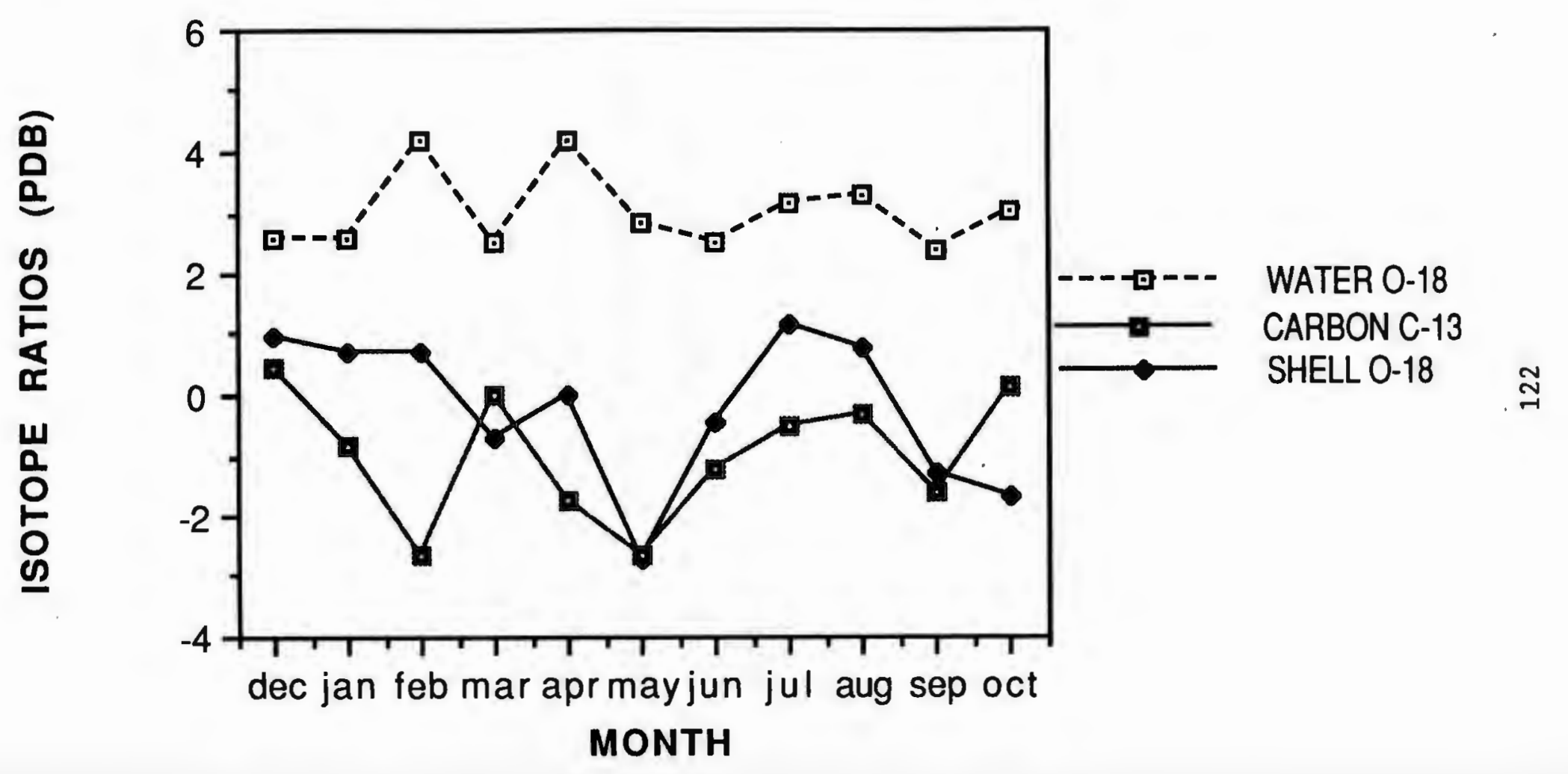


FIGURE 10

OXYGEN ISOTOPE RATIO PLOTS FROM THE

MONTHLY APERTURE ANALYSES OF BELLAMYA,

CORBICULA, MUTELA, AND ASPATHARIA SHELLS

COLLECTED BETWEEN DECEMBER, 1985 AND

JANUNARY, 1987 . 


\section{WINAM GULF SHELL 0-18}

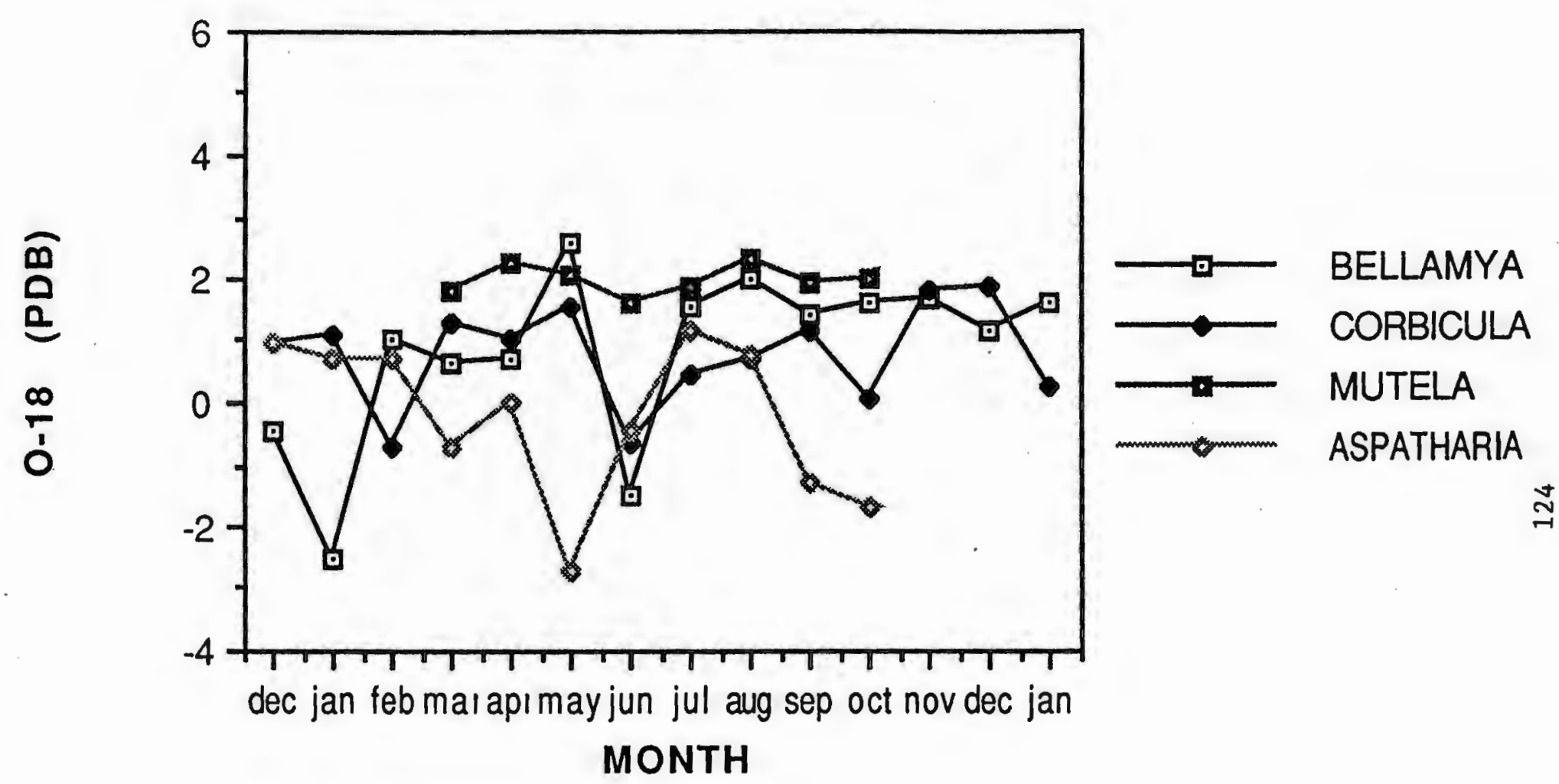




\section{FIGURE 11}

CARBON ISOTOPE RATIO PLOTS FROM THE MONTHLY APERTURE ANALYSES OF BELLAMYA, CORBICULA, MUTELA, AND ASPATHARIA SHELLS COLLECTED BETWEEN DECEMBER, 1985 AND JANUARY, 1987 . 
WINAM GULF SHELL C-13

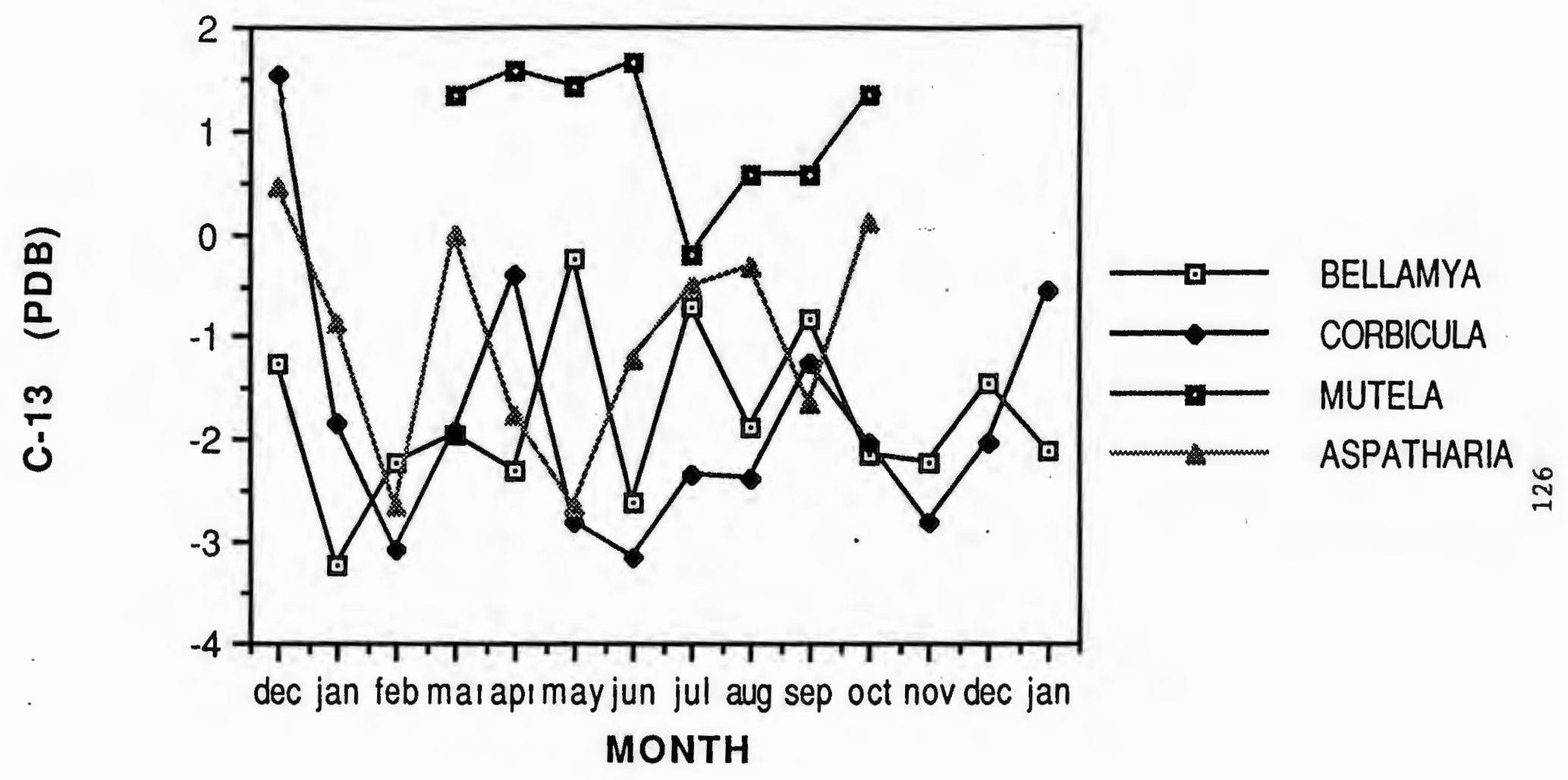


FIGURE 12

OXYGEN AND CARBON ISOTOPE RATIO PLOTS

FROM DETAILED SEQUENTIAL ANALYSIS OF

MUTELA SHELL COLLECTED IN OCTOBER, 1986. 
ISOTOPE RATIOS OF OCT.'86 MUTELA FROM WINAM GULF, LAKE VICTORIA (DET. SEQ.)

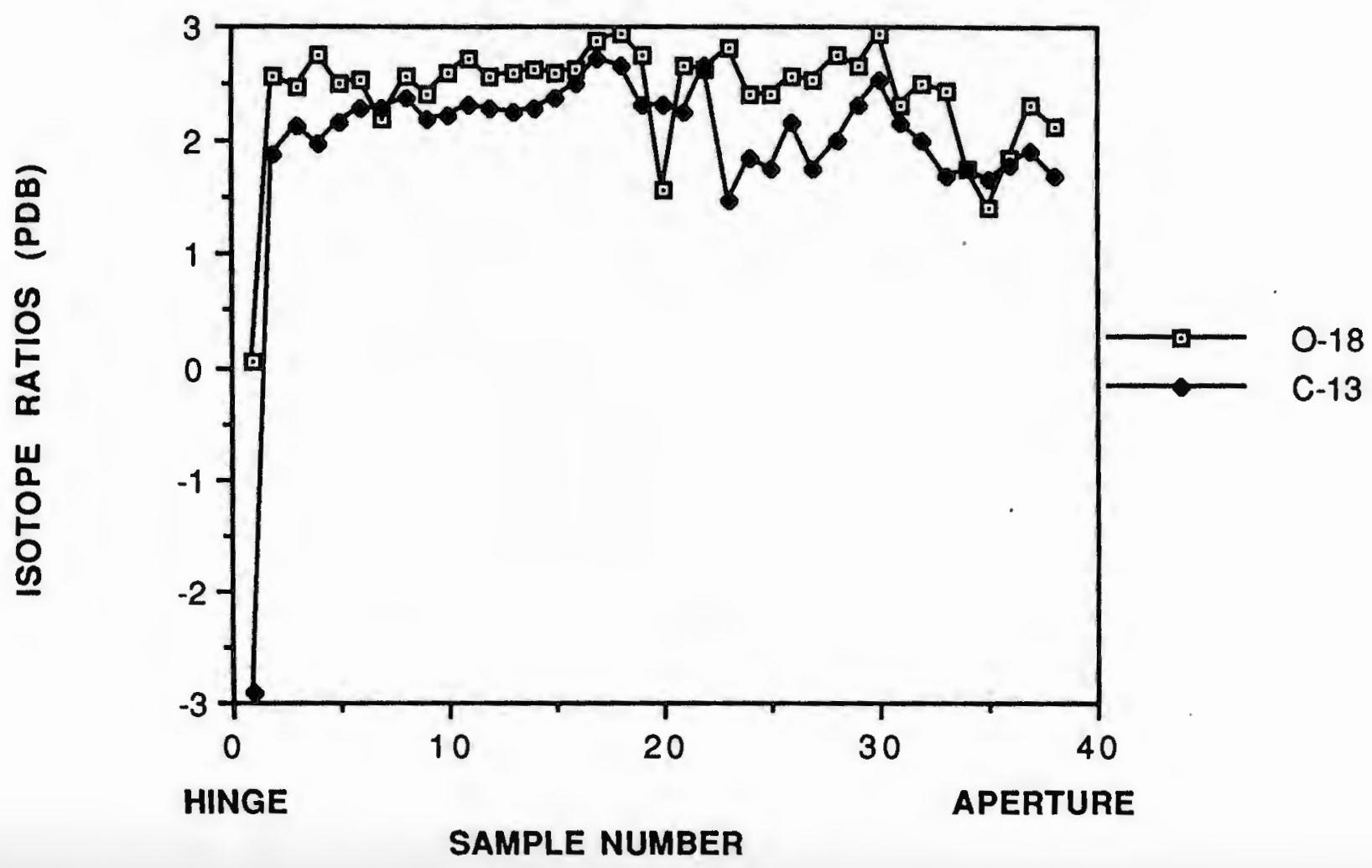




\section{FIGURE 13}

OXYGEN ISOTOPE RATIO PLOTS FROM SEQUENTIAL ANALYSES OF BELLAMYA, CORBICULA, MUTELA, AND ASPATHARIA SHELLS COLLECTED IN MARCH, 1986. 
MAR.'86 WINAM GULF 0-18

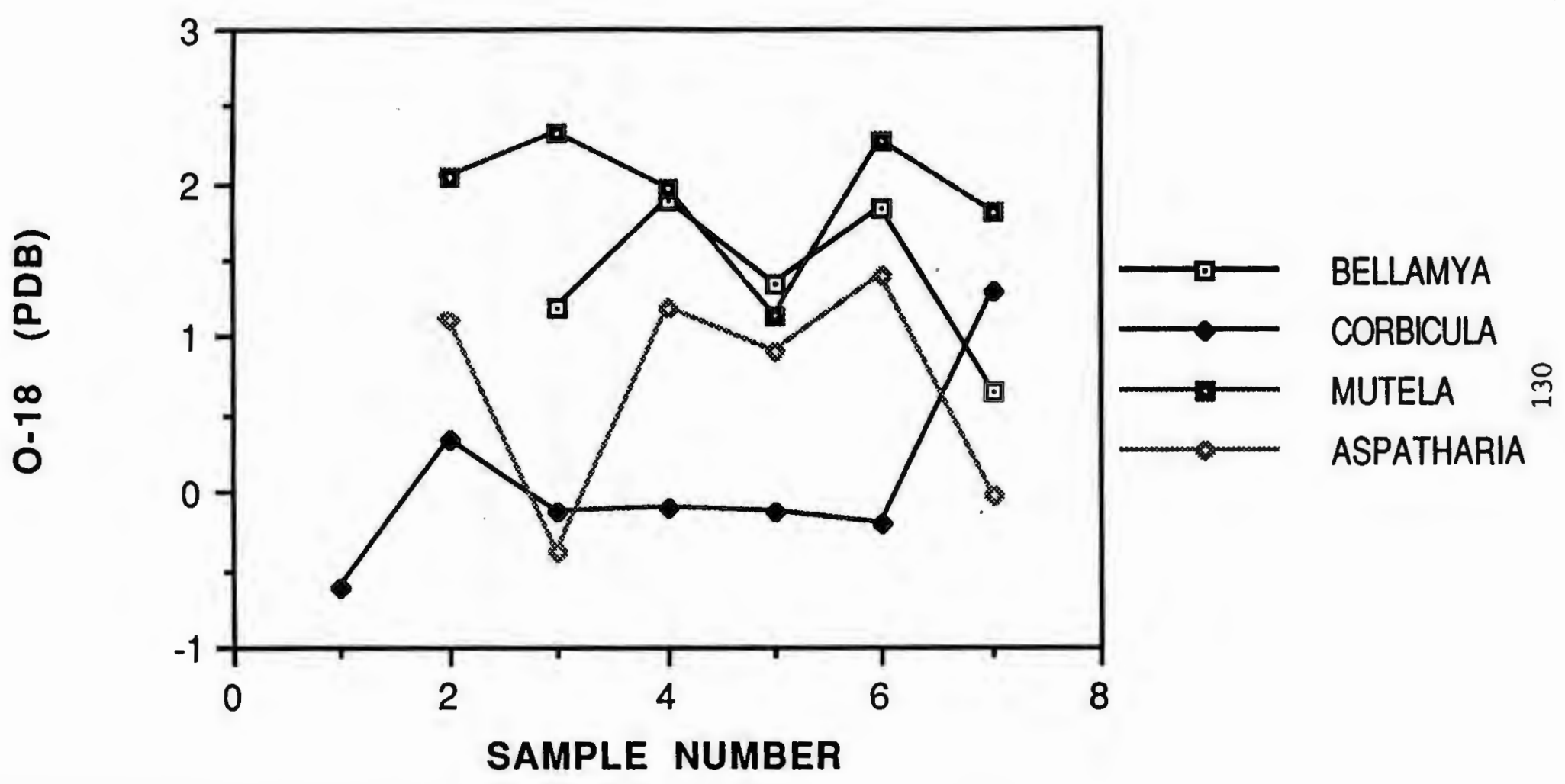




\section{FIGURE 14}

OXYGEN ISOTOPE RATIO PLOTS FROM SEQUENTIAL

ANALYSES OF BELLAMYA, CORBICULA, MUTELA,

AND ASPATHARIA, SHELLS COLLECTED IN APRIL, 1986. 
APR.'86 WINAM GULF 0-18

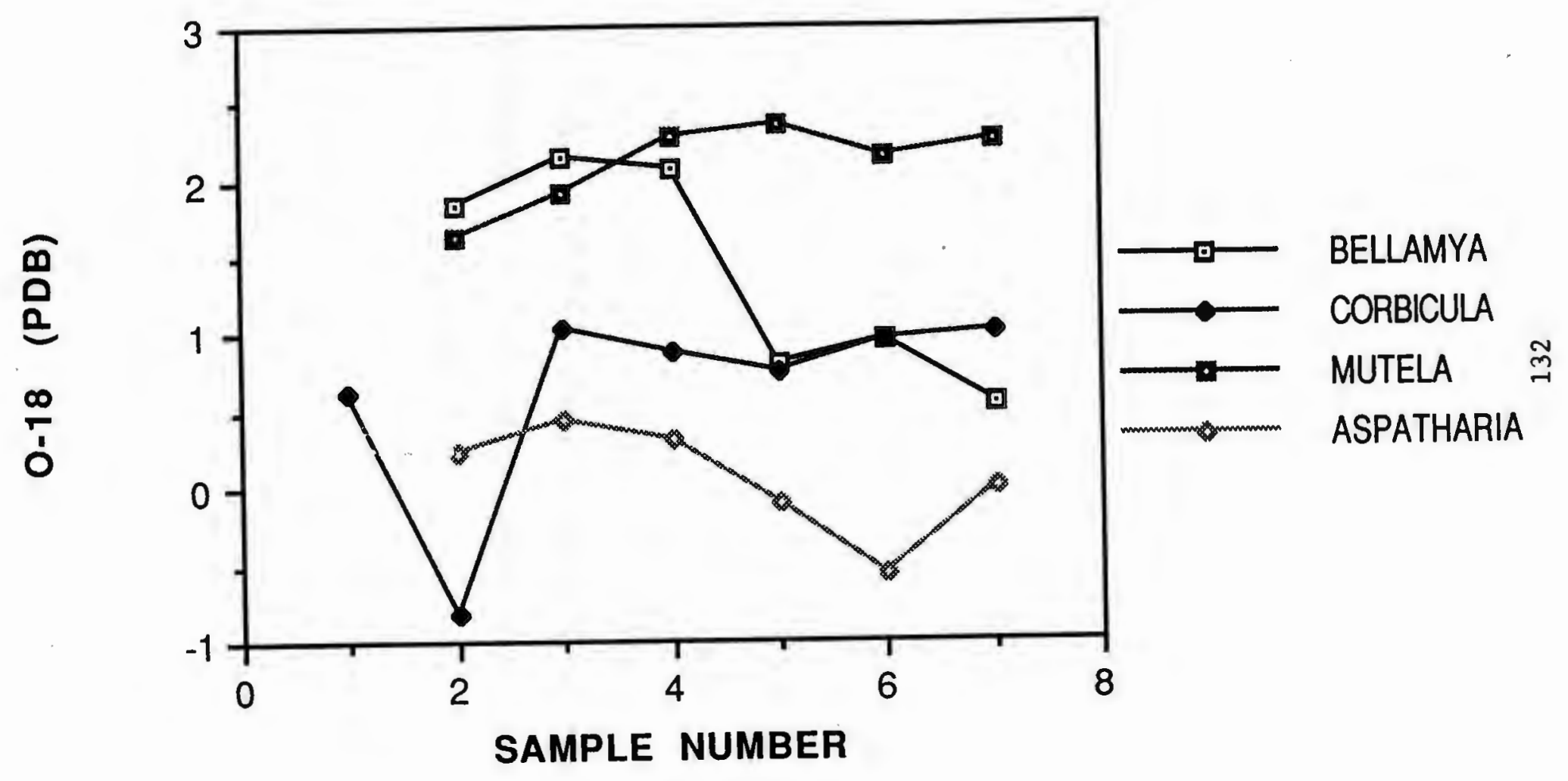




\section{FIGURE 15}

OXYGEN ISOTOPE RATIO PLOTS FROM SEQUENTIAL

ANALYSES OF BELLAMYA, CORBICULA, MUTELA, AND ASPATHARIA SHELLS COLLECTED IN MAY, 1986. 
MAY '86 WINAM GULF 0-18

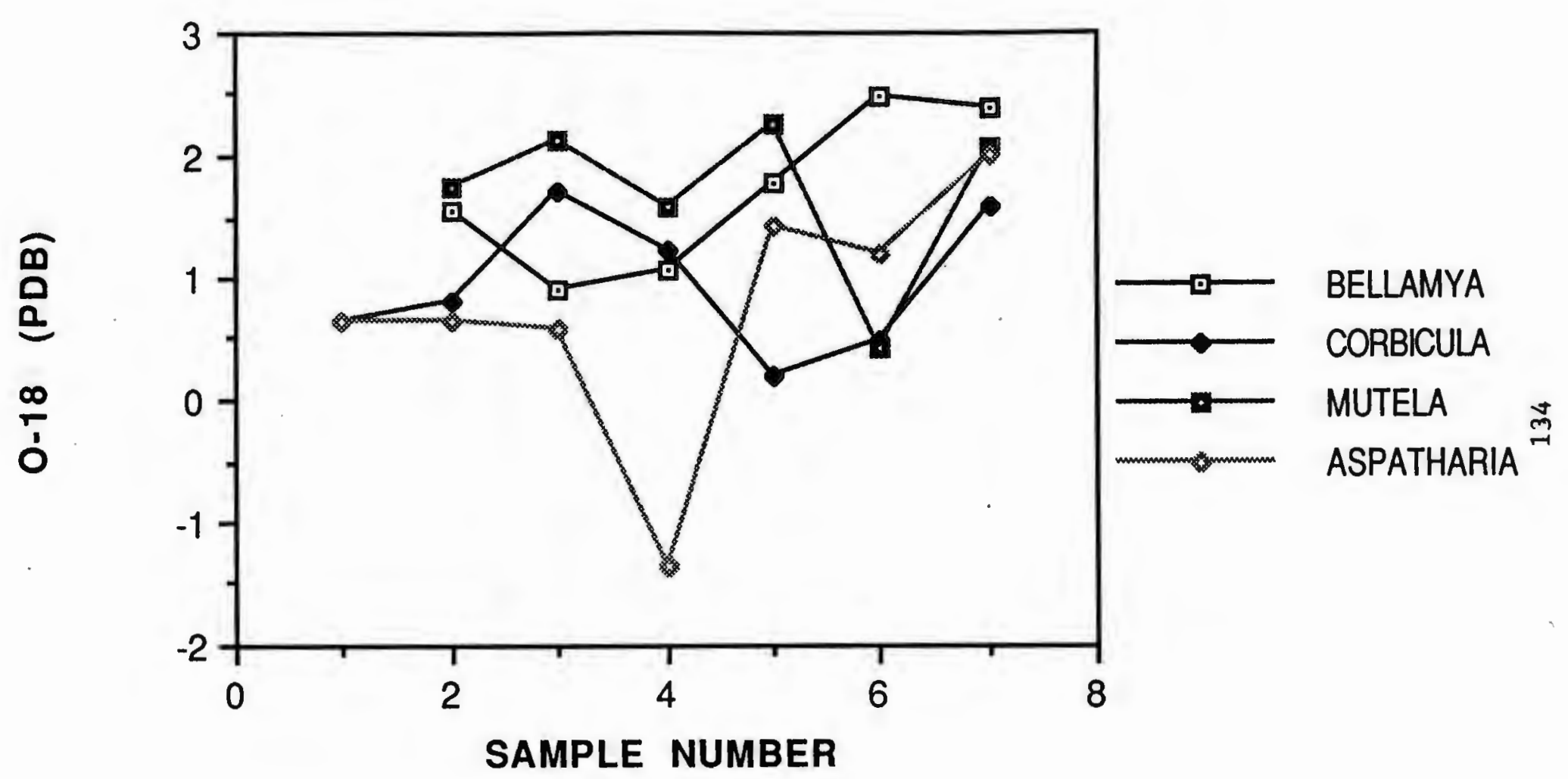


FIGURE 16

OXYGEN ISOTOPE RATIO PLOTS FROM SEQUENTIAL

ANALYSES OF BELLAMYA, CORBICULA, MUTELA,

AND ASPATHARIA SHELLS COLLECTED IN JUNE, 1986. 
JUN.'86 WINAM GULF 0-18

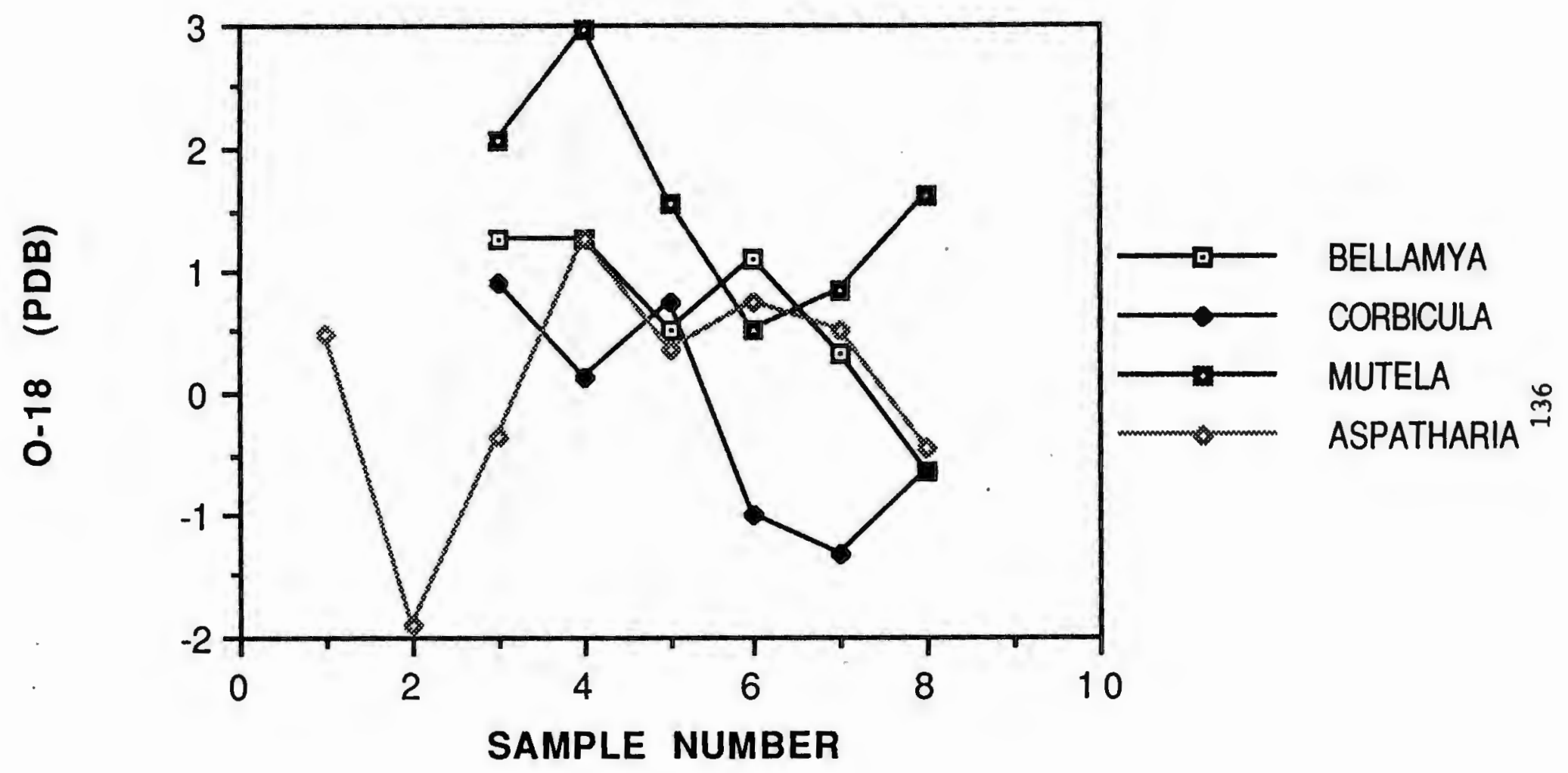




\section{FIGURE 17}

OXYGEN ISOTOPE RATIO PLOTS FROM SEQUENTIAL ANALYSES OF BELLAMYA, CORBICULA, MUTELA AND ASPATHARIA SHELLS COLLECTED IN JULY, 1986. 


\section{JUL.' 86 WINAM GULF 0-18}

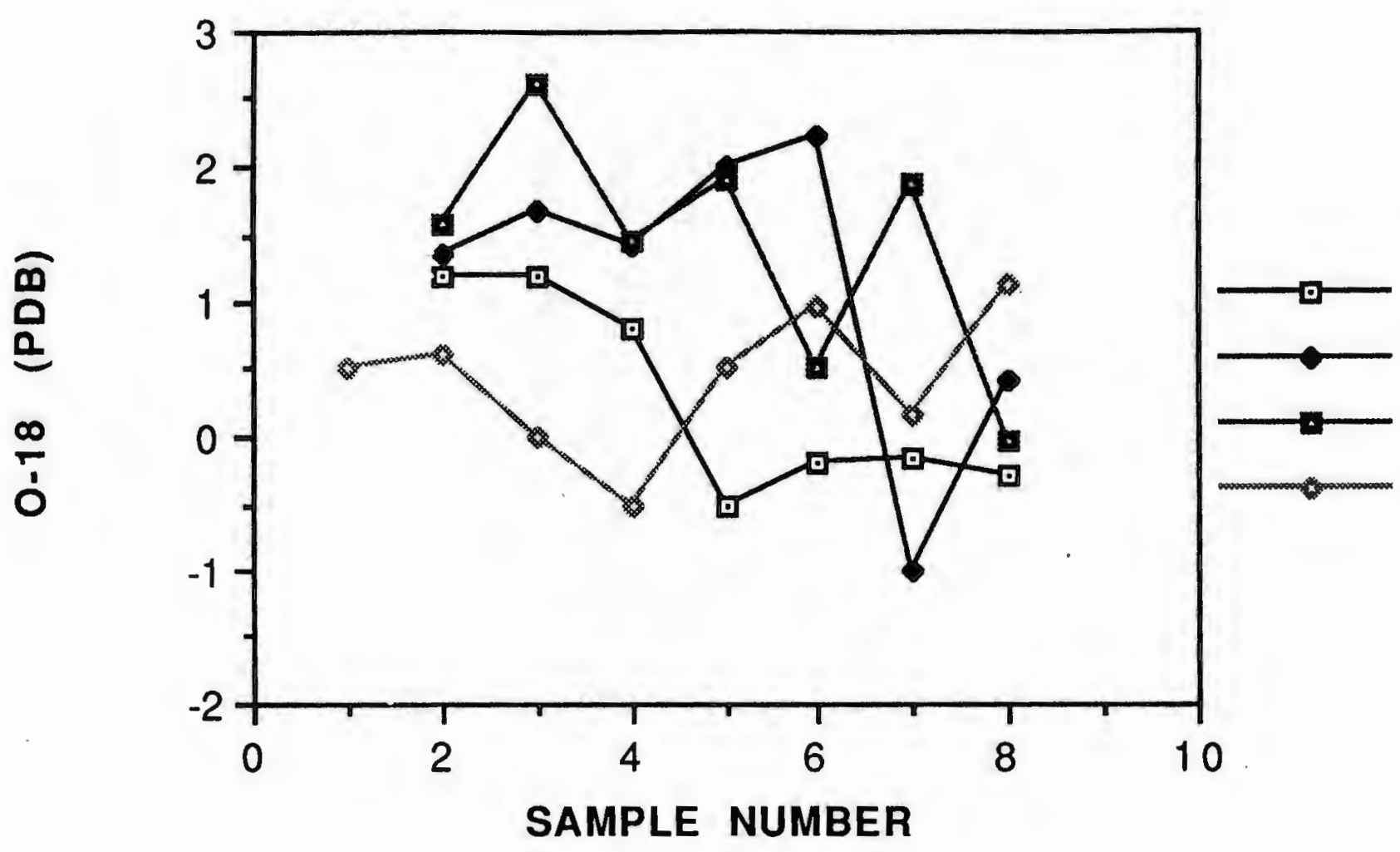




\section{FIGURE 18}

OXYGEN ISOTOPE RATIO PLOTS FROM SEQUENTIAL

ANALYSES OF BELLAMYA, CORBICULA, MUTELA, AND ASPATHARIA, SHELLS COLLECTED IN AUGUST, 1986. 
AUG.'86 WINAM GULF 0-18

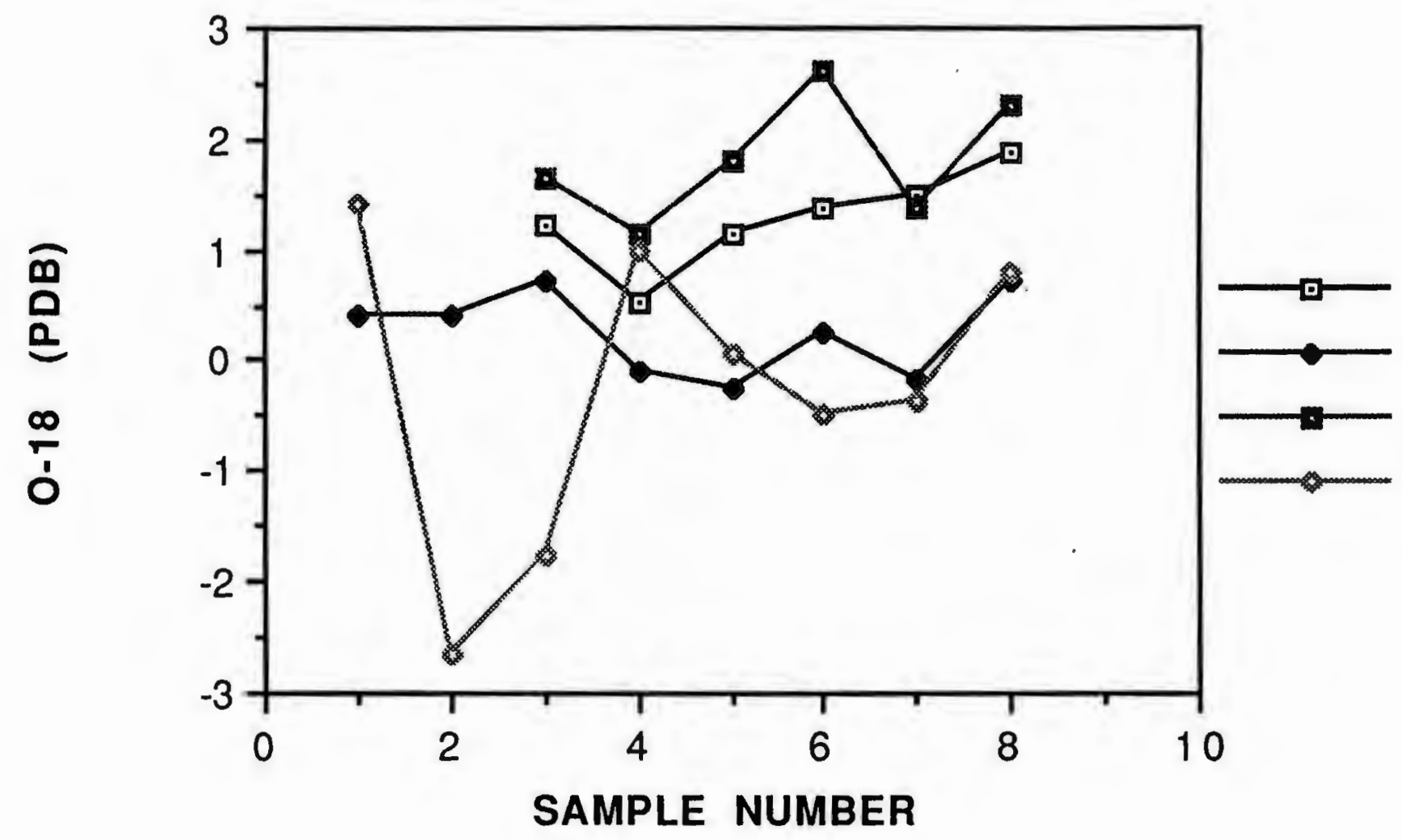




\section{FIGURE 19}

OXYGEN ISOTOPE RATIO PLOTS FROM SEQUENTIAL

ANALYSES OF BELLAMYA, CORBICULA, MUTELA,

AND ASPATHARIA SHELLS COLLECTED IN SEPTEMBER, 1986. 
SEP.'86 WINAM GULF 0-18

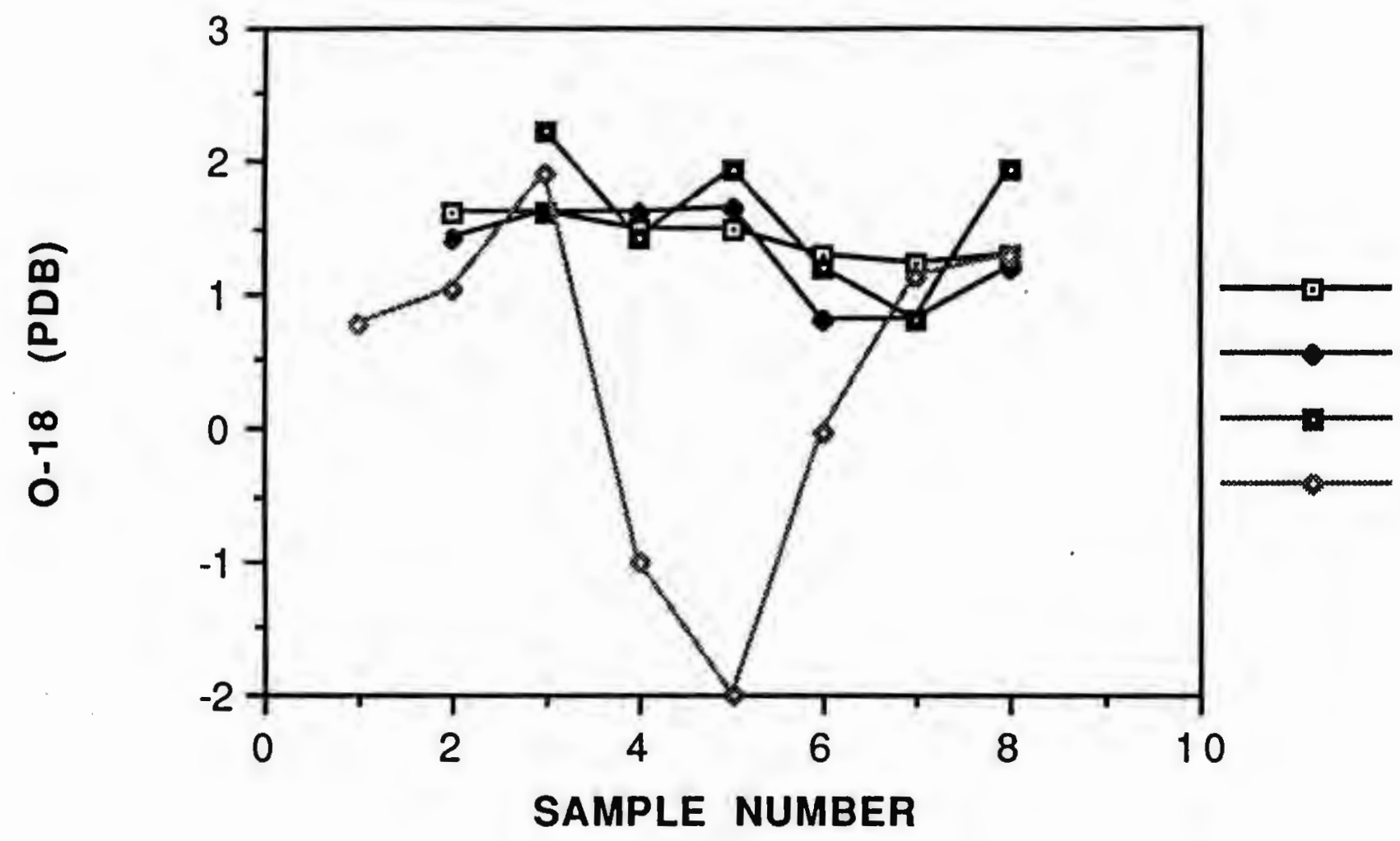

BELLAMYA CORBICULA MUTELA I ASPATHARIA 
FIGURE 20

CARBON ISOTOPE RATIO PLOTS FROM SEQUENTIAL ANALYSES OF BELLAMYA, CORBICULA, MUTELA, AND ASPATHARIA SHELLS COLLECTED IN MARCH, 1986. 
MAR.'86 WINAM GULF C-13

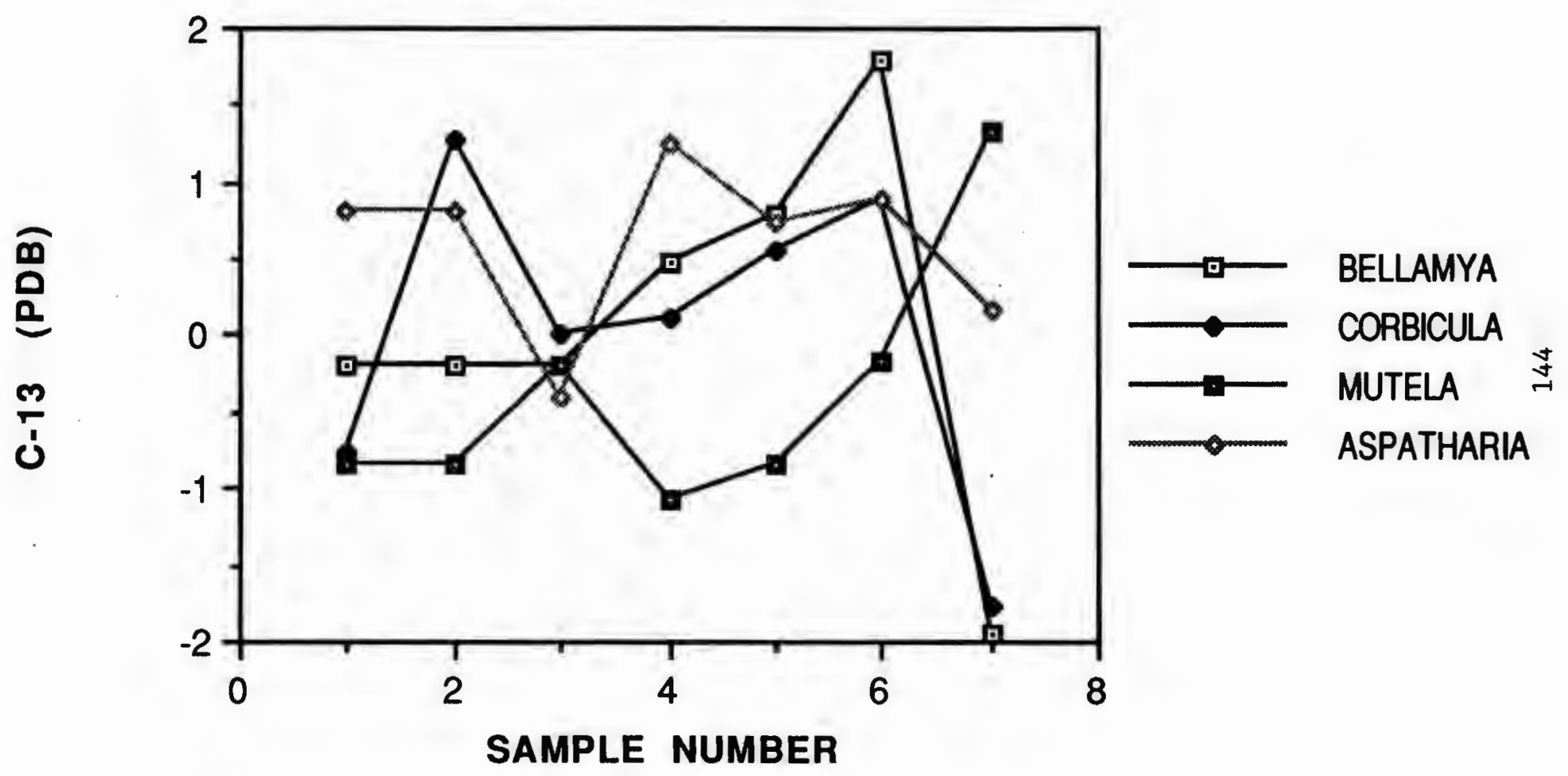


FIGURE 21

CARBON ISOTOPE RATIO PLOTS FROM SEQUENTIAL ANALYSES OF BELLMYA, CORBICULA, MUTELA, AND ASPATHARIA SHELLS COLLECTED IN APRIL, 1986. 
APR.'86 WINAM GULF C-13

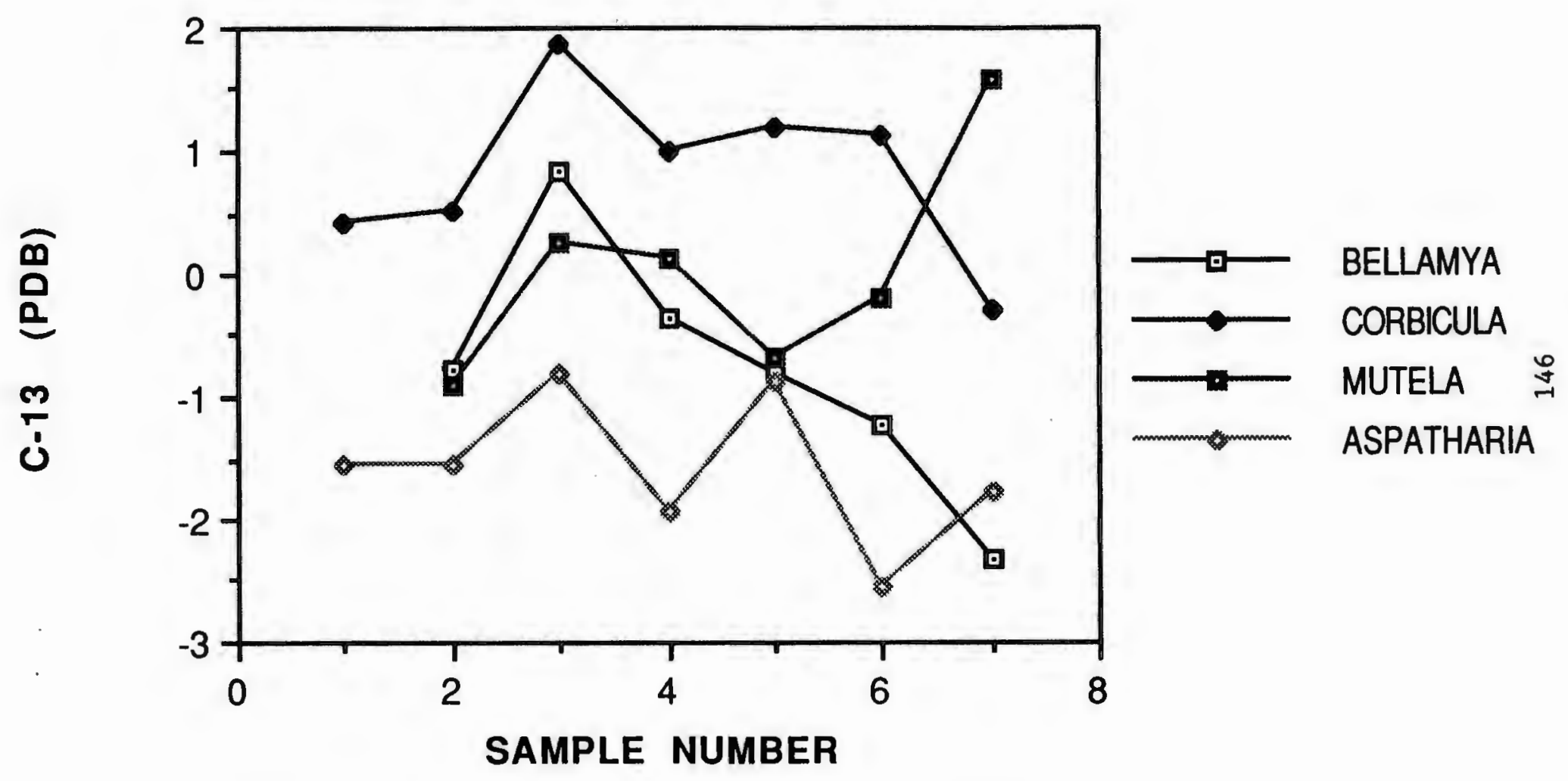


FIGURE 22

CARBON ISOTOPE RATIO PLOTS FROM SEQUENTIAL ANALYSES OF BELLAMYA, CORBICULA, MUTELA, AND ASPATHARIA SHELLS COLLECTED IN MAY, 1986. 
MAY'86 WINAM GULF C-13

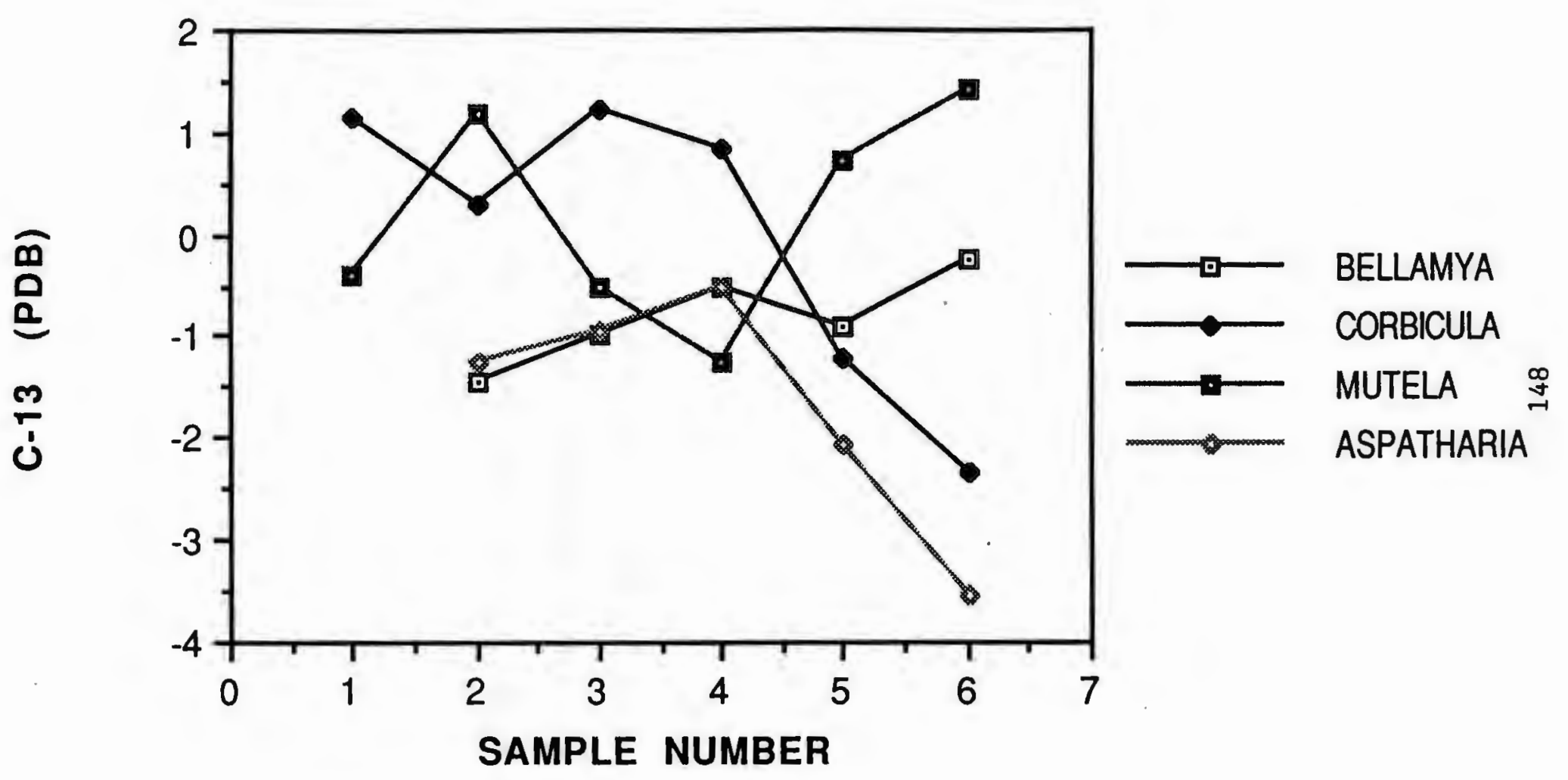


FIGURE 23

CARBON ISOTOPE RATIO PLOTS FROM SEQUENTIAL ANALYSES OF BELLAMYA, CORBICULA, MUTELA, AND ASPATHARIA SHELLS COLLECTED IN JUNE, 1986. 


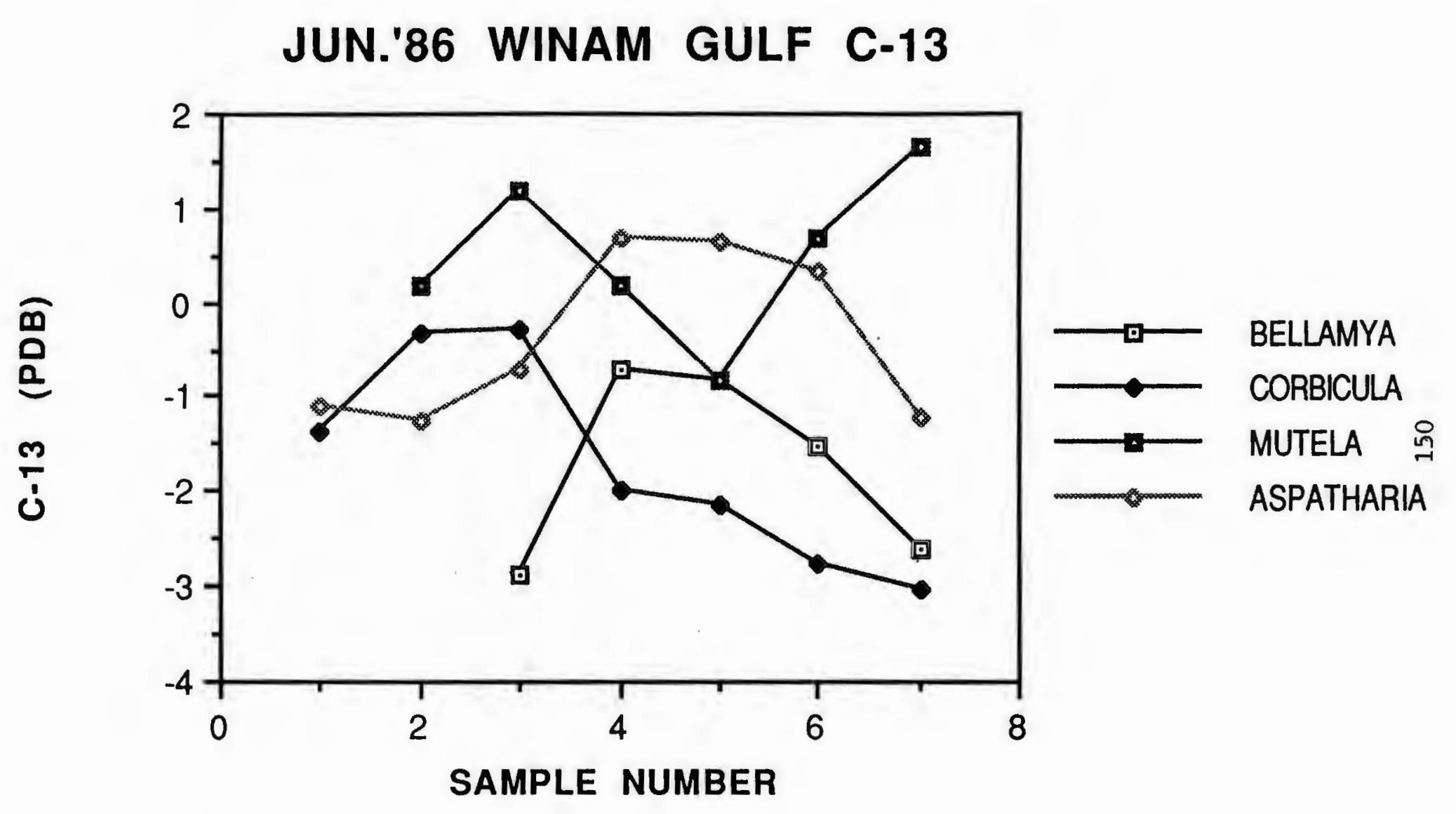


FIGURE 24

CARBON ISOTOPE RATIO PLOTS FROM SEQUENTIAL ANALYSES OF BELLAMYA, CORBICULA, MUTELA, AND ASPATHARIA SHELL COLLECTED IN JULY, 1986. 
JUL.'86 WINAM GULF C -13

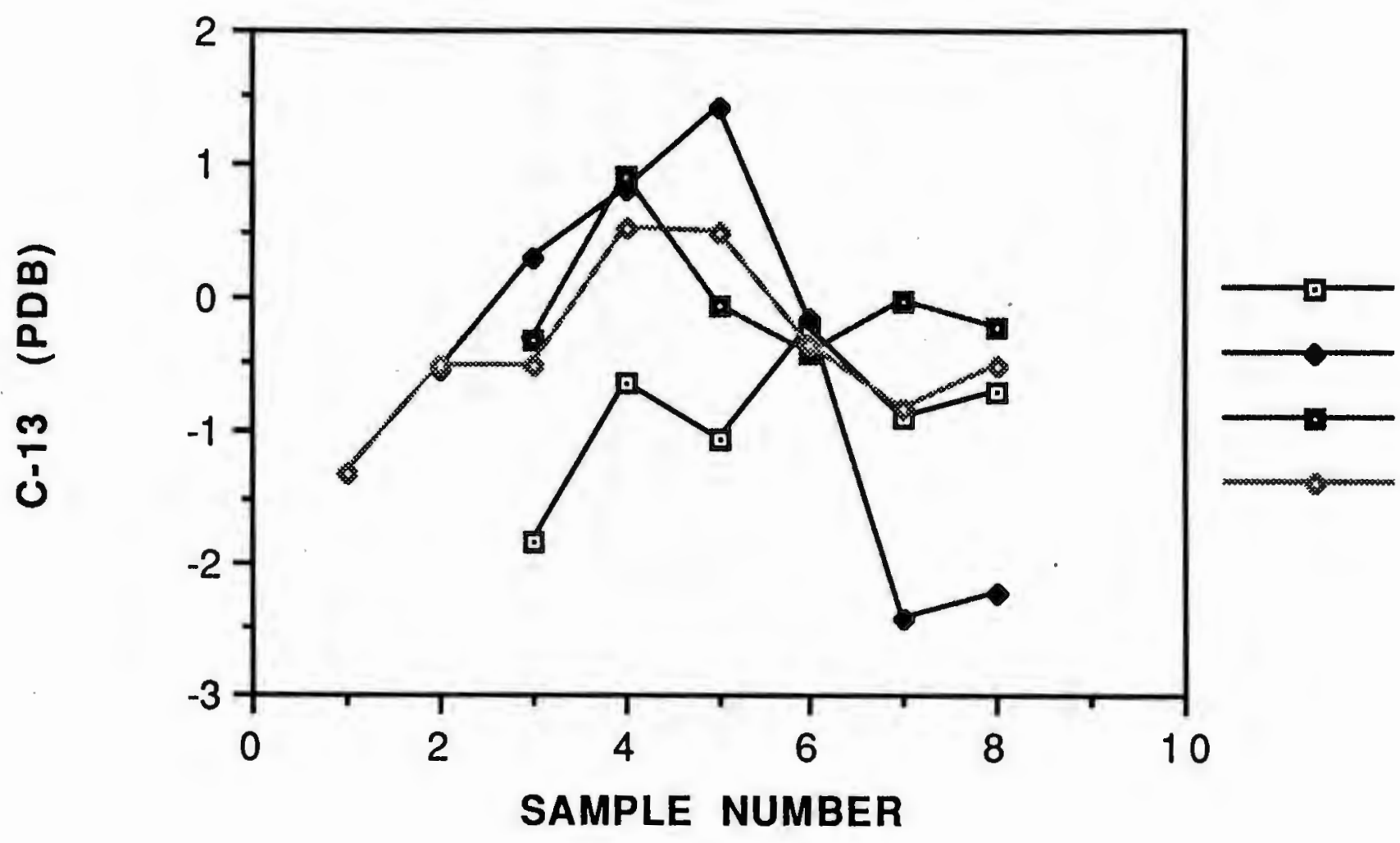




\section{FIGURE 25}

CARBON ISOTOPE RATIO PLOTS FROM SEQUENTIAL ANALYSES OF BELLAMYA, CORBICULA, MUTELA, AND ASPATHARIA SHELLS COLLECTED IN AUGUST, 1986. 


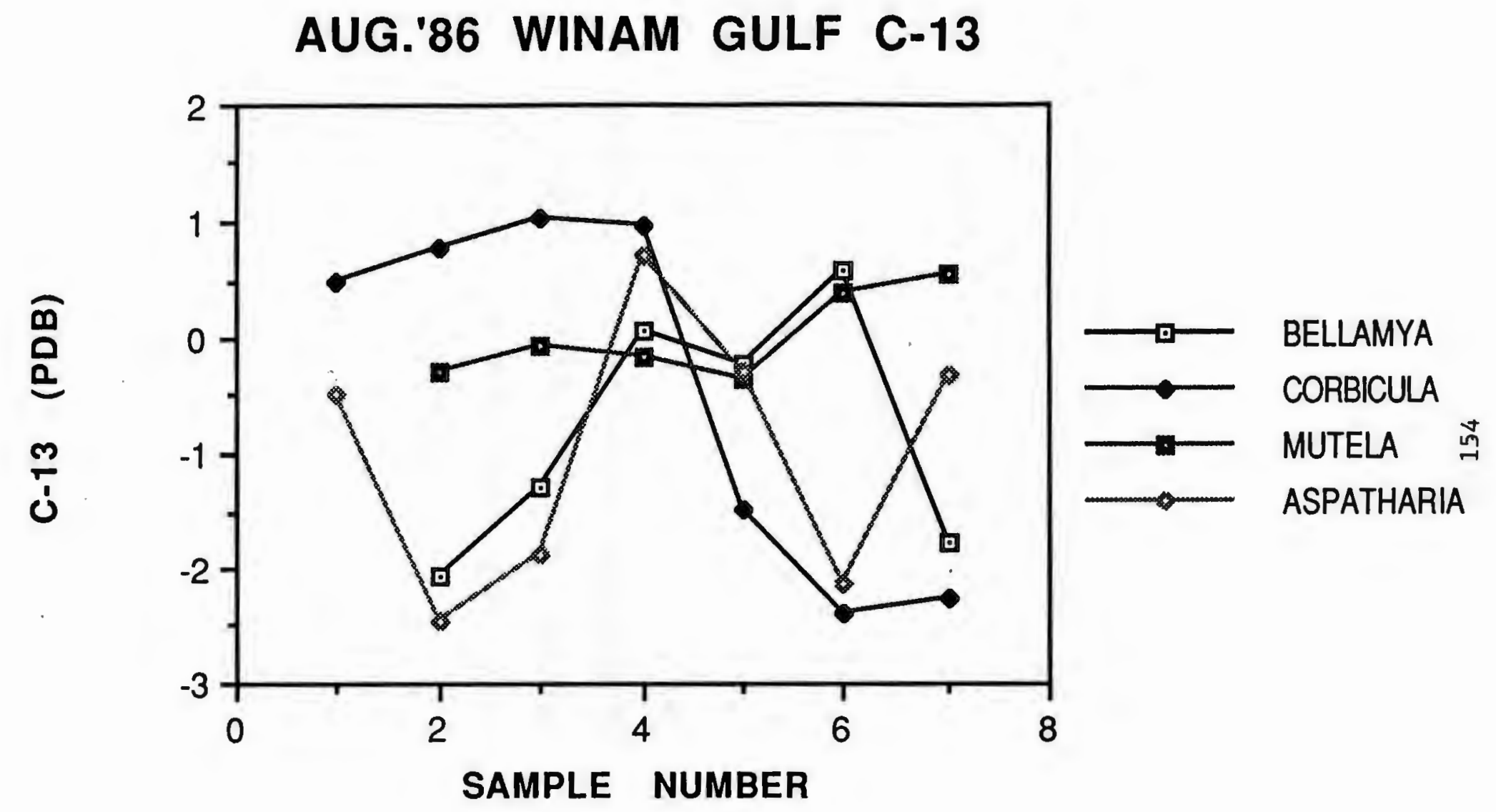


FIGURE 26

CARBON ISOTOPE RATIO PLOTS FROM SEQUENTIAL ANALYSES OF BELLAMYA, CORBICULA, MUTELA, AND ASPATHARIA SHELLS COLLECTED IN SEPTEMBER, 1986. 


\section{SEP.'86 WINAM GULF C-13}

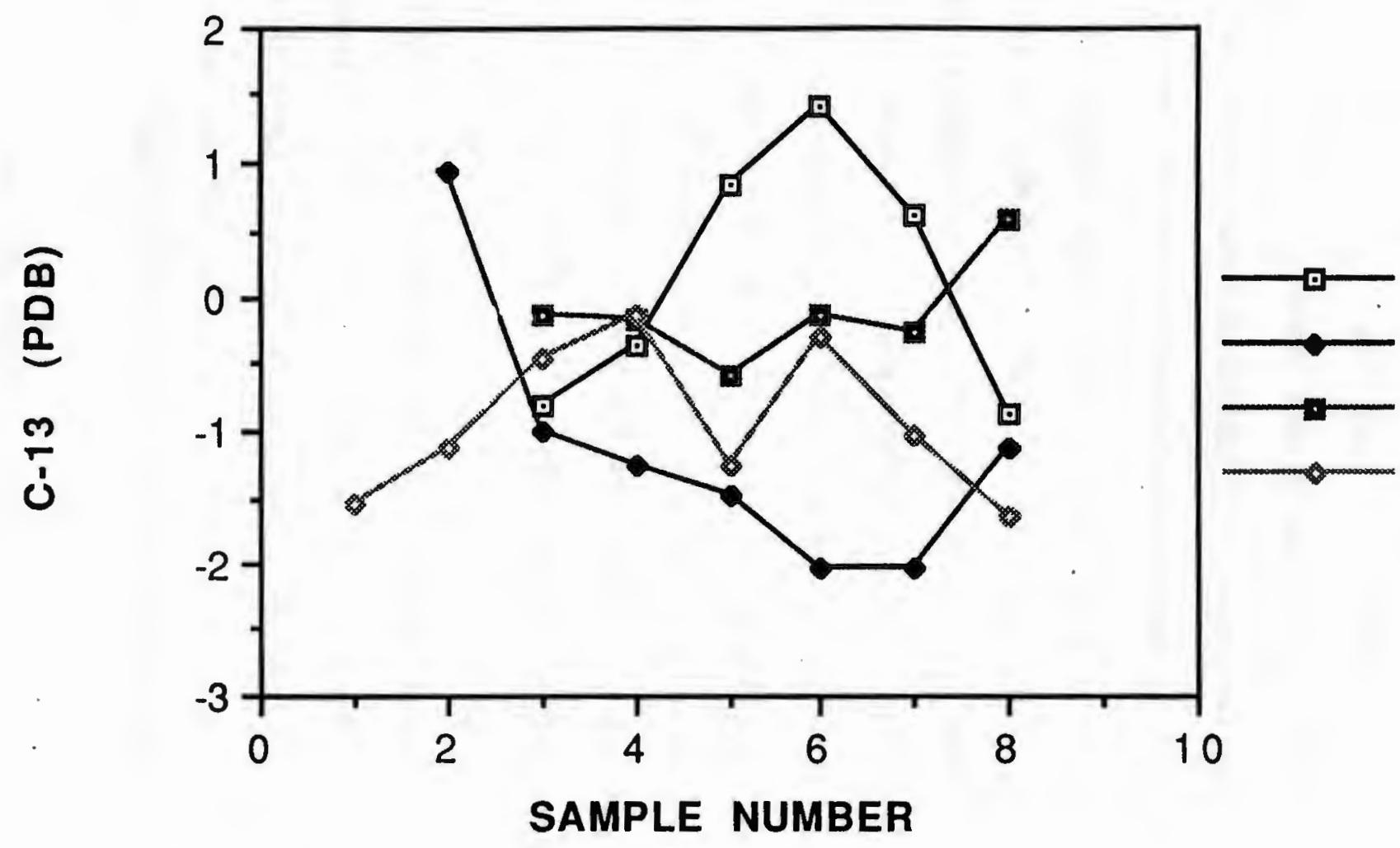

BELLAMYA

CORBICULA

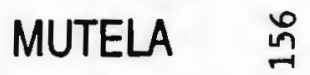
ASPATHARIA 
TSCUSSION OF RESULTS

The environmental factors that influence the isotopic ratios are examined as they will form the basis for the interpretation of our results.

\section{actors That Influence Carbon And Oxygen Isotope Ratios}

The precipitation of calcium carbonate as either calcite or aragonite shows well defined fractionation factors relating the oxygen isotope ratio to the water from which it was precipitated and the temperature of precipitation. The well-known Craig paleotemperature scale (Craig, 1965) is a practical utilization of the temperature control on the oxygen isotope ratio in calcite precipitation. In addition to temperature effects on oxygen isotope ratios, there is a considerable variation derived from the quite different influences on the oxygen isotope ratios in the bodies of fresh water in Africa (covering a range of about $10 \%$ ), which may be dependent on latitude, altitude and amount of rainfall (Dansgaard, 1964; Yurtsever, 1975), as well as post-precipitative evaporation. The latitudinal, altitudinal and amount effects are usually fairly easy to estimate by interpolation from the isotope map of Africa (Abell, 1985), but these effects may be augmented or altered by evaporative effects after the rain has fallen. These evaporative alterations will depend on such factors as regularity of rainfall, humidity, wind speed, air temperature, mass of the water body, efficiency of mixing, etc. This sounds very complicated but the oxygen isotope ratios of gastropod shells from most bodies of water seem to be regulated either by temperature or evaporative effects; in cool, temperate regions, where seasonality is pronounced, temperature controls 
isotope ratio variations, while in equatorial regions, evaporation seems to be the most important factor in controlling the isotope ratios. Precise quantification of oxygen isotope ratios is not possible, but rough estimates are possible. It should be emphasized that evaporative alterations of isotope ratios are not subtle, i.e. a given shell may incorporate a range of oxygen isotope ratios that covers 2 to $3 \%$.

Carbon isotope ratios of gastropod shells are more difficult to predict. Temperature effects are insignificant, and the carbon isotope ratios, of course, are not involved in latitudinal, altitudinal or amount effects in precipitation, nor in post-precipitation evaporation. Nonetheless, there is often a correlation observed between $\delta^{18} 0$ and $\delta^{13} \mathrm{C}$ for shells from a given locality and common age. Scatter diagrams of the two isotope ratios usually have a regression slope of about 2 , a long way from the 0.5 one might expect if atomic masses of carbon and oxygen isotopes were governing the formation of calcite or aragonite. The origins of these correlations remain obscure, but may be related to changes in nutrients with fresh additions of rainwater to a lake. It has been assumed that "vital" effects might also play an important role in carbon isotope ratios. These are effects that are peculiar to the organism being studied, and presume that carbon other than dissolved inorganic carbon may be contributing to the shell aragonite.

There have been few attempts to investigate the magnitude of vital effects, or species variation in such effects, and what studies have been made have been on long-lived marine molluscs. An example, in a different calcareous organism, is the study of Grossman (1987) in which he employed the carbon and oxygen isotopic equilibrium in foraminiferal 
calcite and aragonite in the examination of the characteristics and and causes of disequilibrium. There is an inherent problem in dealing with carbon isotope ratios in gastropod shells, as opposed to oxygen isotope ratios. With oxygen isotopes, there is only one source of the oxygen, the water in which the gastropod lives. But with carbon, the process of shell formation can derive carbon from either the dissolved inorganic carbon, or from the carbon which is passing through the metabolic processes of the gastropod. Furthermore, the dissolved inorganic carbon (DIC) can come from solution of atmospheric $\mathrm{CO}_{2}$, or oxidation in the water column of detrital organic matter, much of it with a very negative isotopic signature because it has been derived from photosynthesizing plants. Dissolved inorganic carbon, derived from atmospheric $\mathrm{CO}_{2}$ which has $\delta^{13} \mathrm{C}$ of about $-7 \%$, will yield $\mathrm{CaCO}_{3}$ with $\delta^{13} \mathrm{C}$ near $0 \%$, but carbon derived from photosynthetic sources can yield $\mathrm{CaCO}_{3}$ with $\delta^{13} \mathrm{C}$ near 27\% (Van der Merwe, 1982), and oxidation of methane produced by methanogenic organisms may give $\delta^{13} \mathrm{C}$ as $10 w$ as $-50 \%$ (Stevens and Engelkeimer, 1988). Clearly, incorporation of either photosynthetic carbon or oxidized methane can lead to shells with quite negative values of $\delta^{13} \mathrm{C}$. There is little information on how shell formation takes place, but it is obviously not simply an inorganic precipitation phenomenon, because it produces the thermodynamically unstable aragonite in most species. In a recent study, in which the crystallization of $\mathrm{CaCO}_{3}$ was controlled under stearic acid monolayers, Mann et al., (1988) observed that in the absence of a monolayer of stearic acid, rhombohedral calcite crystals were formed as opposed to the vaterite formation in the presence of an organized monolayer. Estimates of the 
percent carbon derived from metabolic processes as opposed to DIC have been few. Tanaka et al., (1986) estimate that the marine bivalve Mercenaria mercenaria, derives about $45 \%$ of its shell from metabolic carbon. There have been no estimates from freshwater species.

\section{Gection of Environmental Changes In Shell And Water Isotope Ratios}

From the temperature plots in Figure 4, we notice minimal variability in the recorded water temperatures, with low temperatures recorded between August and January. The maximum temperature $\left(28.5^{\circ} \mathrm{C}\right)$ was recorded for January and March, with the minimum temperature $\left(26.5^{\circ} \mathrm{C}\right.$ ) being recorded in October, November and December (Table 1). This gives an overall temperature range of $2^{\circ} \mathrm{C}$ for the sampling period.

Latitudinal effects produce $\delta^{18} 0$ values near -4 to $-5 \%$ at the equator, and extending to -8 to $-9 \%$ at the northern and southern extremes of Africa. It is known that evaporative conditions in East Africa are clearly delineated with $\delta^{18} 0$ values near +1 to $+2 \%$. According to the observations of Abell (1985), in cool, high and regular rainfall areas, where $\delta^{18} 0$ of shell is -3 to $-5 \%$, in situ evaporation is probably much less important than temperature in controlling $\delta^{18} 0$. In arid and hot areas, where rainfall is light and variation in temperature is minimal, the $\delta^{18} 0$ is mainly controlled by evaporation. At Winam Gulf where temperature variation is minimal, we notice considerable variation in the $\delta^{18} 0$ values (Table 2 ).

According to the rainfall information provided by the meteorological station in Kisumu, and plotted in Figure 5, it rains all year round with highest rainfall in April and May followed by November 
and December. With a rainfall range of $189.9 \mathrm{~mm}$ during sampling from a maximum of $228.5 \mathrm{~mm}$ in March and a minimum of $38.6 \mathrm{~mm}$ in August, the maximum and minimum rainfall and temperature months seem to correspond. High rainfall and low temperatures, we know can cause oxygen isotope ratio depletion for calcium carbonate precipitated under these conditions.

Slow rate of shell growth relative to the fairly rapid changes in oxygen isotope ratios of the water may account for the lack of observation of the same environmental changes in the isotope ratios in the shells. For example, Mutela and Aspatharia $\delta^{18} 0$ lag behind the water $\delta^{18} 0$ by one month (Figures 8 and 9) while Corbicula and Bellamya $\delta^{18} 0$ lag behind the water $\delta^{18} 0$ by one to two months (Figures 6 and 7 ) depending on the section of the plot considered. There is, obviously, no expectation that our sample, taken for example, on April 26, 1986 is going to reflect the $\delta^{18} 0$ of the water of April 26, 1986. Rather, it will integrate the changing water $\delta^{18} 0$ of the previous days or weeks.

\section{TABLE 1}

Summary of Temperature and Rainfall Information

TEMPERATURE ${ }^{\circ} \mathrm{C}$

RAINFALL $(\mathrm{mm})$

WATER MONTH MONTH

$\begin{array}{lrccc}\text { MINIMUM } & 26.5 & \text { Dec. Oct. Nov. } & 38.6 & \text { Aug. } \\ \text { MAXIMUM } & 28.5 & \text { Jan. Mar. } & 228.5 & \text { Mar. } \\ \text { RANGE } & 2.0 & & 189.9 & \\ \text { AVERAGE } & 27.4 & & 98\end{array}$


From Table 2, which summarizes the isotope ratios of the molluscan species as they responded to the environmental changes at the Winam Gulf, the average $\delta^{18} 0$ values of the molluscs are Bellamya, (0.63), Corbicula, (0.78), Mutela, (1.98), and Aspatharia, (.27); the average carbon isotope ratios are $(-1.79),(-1.78),(1.04)$ and $(-0.59)$ respectively. Such $\delta^{18} 0$ values for molluscan shells from bodies of water near the equator are normal under the condition that no extreme temperature or evaporative effects are overriding. Wide range variable isotope ratios indicate variable environmental or seasonality effect during the life span of individual molluscs. (Abell, 1985)

\section{TABLE 2}

\section{Summary of Isotope Ratio Values}

MINIMUM MAXIMUM

$\begin{array}{lccccc}\text { BELLAMYA } & -1.64(-3.24) & 1.87(-0.23) & 3.51(3.01) & 0.63(-1.79) \\ \text { CORBICULA } & -0.72(-3.07) & 1.82(1.54) & 2.45(4.61) & 0.78(-1.78) \\ \text { MUTELA } & 1.62(-0.22) & 2.31(1.67) & .0 .69(1.89) & 1.98(1.04) \\ \text { ASPATHARIA } & -1.70(-2.65) & 2.71(0.45) & 4.40(3.10) & 0.27(-0.59)\end{array}$
$\left(\delta^{13} \mathrm{C}\right.$ values are in parenthesis)

Figures 12-15 summarize carbon and oxygen data on the four molluscan species. In Figure 12, the carbon and oxygen isotope plots parallel each other for the first six months. Not much parallelism is observable in the remaining months of collection. The correlation factor for the carbon and oxygen in this plot is 0.62 (Table 3). 
In Figure 13 the Winam Gulf Corbicula carbon and oxygen isotope ratios show parallelism from December 1985 to 0ctober 1986 after which there is a lag in the Corbicula plots. This is summarized as 20\% correlation between the carbon and the oxygen isotope ratios (Table 3 ). In Figure 14, there is no obvious parallelism between the Mutela carbon and oxygen isotope ratio plots. In Figure 15, there is parallelism between the Aspatharia carbon and oxygen isotope ratios with slight noise. The carbon and oxygen correlation factor observed here is 0.35 . The $\delta^{18} 0$ plots of the Winam Gulf molluscan species are summarized in Figure 16. There is similarity in the isotopic response of all the molluscan shells to environmental changes with slight "noise" here and there which may be ascribed to temporary variations in microhabitat. The $\delta^{18} 0$ values range between -1 to $+2 \%$. This is expected for molluscan species in a body of water near the equator (Abell 1985), where there are seasonal differences in rainfall and evaporative influences. Each of the molluscan species will be discussed in turn to examine the extent to which they responded to monthly changes in the Winam Gulf and also how the molluscs collected monthly and analyzed in detail differ from those of the previous month.

\section{Mutela}

Mutela samples were collected over 8 month period (Mar.-0ct.). Although Mutela sample collection covered a shorter period compared to other bivalves and the gastropod, the shell $\delta^{18} 0$ correlates fairly well with the water $\delta^{18} 0$ with a one month lag (Figure 8). This correlation is improved when the plot of water $\delta^{18} 0$ is shifted forward by an additional month, shown by dotted lines in the figure. 
For Mutela, while some of the $\delta^{18} 0$ near the aperture closely correspond with the $\left(\delta^{18} 0\right)_{\text {water }}$ of Figure 8 , others lag behind. There is, however, a good correlation between their $\delta^{13} \mathrm{C}$ plots. It is difficult to estimate the life span of the Mutela from Figures 13-19, because there appears to be an influence of the freshly deposited isotope ratios on the previous isotope ratios deposited. They appear to average out such that previous enrichments or depletions are no longer as pronounced as when they were first deposited. This is to be expected, as not all shell growth takes place at the aperture, but there is an asymptotically thin film added back inside the shell.

By inspection and comparison of $\delta^{18} 0$ plots in Figure 12 versus Figures 6 and 8 , we estimate the October, 1986 Mutela, which was analyzed in detail, to be approximately 18 months old. This is because by comparing Figure 12 (0ct. $1986 \underline{\text { Mutela })}$ with Figure $8,\left(\delta^{18} 0_{\text {Mutela }}\right.$ and $\delta^{18} 0_{\text {water }}$ ) we estimate that the shell isotope ratio information covers approximately 18 months. We also observe a near superposition of the $\delta^{18} 0$ values from the aperture to the hinge of the Mutela. It appears that, for the purpose of getting a snapshot of the response of molluscan species to environmental change, intermittent sampling along the growth bands of the molluscs is sufficient.

\section{Aspatharia}

Collection of this bivalve covered a period between Dec. 1985 and Oct. 1986 (Figure 9). The $\delta^{18} 0$ value of February is an interpolation; no sample was supplied for that month. The shell $\delta^{18} 0$ values lag behind the water $\delta^{18} 0$ but the lag is eliminated with a one month shift of the water $\delta^{18} 0$, whereupon the correlation between water and the shell $\delta^{18} 0$ 
values becomes obvious (Figure 9).

The September Aspatharia $\delta^{18} 0$ plot (Figure 19) does not reflect growth continuity from the previous month's plot. It has a $\delta^{18} 0$ plot similar to the May Aspatharia $\delta^{18} 0$ plot, probably a manifestation of slow growth. By inspection of the isotope ratio plots in Figure 9 and Figures 13 to 19, we estimate that the Aspatharia is giving us $\delta^{18} 0$ information spanning a period of 7 to 9 months. The lag in the same molluscan species is not uniform. For example, by inspection of Figure 9 versus Figures 13-19 non-uniform growth rate is observed in all molluscan species. This is, of course, not unexpected in a situation where conditions are not uniform over time.

\section{Corbicula}

Correlation between water and shell $\delta^{18} 0$ plots appeared elusive (Figure 7 ), but with one month's shift the correlation becomes obvious. However, the first six month's values appear to lag behind yet another month.

We observe the influence of previously recorded isotopic ratios in the growth bands of the Corbicula by subsequent depositions through inspection of Figure 9 versus Figures $13-19$ and also Figures 20-26. From the same plots, the life span of the Corbicula molluscs analyzed from March to May is estimated to be approximately 4 months and 5-6 months for those from June to August.

\section{Bellamya}

The first 6 month's aperture $\delta^{18} 0$ plots appear to lag behind the $\delta^{18} 0_{\text {water }}$ by two months, while the last five month's plots show a correlation without a shift of the water plots (Figure 6). This may be 
attributed to differences in growth rate at various times of the year.

With the Bellamya gastropods, the $\delta^{18} 0$ values plotted in Figure 6 appear averaged out when compared to the $\delta^{18} 0$ values from sequential analyses plotted in Figures 13-19. Changes in the $\delta^{13} \mathrm{C}$ values from sequential analyses (Figures 20-26) are not as pronounced when compared to the aperture $\delta^{13} \mathrm{C}$ values in Figure 6 . The gastropods are estimated to be providing us with 4 months isotopic ratio information. 
TABLE 3

SUMMARY OF CORRELATION VALUES

SHELL $\delta^{18} 0$

$\underline{\mathrm{H}}_{2} \underline{\mathrm{O}} \delta^{18} \mathrm{O}$

Bellamya

$\underline{\mathrm{R}}$

$\underline{\mathrm{R}^{2}}$

$\underline{\mathrm{R}}$

$\underline{\mathrm{R}^{2}}$

Water Temp.

0.65

0.42

0.53

0.28

Precipitation

0.09

0.01

0.21

0.04

Shell $\delta^{18} 0$

$-$

0.40

0.16

She1l $\delta^{13} \mathrm{C}$

0.62

0.39

0.45

0.19

Corbicula

Water Temp.

0.30

0.09

0.53

0.28

Precipitation

0.36

0.13

0.21

0.04

Shell $\delta^{18} 0$

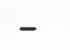

0.12

0.02

Shell $\delta^{13} \mathrm{C}$

0.20

0.04

0.00

0.00

Mutela

Water Temp.

0.49

0.24

0.51

0.26

Precipitation

0.00

0.00

0.41

0.17

Shell $\delta^{18} 0$

0.66

0.44

Shell $\delta^{13} \mathrm{C}$

0.10

0.01

0.13

0.02

Aspatharia

Water Temp.

0.20

0.04

0.56

0.31

Precipitation

0.00

0.00

0.25

0.06

Shell $\delta^{18} 0$

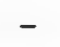

0.35

0.12

0.45

0.19

Shell $\delta^{13} \mathrm{C}$

0.36

0.13 


\section{Yinam Gulf Carbon Isotope Ratios In Mollusc Shells}

From the foregoing, we see that the molluscan species all record very similar $\delta^{18} 0$ values, but with much variation in the $\delta^{13} \mathrm{C}$ values. For example, the $\delta^{13} \mathrm{C}$ values range from -3.24 to $1.67 \%$ giving a range of 4.91\% (Table 2). Although there is correlation of carbon isotope ratios between Corbicula and Aspatharia, there is a month or two lag from March to 0ctober (Figure 11). Corbicula and Mutela carbon isotope ratio plots partially parallel each other between January and 0ctober. The exclusive enrichment of Mutela $\delta^{13} \mathrm{C}$ may be attributed to a vital effect or microenvironmental difference.

Depleted carbon isotope ratios are recorded in the following months: Jan. Feb., May, Jun. Sep. and 0ct. These depletions correspond to months with high rainfall and lower temperatures and, therefore, may possibly be attributed to higher input of dissolved $\mathrm{CO}_{2}$. Stuiver (1970) has attributed such depletions to either evaporative rate changes or changes in the photosynthetic activity associated with temperature changes .

From Table 3 we observe that with the exception of Bellamya, a gastropod, which shows a good correlation between $\delta^{13} \mathrm{C}$ and $\delta^{18} 0$, the other molluscan species, all bivalves, show a poor correlation between their $\delta^{13} \mathrm{C}$ and $\delta^{18} 0$. This may be an indication that the molluscs may not be taking their carbon from the same source or that they are not governed by the same factors governing distribution of carbon sources when it comes to shell accretion. We know that there are several sources of carbon, which gives the molluscs a choice of either DIC or 
metabolic carbon or different percentages of each.

Since all the molluscan $\delta^{13} \mathrm{C}$ values in this study are all fairly close in their isotopic ratios with respect to $\delta^{13} \mathrm{C}_{\text {Bicarbonate }}(-0 \%)$, we suggest that the percentage of metabolic carbon incorporated into the shells of the Melanoides tuberculata is minimal or that whatever amount of metabolic carbon available, has become enriched through increased lake productivity, a process which causes enrichment of the $\delta^{13} \mathrm{C}$ left behind (Deuser et al., 1968, Calder and Parker, 1973, Herczeq and Fairbanks, 1987). The $\delta^{13} \mathrm{C}$ values reported in this study fall within the range $(-9$ to +2$)$. This range seems to be the $\delta^{13} \mathrm{C}$ signature range for African lakes in the study of paleoenvironments because of the high frequency with which this $\delta^{13} \mathrm{C}$ range has been reported for molluscan species collected from most African lakes. For example, molluscs from paleo-Lakes Erer, and Besaka in the Afar region of Ethiopia recorded $\delta^{13} \mathrm{C}$ values ranging from as high as -5 to $-1 \%$. (Abell and Williams, 1989). Unpublished data (Abell and Amegashitsi) on the gastropod shell isotope ratios of Lakes Malawi and Tanganyika, recovered from depths to $250^{\prime}$, show carbon isotope ratios +0.5 to $-2 \%$. On the other hand, most of the molluscs in streams and rivers of West Africa studied in our laboratory gave a $\delta^{13} \mathrm{C}$ value range of -19 to $-10 \%$. (Figure 27) Obviously, there are quite different factors influencing carbon isotope ratios, with no obvious explanations for these differences. 
FIGURE 27

SCATTER PLOT OF ISOTOPE RATIOS IN

MELANOIDES FROM WEST AFRICAN RIVERS 
ISOTOPE RATIOS IN WEST AFRICAN RIVERS

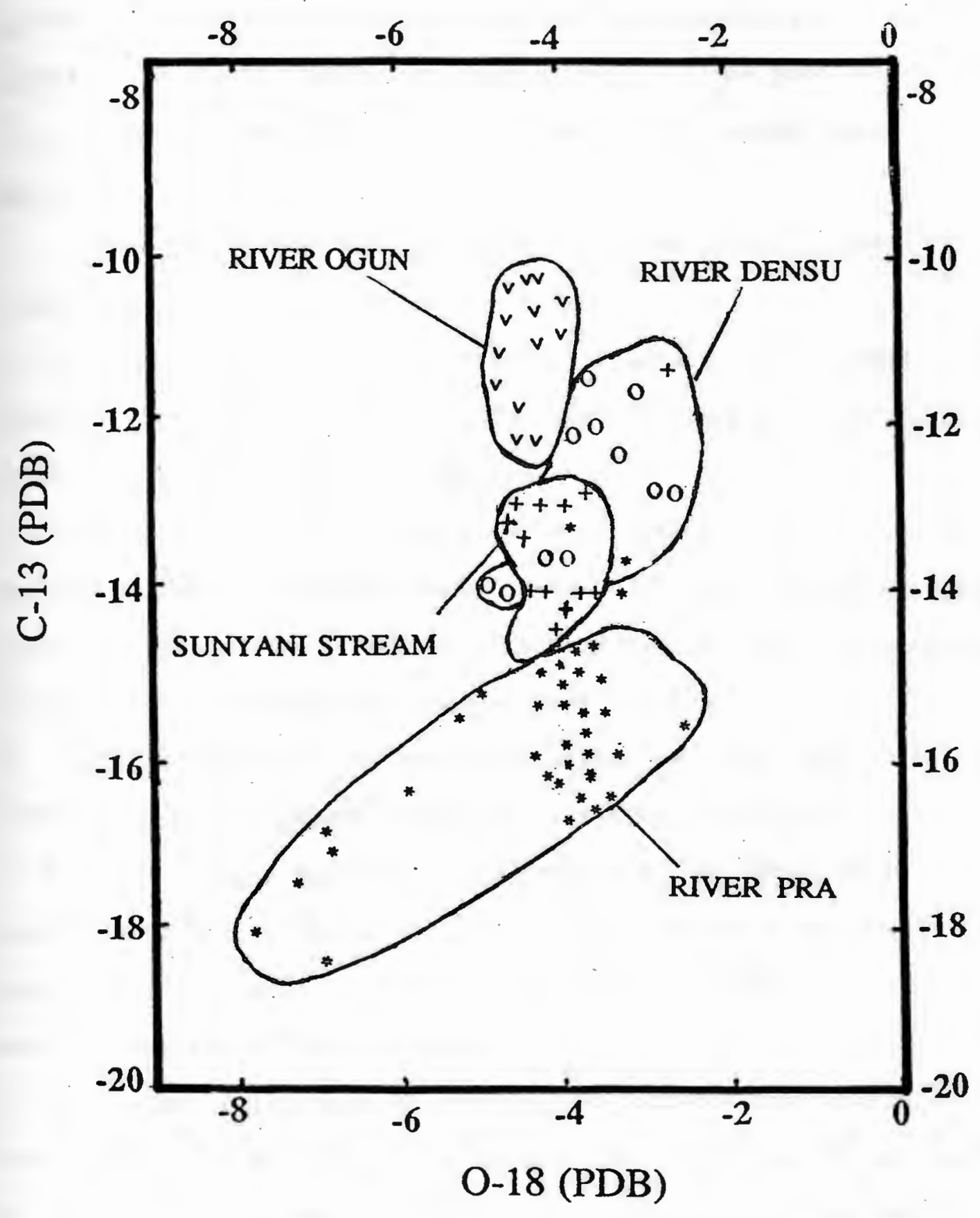




\section{CONCLUSIONS}

In summary, this project offered a chance to study carbon isotope ratios as a function of shell growth, and yielded some rather unexpected results. We do not pretend to have solved all the problems, but only that we have an emerging picture of the carbon isotope sources of the molluscs.

Upon completion of this study we have come to the following conclusions :

1. In general the $\delta^{18} 0$ and $\delta^{13} \mathrm{C}$ plots paralleled one another. While there is no theoretical reason for this correlation, it is clearly evident in most of the shells studied.

2. There is continuity in growth patterns, which can be traced through monthly sequential analyses plots within the same molluscan species. This continuity gives a way of utilizing mollusc shell isotope ratios for reconstructing short segments of past climates.

3. Heteroscedasticity of scatter plots of $\delta^{13} \mathrm{C}$ and $\delta^{18} 0$ gives information on the extent of seasonal climatic variations.

4. The $\delta^{13} \mathrm{C}$ of the Mutela is different from the other three species. Since the $\delta^{13} \mathrm{C}$ values of the other three molluscan species are more negative, it may well be that their utility of metabolic carbon may be more extensive than that of Mutela.

5. Estimation of life span of molluscs is possible from aperture, water and sequential $\delta^{18} 0$ plots. For example, the life span of the Bellamya is estimated to be 4 months and that of the Corbicula is estimated to be 6 months. We estimate the life span of Mutela and Aspatharia to be in 
the range of 7-9 months. Knowledge of the life span of the molluscan species is important, as it determines the extent of utility of the molluscan shell isotope ratios for the reconstruction of paleoclimates and paleoenvironments. In other words, it provides the information span of the isotope ratios of the shell.

6. The use of the same molluscan species in the study of different paleoenvironments will minimize errors in data analysis, as it tends to cancel out vital effects and micro-habitat effects. 


\section{REFERENCES}

Abell, P. I. (1982). Paleoclimates at Lake Turkana, Kenya, from oxygen isotope ratios of gastropod shells. Nature, $\underline{297}, 321-323$

Abell, P. I. (1985). Oxygen Isotope Ratios in Modern African Gastropod Shells: A data base for Paleoclimatology. Chemical Geology, $\underline{58} 183-$ 193.

Abell, P. I., and Nyamweru, C., (1988). Paleoenvironments in the Chalbi Basin of Kenya. Isotope Geosci., 2, 283-291.

Abell, P. I., and Williams, M. A. J., (1989). Oxygen and carbon isotope ratios in gastropod shells as indicators of paleoenvironments in the Afar region of Ethiopia. Palaeogeogr., Palaeoclimatol., Palaeoecol., 74, 265-278.

Arthur, M. A., Williams, D. F. and Jones; D. S. (1983). Seasonal temperature-salinity changes and thermocline development in the midAtlantic Bight as recorded by the isotopic composition of bivalves. Geology, 11 655-659

Beadle, L. C., (1974). The Inland Waters of Tropical Africa - An introduction to Tropical Limnology. Longman Group Limited.

Boucher, K., (1975). "Global Climate" The English Universities Press 
Ltd. London. pp326.

Brown, D. S., (1980). Freshwater Snails of Africa and Their Medical Importance. Taylor and Francis, London, pp487.

Burchardt, B., (1977). 0xygen isotope ratios from shell material from the Danish Middle Pleistocene (Selandian) deposits and their interpretation as paleotemperatures. Paleogeog. Paleocli. Paleoecol., $\underline{22}$ (3). 209-230.

Calder, J. A., and Parker, P. L. (1973). Geochemical implications of induced changes in ${ }^{13} \mathrm{C}$ fractionation by blue-green algae. Geochim. Cosmochim. Acta 37, 133-140.

Craig, H., (1965). The measurement of oxygen isotopre palaeotemperatures. In : E. Tongiorgi (Editor), Stable Isotopes in Oceanographic Studies and Paleotemperatures. Pisa, Cons. Nat. Ric. Lab. Geol. Nucl., pp161-182.

Dansgaard, W., (1964). Stable isotopes in precipitation. Tellus, $\underline{16}$, 436-468.

Deuser, W. G., Degens, E. T., and Guillard, R. R. L. (1968). Carbon isotope relationships between plankton and seawater. Geochim. Cosmochim. Acta $\underline{32}, 657-660$. 
Epstein, S., Buchsbaum, R., Lowenstam, H. A. and Urey, H. C. (1951). Carbonate-water isotopic temperature scale. Geol. Soc. Amer. Bull., $\underline{62}$, $417-426$.

Epstein, S., Buchsbaum, R., Lowenstam, H. A. and Urey, H. C., (1953). Revised carbonate water isotopic temperture scale. Geol. Soc. Amer. Bull. 64, 1315-1326.

Epstein, S. and Lowenstam, H. A.,(1953). Temperature-shell growth relations of recent and interglacial Pleistocene shoal-water biota from Bermuda. J. Geol., $\underline{61}$ (5), 424-438.

Epstein, S. and Mayeda T. K., (1953). Variations of the ${ }^{18} 0 /{ }^{16} 0$ ratios in natural waters. Geochim. Cosmochim. Acta, 4: 213-4.

Fritz, P. and Poplawski, S., (1974). Oxygen-18 and Carbon-13 in the shells of freshwater mollusks and their environments. Earth Planet. Sci. Lett. , 24 91-98.

Grossman, E. L. (1987) Stable Isotopes in Modern Benthic Foraminifera: A Study of Vital Effect. Journ. of Foraminiferal Research 17 :1 48-61.

Hamilton, A. C., (1982). Environmental History of East Africa - A Study of the Quarternary. Academic Press. London. pp10-19.

Herczeg, A. L. and Fairbanks, R. G. (1987). Anomalous carbon isotope 
fractionation between atmospheric $\mathrm{CO}_{2}$ and dissolved inorganic carbon induced by intense photosynthesis. Geochim. Cosmochim. Acta 51, 895899.

Jones, D. S., Williams, D. F. and Arthur, M. A., (1983). Growth history and ecology of the Atlantic surf clam, Spisula solidissima (Dillwyn), as revealed by stable isotopes and annual shell increments. J. Exp. Mar. Biol. Ecol., 푸, 225-242.

Kitaka, G. E. B., (1971). An instance of cyclonic upwelling in the southern offshore waters of Lake Victoria. Afr. J. Trop. Hydrobiol. Fish, 1 , 85-92.

Keith, M. L., Eichler, R. and Parker, R. H., (1960). Carbon and oxygen isotope ratios in. marine and freshwater mollusk shells (abstract). Geol. Soc. Amer. Bull., 711901.

Keith, M. L., and Anderson, G. M., (1964). Carbon and oxygen isotopic composition of mollusk shell from marine and freshwater environments. Geochim. Cosmochim. Acta, 28, 1757-1786.

Keith, M. L., and Parker, R. H., (1965). Local variation of carbon-13 and oxygen-18 of mollusk shells and the relatively minor temperature effect in marginal environments. Mar. Geol., 3 , 115-129.

Lee, C. A., (1979). 0xygen isotopes in the seasonal growth bands of 
Pismo clam. M.S. thesis, Dept. of Geology, UCLA.

Lévêque, C., (1973). Dynamique des peuplements, biologie et estimations de la production des mollusques benthiques du Lac Tchad. Cah. Off. Rech. Sci. Tech. Outre-Mer, Ser. Hydrobiol. I, 117-147.

Mann, S., Heywood, B. R., Rajam, S., \& Birchall, J. D., (1988). Controlled crystallization of $\mathrm{CaCO}_{3}$ under stearic acid monolayers. Nature $334,692-695$.

McKinney, C. R., McCrea, J. M., Epstein, S., Allen, H. A. and Urey, H.C. (1950). Improvements in mass spectrometers for the measurement of small differences in isotope abundance ratios. Rev. Sci. Instr. 21, 724730.

Mills, G. A., and Urey, H. C. (1940). The Kinetics of Isotopic Exchange Between Carbon Dioxide, Bicarbonate Ion, Carbonate Ion and Water. Journ. Amer. Chem. Soc. 62, 1019.

Mook, W. G., (1971). Paleotemperatures and chlorinities from stable carbon and oxygen isotopes in shell carbonates. Paleogeog., Paleocli., Paleoecol., 9 , 245-263.

Mook, W. G., (1977). Stable carbon and oxygen isotopes in natural waters in Netherlands. International Atomic Energy Agency Conf. Proc. Uses of Isotopes in Hydrology, Vienna. pp 163-190. 
Stevens, C. M., and Engelkeimer, A., (1988). Stable Carbon Isotopic Composition of Methane from some Natural and Anthropogenic sources. J. Geophy. Res. 93, 725-733.

Stuiver, M. (1970) 0xygen and Carbon Isotope Ratios of Fresh-Water Carbonates as Climatic Indicators. Journ. of Geophysical Research $\underline{75}$ $5247-5257$.

Talling, J. F., (1964). The annual cycle of stratification and primary production in Lake Victoria (E. Africa). Verh. int. Ver. Limnol., 15, $384-5$.

Tanaka, N., Monaghan, M. C., \& Rye, D. M., (1986). Contribution of metabolic carbon to mollusc and barnacle shell carbonate. Nature $\underline{320}$, $520-523$.

Urey, H. C. (1947). The thermodynamic properties of isotopic substances. J. Chem. Soc., 562-581.

Van der Merwe, N. J., (1982). Carbon isotopes, photosynthesis and archaeology. Amer. Scientist, $\underline{70}, 596-606$.

Yurtsever, Y., (1975). Worldwide survey of stable isotopes in precipitation. I. A. E. A. (Int. At. Energy. Agency), Vienna, Rep., report, Sect. Isot. Hydrol., pp 53. 
APPENDIX A 


\section{BIBLIOGRAPHY}

Abell, P. I., (1982) Paleoclimates at Lake Turkana, Kenya, from oxygen isotope ratios of gastropod shells. Nature, 297, 321-323

Abell, P. I., (1985). 0xygen Isotope Ratios in Modern African Gastropod Shells : A data base for Paleoclimatology. Chemical Geology, 58, 183193

Abell, P. I., and Nyanmweru, C., (1988). Paleoenvironments in the Chalbi Basin of Kenya. Isotope Geosci., 2, 283-291.

Abell, P. I., and Williams, M. A. J.,(1989). 0xygen and carbon isotope ratios in gastropod shells as indicators of paleoenvironments in the Afar region of Ethiopia. Palaeogeogr., Palaeoclimatol., Palaeoecol., 74, 265-278.

Adams, D. T. (1960). A Ghana Geography Second edition, University of London Press Ltd. p.

Arthur, M. A., Williams, D. F. and Jones, D. S. (1983). Seasonal temperature-salinity changes and thermocline development in the midAtlantic Bight as recorded by the isotopic composition of bivalves. Geology, 11, 655-659

Barnett, T. P., (1978). The role of the oceans in the global climate 
system, in Climatic Change, ed. J. Gribben, University of Cambridge Press, Cambridge, England, pp157-177

Beadle, L. C., (1974). The Inland Waters of Tropical Africa- An introduction to Tropical Limnology. Longman Group Limited, p. 32

Boateng, E. A., (1967). A Geography of Ghana, Cambridge University Press, Second edition.

Boucher, K., (1975). "Global Climate" The English Universities Press Ltd. London. pp326.

Brown, D. S., (1980). Freshwater Snails of Africa and Their Medical Importance. Taylor and Francis, London, pp 487

Budyko, M. I., (1978). The heat balance of the earth. In Climatic Change, ed. J. Gribben, University of Cambridge Press, Cambridge, England. pp85-113.

Burchardt, B., (1977). Oxygen isotope ratios from shell material from the Danish Middle Pleistocene (Selandian) deposits and their interpretation as paleotemperatures. Paleogeog. Paleocli. Paleoecol., $\underline{22}$ (3). 209-230.

Calder, J. A., and Parker, P. L. (1973). Geochemical implications of induced changes in ${ }^{13} \mathrm{C}$ fractionation by blue-green algae. Geochim. 
Cosmochim. Acta 37, 133-140.

Cerling, T. E., Quade, J., Wang, Y. \& Bowman, J. R. (1989). Carbon isotopes in soils and palaeosols as ecology and palaeoecology indicators. Nature, $\underline{341}, 138-139$.

Craig, H., (1961). Standard for reporting concentrations of deuterium and oxygen-18 in natural waters. Science, $133,1833-1834$

Craig, H., (1965). The measurement of oxygen isotopre palaeotemperatures. In : E. Tongiorgi (Editor), Stable Isotopes in Oceanographic Studies and Paleotemperatures. Pisa, Cons. Nat. Ric. Lab. Geol. Nucl., pp161-182.

Dansgaard, W., (1964). Stable isotopes in precipitation. Tellus, $\underline{16}, 436-468$

Deuser, W. G., and Degens, E. T., (1967). Carbon isotope fractionation in the system $\mathrm{CO}_{2 \text { (gas) }}-\mathrm{CO}_{2 \text { (aqueous) }}-\mathrm{HCO}_{3}$ (aqueous) $_{\text {(a }}$. Nature 215, 1033-1035.

Deuser, W. G., Degens, E. T., and Guillard, R. R. L. (1968). Carbon isotope relationships between plankton and seawater. Geochim. Cosmochim. Acta $\underline{32}, 657-660$.

Dobzhansky, T., (1962). Mankind evolving. Yale University Press, New Haven, Conn. 
Ehhalt, D., et al. (1963). Deuterium and oxygen-18 in rain water. Journ. Geophys. Research, 68, pp 3775-80.

Epstein, S., Buchsbaum, R., Lowenstam, H. A. and Urey, H. C. (1951). Carbonate-water isotopic temperature scale. Geol. Soc. Amer. Bull., $\underline{62}$, $417-426$

Epstein, S., Buchsbaum, R., Lowemstam, H. A. and Urey, H. C., (1953). Revised carbonate water isotopic temperature scale. Geol. Soc. Amer. Bull., 64, 1315-1326

Epstein, S. and Lowenstam, H. A., (1953). Temperatue-shell growth relations of recent and interglacial Pleistocene shoal-water biota from Bermuda. J. Geol., 61, (5), 424-438

Epstein, S. and Mayeda, T., (1953). Variation of ${ }^{18} 0$ content of waters from natural sources. Geochim. et Cosmochimica Acta, 4, 213-224.

Epstein, S., (1956). Variations of the ${ }^{18} 0 /{ }^{16} 0$ ratios of freshwater and ice. Nat. Acad. Sci., Nucl. Sci. Ser., Rep. No.19, pp20-25

Eriksson, E., (1964). The history of the major pulses of tritium in the stratosphere. Tellus, $\underline{16}$

Friedman, I., Machta, L., and Soller, R., (1962). Water vapor exchange 
between a water droplet and its environment. Journ. Geophys. Res., 67, pp 2761-70.

Friedman, I. and 0'Niel, J. R., (1977). Compilation of stable isotope fractionation factors of geochemical interest. Geol. Sur. Prof. Paper 440-kk. U. S. Gov. Printing Office, Washington, D. C.

Fritz, P. and Poplawski, S., (1974) ${ }^{18} 0$ and ${ }^{13} \mathrm{C}$ in the shells of freshwater mollusks and their environments. Earth Planet. Sci. Lett., 24: $91-98$

Griffiths, J. F., ed. (1972). World Survey of climatology, Vol. 10, Climates of Africa. Elsevier Publ. Co., Amsterdam, pp 604

Grossman, E., (1982). Stable isotopes in live benthic foraminifera from the southern California Borderland. Ph. D. Dissertation, University of Southern California, Los Angeles, Calif.

Grossman, E. L., (1987). Stable isotopes in modern benthic foraminifera: A Study of Vital Effect. Journal of Foraminiferal Research, $\underline{17}, 48-61$

Hamilton, A. C., (1982). Environmental History of East Africa - A Study of the Quarternary. Academic Press. London. pp10-19.

Hem, J. D. (1970). Study and interpretation of the chemical 
characteristics of natural water. U. S. Geol. Surv. Water-Supply Paper 1473.

Herczeg, A. L. and Fairbanks, R. G. (1987). Anomalous carbon isotope fractionation between atmospheric $\mathrm{CO}_{2}$ and dissolved inorganic carbon induced by intense photosynthesis. Geochim. et Cosmochim. Acta $\underline{51} 895-$ 899.

Hitchon, B. and Krouse, H. R., (1972). Hydrogeochemistry of the surface waters of the MacKenzie River drainage basin, Canada, III. Stable isotopes of oxygen, carbon and sulfur. Geochim. Cosmochim. Acta, $\underline{36}$ : $1337-1357$

Jones, D. S., Williams, D. F. and Arthur, M. A., (1983). Growth history and ecology of the Atlantic surf clam, Spisula solidissima (Dillwyn), as revealed by stable isotopes and annual shell increments. J. Exp. Mar. Biol. Ecol., 73, 225-242.

Keith, M. L., Eichler, R. and Parker, R. H.; (1960). Carbon and oxygen isotope ratios in marine and freshwater mollusk shells (abstract). Geol. Soc. Amer. Bull., 711901.

Keith, M. L., and Anderson, G. M., (1964). Carbon and oxygen isotopic composition of mollusk shell from marine and freshwater environments. Geochim. Cosmochim. Acta, 28, 1757-1786. 
Keith, M. L., and Parker, R. H., (1965). Local variation of carbon-13 and oxygen-18 of mollusk shells and the relatively minor temperature effect in marginal environments. Mar. Geol., 3 , 115-129.

Keith, M. L. and Weber, J. N., (1964). Carbon and oxygen isotope composition of selected limestones and fossils. Geochim. Cosmochim. Acta, 28, $1787-1816$

Kerr, R. A. (1986). Ancient River System Across Africa Proposed. Science $\underline{233}, 940$.

Kitaka, G. E. B., (1971). An instance of cyclonic upwelling in the southern offshore waters of Lake Victoria. Afr. J. Trop. Hydrobiol. Fish, 1, 85-92.

Lee, C. A., (1979). Oxygen isotopes in the seasonal growth bands of Pismo clam. M.S. thesis, Dept. of Geology, UCLA.

Lévêque, C., (1973). Dynamique des peuplements biologie, et estimation de la production des mollusques benthique du Lac Chad. Cah. off. Rech. Sci. Tech. Outre-Mer, ser. Hydrobiol. I, 117-147.

Mann, S., Heywood, B. R., Rajam, S., \& Birchall, J. D., (1988). Controlled crystallization of $\mathrm{CaCO}_{3}$ under stearic acid monolayers. Nature 334, 692-695. 
McCauley, J., et al., (1986). Paleodrainages of eastern Sahara - The radar rivers revisited, IEEE Trans. Geoscience GE-24 624 .

McKinney, C. R., McCrea, J. M., Epstein, S., Allen, H. A. and Urey, H. C. (1950). Improvements in mass spectrometers for the measurement of small differences in isotope abundance ratios. Rev. Sci. Insr. 21, 724730.

Mills, G. A., and Urey, H. C. (1940). The Kinetics of Isotopic Exchange Between Carbon Dioxide, Bicarbonate Ion, Carbonate Ion and Water. Journ. Amer. Chem. Soc. 62, 1019-1026.

Mook, W. G., (1971). Paleotemperatures and chlorinities from stable carbon and oxygen isotopes in shell carbonates. Paleogeog., Paleocli., Paleoecol., $\underline{9}, 245-263$.

Mook, W. G., (1977). Stable carbon and oxygen isotopes in natural waters in Netherlands. International Atomic Energy Agency Conf. Proc. Uses of Isotopes in Hydrology, Vienna. pp 163-190.

Oboli, H. 0. N. (1963). An Outline Geography of West Africa. $3^{\text {rd }}$ edition, George G. Harrap \& Co. Ltd. London.

Quade, J., Cerling, T. E. and Bowman, J. R. (1989). Development of Asian monsoon revealed by marked ecological shift during the latest Miocene in northern Pakistan. Nature 342, 163-166. 
Rau, G., (1978). Carbon-13 depletion in a subalpine lake: Carbon flow implications. Science 201, 901-902.

Schneider S. H. and Londer R., (1984). The Coevolution of Climate and Life. Sierra-Club Books. San Francisco. p45.

Siegenthaler, $U$ and Oeschger, H. (1980). Correlation of ${ }^{18} 0$ in precipitation with temperature and altitude. Nature Vol $\underline{285}$ 314-317

Stevens, C. M., and Engelkeimer, A., (1988). Stable Carbon Isotopic Composition of Methane from some Natural and Anthropogenic sources. J. Geophy. Res. 93, 725-733.

Stuiver, M., (1970). Oxygen and Carbon Isotope Ratios of Fresh-Water Carbonates as Climatic Indicators. Journ. of Geophysical Research 75 , $5247-5257$.

Talling, J.F., (1964). The annual cycle of stratification and primary production in Lake Victoria (E. Africa). Verh. int. Ver. Limnol., 15, $384-5$.

Tanaka, N., Monaghan, M. C., and Rye, D. M., (1986). Contribution of metabolic carbon to mollusc and barnacle shell carbonate. Nature $\underline{320}$, 520-523. 
Tucker, C. J., Townshend, J. R. G. and Goff, T. E., (1985). African land-cover classification using satellite data. Science, 227, 369-375

Urey, H. C., (1947). The thermodynamic properties of isotopic substances. J. Chem. Soc., pt. 1. p562-581

Van der Merwe, N. J. (1982). Carbon isotopes, photosynthesis and archaeology. Amer. Scientist, $\underline{70}$, 596-606.

Varley, W. J. \& White, H. P. (1958). The Geography of Ghana. $1^{\text {st }}$ edition, Longmans, Green and Co. Ltd. London.

Vogel, J. C., Fuls, A. and Ellis, R. P. (1978). The geographical distribution of Kranz species in southern Africa. South Afr. J. Sci. 75, 209-15.

Wendt, I., (1968). Fractionation of carbon isotopes and its temperature dependence in the system $\mathrm{CO}_{2}-\mathrm{gas}_{-} \mathrm{CO}_{2}$ in solution and $\mathrm{HCO}_{3}-\mathrm{CO}_{2}$ in solution. Earth Planet. Sci. Letters 4 , 64-68.

Yurtsever, Y., (1975). Worldwide survery of stable isotopes in precipitation. I. A. E. A. (Int. At. Energy. Agency), Vienna, Rep., report, Sect. Isot. Hydrol., pp 53. 